\title{
RE-IMAGINE PICKERING HERE: A VISION FOR PICKERING NUCLEAR PARK \\ by
}

Taylor Alicia Lena Marquis

Bachelor of Architectural Studies, Carleton University, 2014

\author{
A Major Research Project \\ presented to Ryerson University \\ in partial fulfillment of the \\ requirements for the degree of \\ Master of Planning \\ in \\ Urban Development
}

Toronto, Ontario, Canada, 2016

(C) Taylor Alicia Lena Marquis 2016 


\section{AUTHOR'S DECLARATION FOR ELECTRONIC SUBMISSION OF A MRP}

I hereby declare that I am the sole author of this MRP. This is a true copy of the MRP, including any required final revisions.

I authorize Ryerson University to lend this MRP to other institutions or individuals for the purpose of scholarly research

I further authorize Ryerson University to reproduce this MRP by photocopying or by other means, in total or in part, at the request of other institutions or individuals for the purpose of scholarly research.

I understand that my MRP may be made electronically available to the public. 


\title{
RE-IMAGINE PICKERING HERE: A VISION FOR PICKERING NUCLEAR PARK \\ (C) Taylor Alicia Lena Marquis 2016 \\ Master of Planning \\ in \\ Urban Development \\ Ryerson University
}

\begin{abstract}
In 2024, all commercial operations at the Pickering Nuclear Generation Station cease and the station will begin its decommissioning process. Ontario Power Generation is currently looking developing a repurposing strategy for the site throughout the decommissioning process, which is expected to be complete by 2064. This project presents a unique opportunity to re-imagine the future of this site, while setting a precedent for the reuse of nuclear sites and facilities once they have reached the end of their life cycle - an issue that will be more prevalent in the coming years. This project proposes a vision for the site to be transformed into parkland using ecological restoration practices, and establishing a Centre for Clean Energy Technology. Using design as a form of research, the project was informed by background research that included a review of existing literature on post-industrial site redevelopment, precedent studies, and site reconnaissance.
\end{abstract}

Key Words:

nuclear site redevelopment; Pickering Nuclear Generating Station; design as research 


\section{ACKNOWLEDGEMENTS}

Firstly, I would like to express my sincere gratitude to my supervisor Nina-Marie Lister for her guidance, continuous support, and inspired conversations, especially during moments when I needed direction in my research. A special thank you to Lisa Rochon for acting as my second reader and for her insightful comments on an earlier draft.

\section{DEDICATION}

This project is dedicated to my family and friends for their love and support throughout this journey.

To my bother, Brandon, my role model, who reminds me everyday to never give up. To my mom, my rock, who taught me to be true to myself. 


\section{TABLE OF CONTENTS}

INTRODUCTION 1

1.0 METHODOLOGY 3

1.1 DESIGN AS RESEARCH 3

1.2 RESEARCH STRATEGY 5

2.0 LITERATURE REVIEW 7

3.0 SITE CONTEXT 15

3.1 THE CITY OF PICKERING 15

3.2 THE PICKERING WATERFRONT 18

3.3 PICKERING NUCLEAR GENERATING STATION 23

4.0 NUCLEAR POWER IN CANADA AND THE PICKERING NUCLEAR POWER GENERATING STATION 28

4.1 HISTORY OF NUCLEAR POWER IN CANADA AND THE PICKERING NUCLEAR POWER GENERATING STATION

29

4.2 HOW THE CANDU PLANT WORKS 32

4.3 PLANT DECOMMISSIONING PROCESS 34

4.4 NUCLEAR SITE REDEVELOPMENT 36

$\mathbf{5 . 0}$ PRECEDENT STUDIES 38

5.1 LANDSCHAFTSPARK, DUISBURG-NORD, GERMANY 39

5.2 FRESH KILLS PARK - LIFESCAPE, NEW YORK, USA 43

6.0 PICKERING NUCLEAR PARK 48

6.1 THE VISION 49

6.2 DESIGN PRINCIPLES 51

6.3 PHASING 52

6.4 PROGRAMMING 62

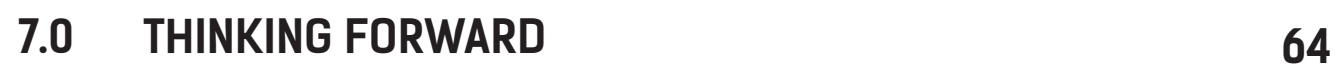

REFERENCES $\quad 65$ 


\section{LIST OF FIGURES}

FIGURE 1: An aerial image of the Pickering Nuclear Generating Station. 1

Figure 2: Site location within the greater regional context. 15

Figure 3: Areas targeted for growth around the study area 16

FIGURE 4: Natural features in Pickering, Ajax, and Rouge Park in Toronto 17

FIGURE 5: Pickering Waterfront and Frenchman's Bay area natural features 18

FIGURE 6: Nautical Village main street, Liverpool Road 19

FIGURE 7: Millennium Square 19

FIGURE 8: Beachfront Park 19

FIGURE 9: Alex Robertson Community Park 20

FIGURE 10: Rotary Frenchman's Bay West Park 20

FIGURE 11: White-tailed deer 21

FIGURE 12: Hydro Marsh 22

FIGURE 13: Juvenile long-billed Dowitcher at the Hydro Marsh 22

FIGURE 14: Site boundary 23

FIGURE 15: Planning zones defined for the Repurposing Pickering land use assessment 24

FIGURE 16: Repurposing potential over time during the decommissioning process 25

Figure 17: Canadian Nuclear History Timeline 29

Figure 18: Pickering Nuclear Generating Station under construction in 1972, and in 1975 once completed. 18

Figure 19: Schematic diagram of CANDU reactor 32

Figure 20: Main timeline assumed for purpose of the 'Repurposing Pickering' assessment $\quad 35$

FIGURE 21: An aerial photograph of Landschaftspark. 39

FIGURE 22: Photographs of some of the key design elements in the park. Image 2 is a garden that is created in a disused tank. Image 3 is the Metallic Square which was built in the unoccupied space between furnace buildings.

FIGURE 23: Former ore bunkers are transformed into new public spaces. 41

FIGURE 24: The blast furnace was repurposed as a viewing platform and offers a view of the entire site. 
FIGURE 25: The Lifescape project aims to create a diverse range of parkland for wildlife, cultural and social activities, and recreation opportunities.

FIGURE 26: The development plan for the site will be implemented in six stages over thirty years.

FIGURE 27: Renderings of key features and proposed uses of the park. 45

FIGURE 28: A view of Manhattan from restored marshlands on the site. 46

Figure 29: Proposed vision for the Pickering Nuclear Generating Station site 49

Figure 30: Site Plan 50

Figure 31: Phasing Diagram 52

Figure 32: The park in 2029 53

Figure 33: The park in 2034 54

Figure 34: The park in 2039 55

Figure 35: The park in 2044 56

Figure 36: The park in 2049 57

Figure 37: The park in 2054 58

Figure 38: The park in 2059 59

Figure 39: The park in 2064 60

Figure 40: The park after 2064, once the vision is complete 61

Figure 4l: Potential site programming 62

Figure 42: Potential site uses 63 


\section{INTRODUCTION}

The Pickering Nuclear Generating Station is expected to end its commercial production of nuclear power in 2024. The plant currently generates 14\% of Ontario's power, but has reached the end of its life cycle after nearly 50 years of production. This project builds on the "Repurpose Pickering" initiative that is currently being undertaken by the Ontario Power Generation (OPG), as they develop a long-term strategy and action plan for redeveloping available site lands during and after decommissioning process, which is expected to be completed in 2064. "Repurposing Pickering is striving to be a global, leading-edge example for repurposing, land use redevelopment and community engagement in the nuclear sector" (Ontario Power Generation, 2015, p. 193)

The 400-acre site is located in the City of Pickering along the waterfront of Lake Ontario. This site presents a unique opportunity to re-imagine a prime piece of waterfront property that has remained inaccessible by the public for over 40 years; to explore new ecological restorative technology to renew this degraded and 'disturbed' landscape. The objective of this project is to generate a new discussion on the future use of nuclear sites once they have reached the end of their life cycle. The proposed vision explores an ecological approach to the site, and aims to reclaim the site as natural parklands, while facilitating a dynamic and experiential conversation between its nuclear past, and the future role within the energy industry.

Using design as a form of research, background research was conducted to inform and develop the design vision and related design principles. This project begins with an introduction to the concept of 'design as research' and how it was used to frame the structure of this research project.

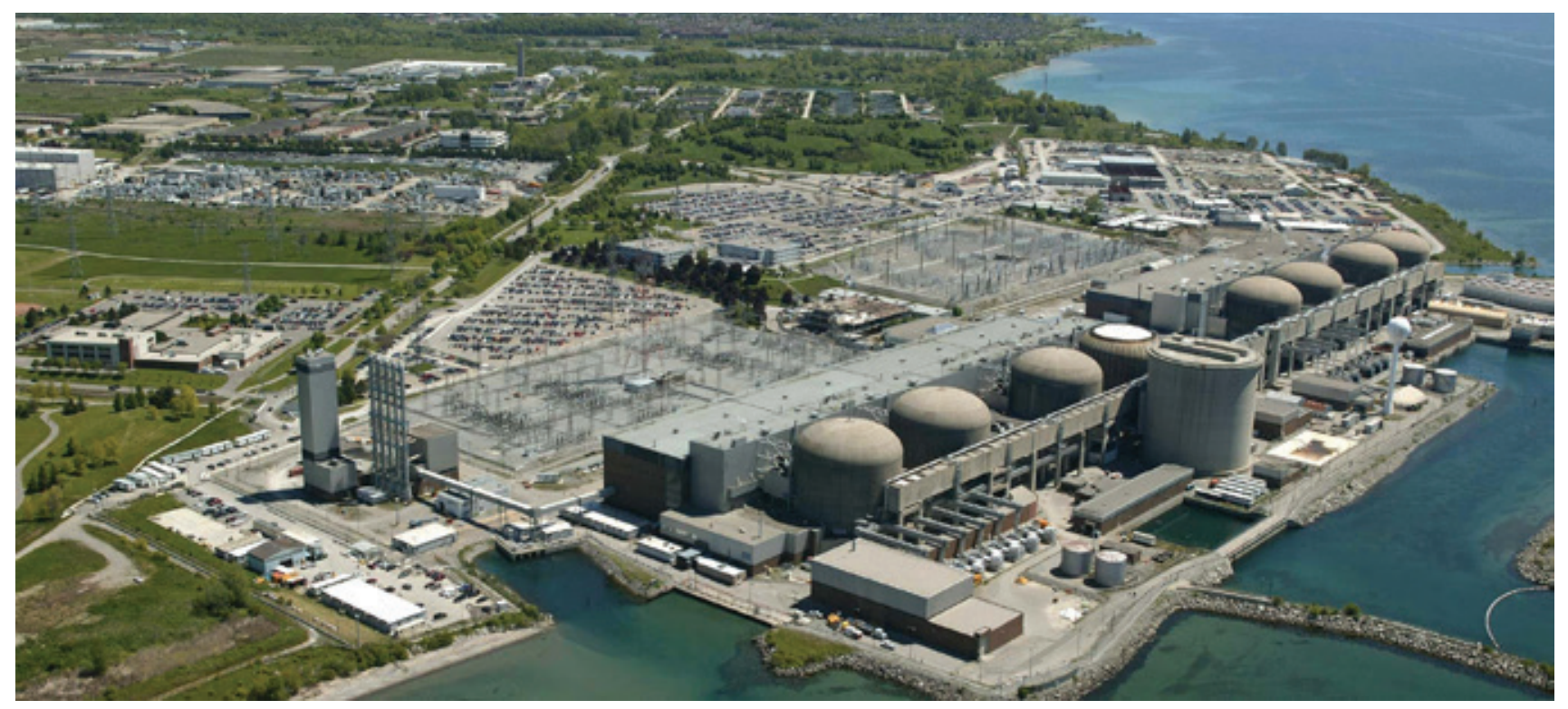

FIGURE l: An aerial image of the Pickering Nuclear Generating Station, 2010 (Image source: Ontario Power Generation) 
Following chapter l, a literature review of the emerging literature around post-industrial and 'disturbed' sites reveals alternative approaches to understanding the complex cultural history of these sites and their role in creating a conversation between our culture of production and consumption, and its lasting impact on our landscapes (Meyer, 2007). Meyer claims that the reuse of degraded sites as parks provide a vehicle for engendering new connections between private actions and public values, between individuals and the world. This theoretical understanding of the role and importance of post-industrial and 'disturbed' landscapes were used to establish a framework that was applied to the research conducted.

Chapter 3 reviews the site's context within the City of Pickering to establish its role within the greater community, its role within and between its surrounding natural systems and corridors, and determining which future uses would be most appropriate and supportive of the future growth and direction of the city.

Chapter 4 includes the history of nuclear energy in Canada, the technical aspects of CANDU nuclear generating stations and its decommissioning process, which also informed the design and phasing strategy.

In Chapter 5, two projects: Landschaftspark (Duisburg, Germany and Freshkills Park (New York, USA) were further studied, and were used provide insight into different design, implementation, and intervention strategies that have been applied in developing parks on sites of this nature.

This project concludes with the vision for the reuse of the site. It includes several design principles that will guide the repurposing of the site, and a phasing strategy that indicates the release and ecological restoration of the site, and future uses. 


\subsection{METHODOLOGY}

Due to the fact that nuclear energy is a relatively new technology, there has not been an opportunity to explore the redevelopment potential of post-nuclear sites in North America. As a result of the exploratory nature of this research, it was determined that research through design would be an appropriate method to develop an understanding of these sites, and as a means to re-imagine the future vision for the site and its potential uses.

\subsection{DESIGN AS RESEARCH}

"To design means to search for ideas, for the new. In this sense, designing is closely related to invention. To design means to draw up a hypothesis of possible answers to a question. The translation of an idea into something that can be read and understood and the testing of its validity is an intrinsic part of designing."

(Von Seggern and Werner, 2008, p. 35)

Von Seggern and Werner claim that the process of spatial design searches for interpretations, for development possibilities, and is a spatial form that is able to unite multiple requirements - from function, to process, aesthetics, construction, material, symbolism and ageing - into a convincing whole (Von Seggern and Werner, 2008). While design and its results cannot be fully described in rational terms, the quality of design "lies in the conscious combination of analytical, intuitive and emotional faculties used to grasp complex relationships and to formulate possible solutions" (Von Seggern and Werner, 2008, p. 37). For this reason, Von Seggern and Wener (2008) believe that designing is fundamentally appropriate method for the generation of new ideas.

There is a rich body of literature in recent years that have been attempting to build a case for design as research. It was first encapsulated in a research paper from the Royal College of Art in London (Frayling, 1993). This was reiterated by two leading design theorists from the 1960s, Nigel Cross and Bruce Archer, who advocated for the legitimacy of "research into, for, and through design" (cited in Bowering 1999). ${ }^{1}$

The argument for design as research builds on the fact that design involves empirical research to understand the context of a project and to develop a design program (Deming \& Swaffield, 2011). Further justification is drawn from the way that theoretically informed design frequently involves the discovery and the creation of new ideas, concepts, configurations, and products, as in "research and development" (Deming \& Swaffield, 2011). The reflexive and reflective nature of design thinking is also a key feature that indicates its "research credentials" (Deming \& Swaffield, 2011).

\footnotetext{
${ }^{1}$ Other architectural educators expressed their advocacy for design to be considered as valid form of research in the Journal of Architectural Education in 2007 [Vol. 61, Issue 1]. See Kieran, 2007; Furjan, 2007; Wortham, 2007.
} 
According to Deming and Swaffield (2011), advocates for design research follow diverging lines of argument. One group claims that "design has all the attributes of research, broadly defined, and should, therefore claim status and validity as research" (Deming \& Swaffield, 2011, p. 38). This is illustrated through the way advocates frequently adopt the language of science, talking of "design experiments" (Deming \& Swaffield 2011, Steenbergen 2008).

Steenbergen (2008) uses the term 'design experiment' and 'experimental design' to describe research by design. He claims that design experiments are set within a specific context, and the investigation applies different design-based strategies to investigate the possibilities. The research question will typically explore how new knowledge, values, or priorities might emerge from the creative transformation of familiar design contexts (Steenbergen, 2008). Conversely, experimental design is the projection of a new landscape composition that may be applied in different settings - the context and design intervention are variable. In this case, the research question is typically driven by a desire to generate new types of conceptual design solutions (Steedbergen, 2008). Deming and Swaffield (2011) frame this approach as a case-study approach.

According to Deming and Swaffield (2011), research by design corresponds with the process of "abduction" - an investigation of what might be. This exploration into ' finding out what might be' is undertaken in a systematic way and is embedded in the design process. They claim that designers commonly use research-like methods and techniques in order to frame and respond to the problem (Deming \& Swaffield, 2011). The combination of the methods and techniques used is dependent on how the project design research strategy is expressed (Deming \& Swaffield, 2011).

While Von Seggern and Werner (2008) acknowledge that these technical-functional (rational) methods are fundamental to design, they claim that the intuitive and emotional aspects contribute to the design process. However, they acknowledged that their meaning and relevance remain "diffuse and unqualified" and, as such, their potential remains largely underutilized and are often left out of the design process equation - treated as a kind of "black box" (Von Seggern and Werner, 2008). Through their research, they have determined that it is not possible to objectify the role of intuition, emotion, and creativity in the design process, but state that if "intuition were to be regarded as a self-evident component of designing, it would obviate the need to describe those enigmatic, in my respects mysterious, aspects of design that cannot be proved" (Von Seggern and Werner, 2008, p. 49].

Von Seggern and Werner (2008) claim that in order to understand design as a way of thinking and a transdisciplinary and integrative mode of activity, it must acknowledge that there are limits to rationality and that 
there is a "mystery" to creativity. They reveal that the evolutionary character of design is apparent in its ability to bring both rationality and creativity together. Within that ability lies the special contemporary relevance of design activities. They claim that, especially at the large scale, intuition gives designers the ability to creatively respond to the unpredictability of and complexities space with the ability of still being able to see the whole "regardless of the fuzziness" (Von Seggern and Werner, 2008, p 51). Consequently, they reveal that design as an approach "that specifically incorporates intuition and emotion, allows us to identify an "an image as a whole" at a relatively early stage, in spite of the degree of complexity, and this to formulate a first idea" (2008, p. 51).

\subsection{RESEARCH STRATEGY}

Using Steenbergen's understanding of design experiment as design research, this research intends to be a design-experiment into the redevelopment potential of nuclear power plant sites, using the Pickering Nuclear Power Generating Station as a case study. It will use empirical research to understand the context of the project, and develop a design program to generate new ideas, and concepts for the future use of the site.

This study will employ traditional research methods to conduct background research that will be used to generate a vision for the site. The methods used include a literature review, precedent studies, and a site review and reconnaissance.

\section{Literature Review}

Due to the limited academic literature around post-nuclear sites, this research reviewed emerging literature around the redevelopment of post-industrial sites. This juxtaposition is in line with previous research completed by the International Atomic Energy Association [2006 \& 2011], which looked at a number of post-industrial site redevelopment projects as case studies and lessons learned for future post-nuclear site redevelopment. The literature reviewed is predominately from the field of landscape architecture, which presents a multidimensional design approach to studying and understanding these landscapes. This literature is in line with the objective of developing an alternative and in-depth understanding of the site and design solution that is different than the mainstream economic approach.

A review of literature and technical documents around the history of nuclear power in Canada, the Pickering

Nuclear Generating Station, and its related operating, decommissioning, and redevelopment opportunities, the buildings on site, and the process that will guide its final closure.

\section{Site Review and Reconnaissance}

A site review and reconnaissance was undertaken to gain a better understanding of the existing conditions of the site and its context within the City of Pickering. This was used to ensure that what was proposed is not 
only appropriate for the site, but for the greater community that surrounds it. This was completed by a review of secondary information and a number of site visits. Three site visits were conducted during the months of October 2015, and January 2016. Field notes and photographs were taken during each site visit.

\section{Precedent Studies}

An initial high-level review of international post-industrial park projects was undertaken, and two notable projects, Landschaftspark, Duisburg-Nord, and Fresh Kills Park, were selected and further studied to provide insight into different design, implementation, and intervention strategies that could be applied to the site. These projects were chosen due to their different approaches undertaken in regards to their design and theoretical approaches, their applicability to the site, and due to the fact that they are often referred to as revolutionary projects that have transformed our understanding of industrial and 'disturbed' landscapes.

In an attempt to illustrate the design process of integrating the research into the final plans, key findings are presented within a 'black box', with a description on how it informed the development of the final vision and design principles. It is intended that by clearly defining research process and systematically reporting what was learned, and how it will be used to inform the design process, itwillimprovetheintegrityand thevalidityof theproposedplan, and its contribution to the discussion around post-nuclear site redevelopment. 


\subsection{LITERATURE REVIEW}

"Post-industrial sites are simultaneously iconic reminders of the ongoing de-industrialization, and locations to re-imagine, reinvent and recover landscapes as agents for cultural, social, economic and ecological change."

(Langhost, 2014, p. 1111-1112)

The redevelopment of derelict industrial areas has received a lot of attention in recent years. Since the mid1980s, planners and designers have been paying more attention to sustainable development and improving the quality of life in urban areas (Loures and Panagopoulous, 2007). Situated in advantageous locations often near city centers, along waterways, and adjacent to residential communities, these areas have become prime targets for urban revitalization (Loures and Panagopoulous, 2007).

The globalization of industry has had an impact of industrial areas all over the world. The restructuring of the global economy, the automation of production, and the relocation of industry have led to an increase of underused and derelict post-industrial sites within cities ([3] [Loures, 2008)]. Historically, industry often abandoned the sites without performing any reclamation work, leaving the sites largely polluted left to decay. These sites were regarded as relics of manual labour and abusive working conditions, and consequently, some were swept away in urban development or land clearance schemes (IAEA, 2011). These derelict sites were interpreted as symbols of the failure of the industrial age, and were the subject of negative public perception due to concerns related to the environment [pollution], reduced economic development potential and quality of life (Loures, 2008).

In the past decade, the environmental concerns about these sites have been the catalyst to the redevelopment and renaissance of these landscapes (Loures, 2008). The fact that these landscapes became economically disadvantaged, environmentally degraded and socially distressed through industrial contamination indicated that reclamation projects should enable the redefinition of these landscapes (Loures, 2008). The practice of landscape architecture has been at the forefront of projects that have attempted to redefine these derelict and abused sites.

Braae [2015) and Langhost [2014] present alternative approaches that can be taken when redeveloping industrious areas. These approaches include economic development, and preservation and re-use.

The economic development approach follows the agendas of global development and capitalization. Focusing on the political and economic interests, this approach is tied to the processes of urban renewal, and redevelopment and rebranding (Langhost, 2014). It is also in line with the term "land recycling", which 
according to Thomas (2002), is when economic development corporations (private developers or departments within local government] seek to turn "brownfield sites into goldfields". All traces of industrial use are removed, and the redevelopment can occur on a blank slate, similar to a traditional building project. A number of these former industrial sites are located in areas where land prices and the pressure for urbanization are high and there is good business potential (Braae, 2015). This approach is often supported by modern urban policy since emphasis has recently been placed on achieving urban and economic regeneration of these areas, and to prevent new development from occurring the greenfields outside of the city (sprawl). However, Langhost argues that this mainstream approach to the redevelopment of these sites end up producing conditions that are economically, socially and environmentally uneven and unjust.

The preservation and re-use approach does not seek to clear the site, but work with the industrial remnants and all of its embedded cultural implications (Braae, 2015). Preservation is associated with the something that has existed and re-use is more closely associated with visions of something that can become something else (Braae, 2015). The preservation of a site or building is often linked to institutionalized representative examples - something that is the first of its kind, or the largest; something that is associated with collective memories, or to more popular aesthetic standards - something that is architecturally unique or pleasing, or sublime (Braae, 2015). Because industry is a new field of study, Braae suggests that as we accumulate insights of the rationale of industry, its significance and its leaving, efforts of preservation will increase correspondingly (Braae, 2015).

While the preservation of industrial remnants will increase, Braae also suggests that interests of re-use will increase, both by will and necessity (Braae, 2015). She claims that the willingness for re-use is fed by many examples in ruinous landscapes that "demonstrate great potential for creativity, suggesting approaches to the nature of the place and local answers to the, in principle, global challenge of de-industrialization" (Braae, 2015, $p$ 229]. The necessity for re-use is due to the increasing number of industrial areas. They occupy sites that are so extensive that it makes little sense culturally or with regards to resources, to remove what has been built and returning the site into a green field for redevelopment (Braee, 2015). Braae claims that this approach contributes to local diversity and is a responsible use of materials in the light increasingly scare resources. She believes that rethinking inactive industrial areas is a central and cultural challenge in terms of society, resources, and industry and that it is essential that designers improve their understanding of what it means to transform industrial areas (Braae 2015). 
Emerging writing on post-industrial landscapes by designers has begun to explore the importance of understanding the historic and cultural significance of these complex sites. Landscape architecture and urbanism is at the forefront of this research. This can largely be attributed to the fact that landscape architecture and landscape urbanism having the inherent ability to relate and adapt to the many forces and complexities that are implicit within landscapes, and posits landscape and place as both results of cultural production and agents for cultural change (North 2013, Loures and Panagopoulous 2007). This literature also explores design strategies that make this past visible while connecting it to individual human behaviour, larger ecological processes, and the temporal and dynamic character of landscape design (Loures and Panagopoulous 2007, Meyer 2007, Braae 2015).

Braae claims that in recent decades, our traditional understanding of cultural heritage has changed considerably. Our contemporary view of heritage now, in principle, embraces everything from positive and monumental heritage to 'inconvenient' and less monumental heritage. The past 150 years of industrialization has impacted the world more dramatically than any other period in history - from technological advances, to culture, religion, faith, ecology and the environment. The Post-industrial urban landscapes and industrial remnants from this period are a part of our cultural heritage. They are the accumulations of a series of decisions taken over time, which has led to the current stage of urbanization. However, Braae claims that the question and challenge now lies in determining what social, spatial, aesthetic and culture-historical values we can create out of these sites. Meyer's work on disturbed sites provides insight on how the history of these sites, which she defines as 'disturbed sites', can be used to develop inform our understanding of the human history of consumption and production. Meyer uses the term 'disturbed site' to describe a broad range of "polluted or contaminated landscapes previously used for industrial purposes" (Meyer, 2007, p. 59]. She claims that it is tempting for designers to "heroicize and romanticize" the buildings and machines that remain on post-industrial sites, but this strategy privileges the histories of production over the histories of consumption, which are also embedded in these sites. "This allows visitors to distance themselves from the histories of human, material, and chemical flows on and off the site, and limit their own culpability in and responsibility for such histories" (Meyer, 2007, p. 64). Similarly, design strategies that focus primarily on the ecological processes of remediating the toxins from industrial sites dismiss the intermingling of natural, social and industrial process that have permeated the site, and that are responsible for its present condition.

According to Meyer, thinking about landscapes of consumption and production requires thinking of the circulation of need, desire, material, goods, energy, and waste across disciplinary categories such as nature and culture, ecology and technology, and even public and private. She claims that there is a need for design 
strategies that make connections between human behaviour, collective industry, and larger industrial and ecological processes (Meyer, 2007). "This approach could have on re-imagining a society of consumers who are aware of their impact on our habitat, not simply out of self-interestedness but arising from a sense of extended, interconnected community" (Meyer, 2007, p 64). She believes that the transformation of these sites into large parks could allow for spatial practices that connect the personal act to the collective public disturbance, that allow park visitors to consider the difference between thinking green and acting green, between one's values and behaviours.

"Large parks on sites of consumption and production should be more than just symbols of our consumer culture. "They should be recognized as the invisible consequence of our needs and desires, and should be remade, in Engler's words, into "a place were our rejected and silenced cultural values are awakened, provoked, and interrogated."

(Meyer, 2007, pp 64-65)

Like all aspects of the built environment, post-industrial sites are a part of a cycle of urban development. Braae claims that this dynamism is central to the primarily American-driven discourse on urbanism, which focuses on the functions performed by the landscape and the services it provides (Braae, 2015). In a review of the literature, Braae reveals that the dynamic qualities of the landscape include its productive and performing entities, and the diverse services the landscape can offer. The different approaches taken to these sites can emphasize different aspects of their dynamism.

A design-based approach that Braae explores is the role of the sites within the city as a single vast ecosystem. Understanding the cyclic phenomena of nature as well as the open, dynamic systems and quasi-metabolic systems of the city, Braae explains, have the potential to create cohesion between these sites and the urban environment (Braae, 2015). More importantly, the release of industrial areas opens the way for new ecological links across the urban landscape (Braae, 2015). Industries were often sited along waterways, and the rivers and canals were not only used as transportation infrastructure, but as a water supply for the industrial process. As the industries along waterways are dismantled, Braae suggests that it creates an opportunity to create a new continuity along the waterways (Braae, 2015). She also suggests that there is this opportunity with unused and abandoned railway tracks as well. Braae also reveals that many of these abandoned and neglected sites have become refuges or breeding grounds of biodiversity. As the need for large, well-connected green areas increases in urban areas, these former industrial areas reveal ecological potential in re-integration of these green areas into the city. Braae suggests that these areas could take on many different forms with different approaches. This includes a 'land protection' area, which seeks to protect the land on an in-depth and micro- 
ecological scale as this approach is interested in creating space for natural systems to work with the city's systems (Braae, 2015).

Conversely, Meyer explores reveals the understanding that these sites are the byproducts of a cycle of economic policies and societal opinion that viewed nature as a resource that accepted environmental degradation as the inevitable consequence of technological progress. She claims that we have inherited these derelict and toxic landscapes because "we wanted a certain quality of things, a certain level of technological development. We desired newer, more, faster, closer. And we knew there were risks, but we assumed they were small, containable" (Meyer, 2007, 66). However, we no longer have this naïve understanding of the environment and recognize that our consumption of the planet and natural resources is no longer sustainable and will continue to negatively impact the environment in the long term.

Meyer claims that these sites are not only an opportunity to remediate these large landscape, but also an opportunity to change environmental attitudes, construct new constellations of social collectives, and prompt actions. However, she claims that in order to effective as an agent of changing collective identity and environmental values, the design must employ multiple, temporal strategies (Meyer, 2007). Adams suggests that modern society was unable to conceptualize the temporal dimension of industrialization's impact on the environment. Industrial time dominated, and was considered separate from the dynamic processes of nature. This understanding of time intertwines ecological and industrial processes that unfold over time Adams in Meyer, 2007]. Using Landschaftspark, Fresh Kills, and Downsview Park, Meyer states that recent landscape park designs on disturbed sites have employed design strategies that exploit the temporal qualities of the landscape as a dynamic, performative, and open-ended process medium.

Meyer claims that the reuse of degraded sites as parks might resurrect the parks' agency as a vehicle for engendering new connections between private actions and public values, between individuals and the world. They are places where consumer-citizens are allowed the opportunity to recognize the gaps between their alleged environmental values and their patterns of consumption and where a generation of consumerenvironmentalist citizens might find physical manifestations of the their contradictory beliefs, impulses, and actions (Meyer, 2007). In making these processes and the threats or risks associated with them visible or palpable, individuals might acknowledge them and be motivated to act.

Meyer's use of the historical elements of disturbed sites as a tool to understand our cultural and human history of consumption and production can be tied to Howard's (2003) definition of heritage, which includes "everything that people want to save" [2003, p. 1]. This definition reminds us that heritage, which was once understood as the permanent physical remnants of past human behaviour and landscape, now includes the temporary, the 
ephemeral, the behavioural, and the conceptual (Boyd \& Gardiner, 2005). While the discussion of ephemeral heritage is absent in current literature on cultural heritage, Boy \& Gardiner (2005) claim that the "short-term, temporary, cyclical and ephemeral are crucial elements in any definition of landscape" (p. 194).

Qviström and Saltzman (2006) understand landscape as "a material and territorial entity and, at the same time, a way of seeing, a culturally defined way of using and perceiving the physical environment" [p. 22). They believe that there is a constant interaction between the material and immaterial aspects of landscape, as well as between nature and culture within the landscape ISaltzman, 2001; Qviström, 2003). Mitchell (1994; cf. Qviström and Saltzman, 2006) claims that landscapes offer themselves up to different and competing interpretations and interests, and everyday activities and representations are renegotiated and made evident in the landscape. Understanding this constant re-negotiation is fundamental for understanding landscape transformations. Qviström and Saltzman (2006) state that the use of the concept of ephemeral landscapes is also a way to bring forward the everyday aspect of landscapes.

The word ephemeral is derived from the Greek word, ephemeros, which means "living a day", and is now commonly used to mean short-lived, transient or transitory, brief, momentary or temporary (Boyd \& Gardiner, 2005; Qviström and Saltzman, 2006). Paul Brassley, who studied ephemeral landscape in countryside and rural environments, has remarked on the lack of studies in which, the role of weather conditions, seasonal changes and annual variations are examined (Brassley 1998, 1999). According to Brassley, such phonological phenomena are "remarkable and worthy of academic study" (1998, p. 120), and are almost completely ignored within landscape research and literature. Instead, he claims, research pays a lot of attention to the permanent features of the landscape: buildings and other aspects of settlements, woods and forests, roads, railways, and canals, for example, are all landscape components that fit into the 'permanent' category (Brassley, 1999]. Ephemerality is also not well covered in architecture research. Chappel (2010) attributes this void to the connection that architecture has with permanence, and permanent structures.According to Brassley (1998), ephemeral landscapes may be divided into two principle types: the natural and the human-induced. Natural ephemera can range from the slow cyclical progress of the seasons, to the cyclical changes produced by tides, or to the momentary effects of sun and clouds. These are changes that we can expect to happen, and can be termed anticipated ephemera, in contrast to the unanticipated ephemeral change produced by shortterm variations in the weather (Brassley, 1998). These changes may only last for a few days or months, or many years. However, Brassley (1998) claims that the overall result is that it reminds us that the natural landscape is generally one of constant flux. 
In additional to natural ephemeral changes in the landscape, there are ephemeral changes produced by human activities. These human-induced ephemera can be associated with, for example, agriculture through cultivation and harvesting; or with woodlands which have been managed my humans for thousands of years through selective burning and cutting (Brassley, 1989). While this human-induced activity may not be permanently carried out on the landscape, they can physically impact the composition of the landscape for a number of years.

According to Brassley (1998), natural and human-induced ephemeral landscapes may work in combination. Boyd and Gardiner (2005), observe this combination when it relates to the role of historic components within contemporary landscapes as it relates to the remnants of economically irrelevant historic agriculture, which is now seen to be almost part of the natural environment. They claim that the ephemeral nature of these remnants is read as a sign of its historic past (Boy \& Gardiner, 2005). 


\section{POST INDUSTRIAL LANDSCAPES AS CULTURAL HERITAGE:}

This new understanding of cultural heritage allows post-industrial sites to be regarded as important to our cultural heritage, permitting them to be preserved and commemorated and used in new ways. The development of the nuclear industry can be marked as an important milestone in the 20th century, and had an impact both in the energy production, and medical fields. This site plays an important role in commemorating this history.

\section{‘DISTURBED' SITES:}

'Disturbed' sites can be an effective tool to teach society about our human behaviour, our patterns of production and consumption, and its impact it has on the landscape. The reuse of degraded sites as parks might resurrect the parks' agency as a vehicle for engendering new connections between private actions and public values; between individuals and the world. The use of nuclear energy as a 'clean' form of energy production is a sensitive and highly controversial subject. The site presents an opportunity for individuals to understand, both physically and spatially, how nuclear energy is produced and the impact it has on the landscape. It could lead an informed discussion around the validity of this form of 'clean' energy production, and if it can sustainably support our growing energy demands.

\section{EPHEMERAL LANDSCAPES:}

Due to the nature of the current use of the site (radioactive materials) and timeline of the decommissioning process, it could take up to $40+$ years for the site to be fully released. This extended timeframe requires that the ephemerality of the landscapes must be acknowledged and incorporated. The site, and surrounding lands uses will physically and ecologically change throughout the decommissioning process, and the proposed vision and programming should be reflective and embrace this process. 


\subsection{SITE CONTEXT}

\subsection{THE CITY OF PICKERING}

Located 20 miles east of Toronto in Durham Region, the City of Pickering experienced rapid growth between the end of World War II and 2001. It has developed into a predominately suburban community with a population of 94,510 in 2013 (Region of Durham, 2013a). Pickering is home to the largest immigrant population per capita in Durham Region, with visible minorities comprising over 25\% of the City's residents (Statistic Canada, 2011). The City of Pickering encompasses 22,652 ha; 15,200 ha of which is considered Rural Area, and 7,452 ha considered Urban Area (TRCA, 2009).

The southern part of the city is mainly suburban residential, with industrial areas restricted to the areas around the Pickering Nuclear Generating Station. Development in the northern area of the city has been prevented for many years due to City and Province imposed development restrictions to prevent sprawl, and past federal and provincial interventions (Expropriation of land for a proposed international airport in the 1960s, and expropriation by the Province for the north Pickering community known as Seaton).

In 2006, the Province of Ontario designated Downtown Pickering as one of two municipalities in Durham Region as an urban growth centre in the Growth Plan for the Greater Golden Horseshoe. As a result, the City is expected to grow to 190,000 residents by 2031 (Ministry of Infrastructure, 2006). In 2013, the Downtown Pickering Vision \& Redevelopment Framework was developed to provide a framework for

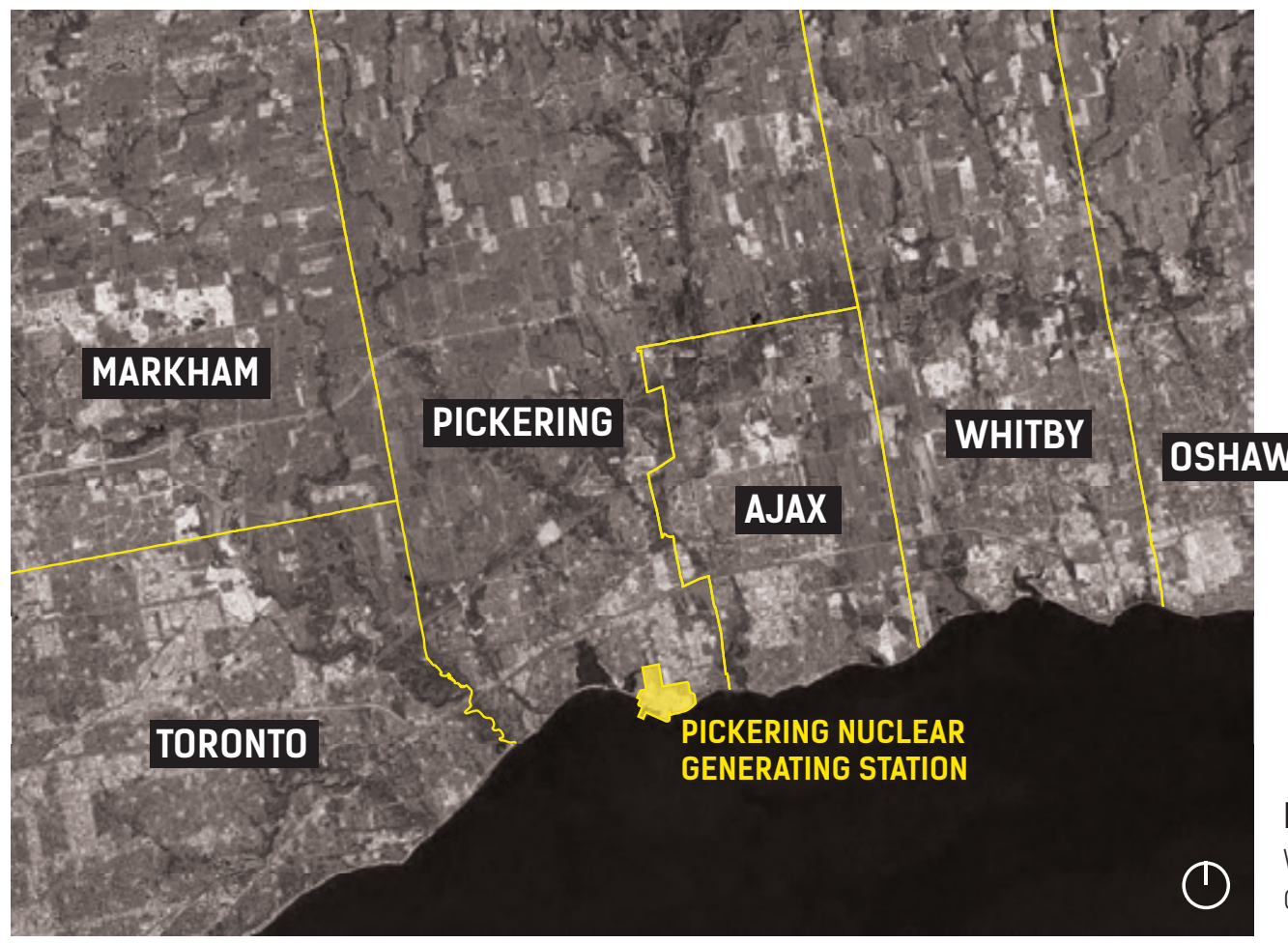

Figure 2: Site location within the greater regional context. 
intensification, investment and growth management in Downtown Pickering to 2031 (City of Pickering, 2013). In 2014, the City began the South Pickering Intensification Study (as a part of their Official Plan Review) to investigate where and to what extent growth and development should occur in South Pickering outside of Downtown Pickering (the Pickering Nuclear Generating Station is included within the study boundary].

New development is also expected in the Seaton Community in northern Pickering. The new community is expected to add 60,000 to 70,000 new residents to Pickering and approximately 35,000 new jobs when fully built out [City of Pickering, 2014].

The City of Pickering has over 220 hectares of open space and parkland, including numerous parks, sports fields and trails, and 3 conservation areas (City of Pickering, 2016c) (See Figure 4).

One of Pickering's gems is its waterfront area around Frenchman's Bay. Of the 7.6 kilometres that border along Lake Ontario, approximately 5 kilometres is publicly accessible, and 2.7 kilometres is beachfront. Pickering also has a number of creeks including the Petticoat, Amberlea, Dunbartion, Pine, Krosno and Duffins Creek, with wooded valley lands that extend from the waterfront, up through the urban areas. Adjacent to the western boundary of Pickering is the Rouge Park. The park, one of the largest urban parks in North America, is a unique combination of woodlands, valleys, meadows and farmlands (TRCA, 2009).

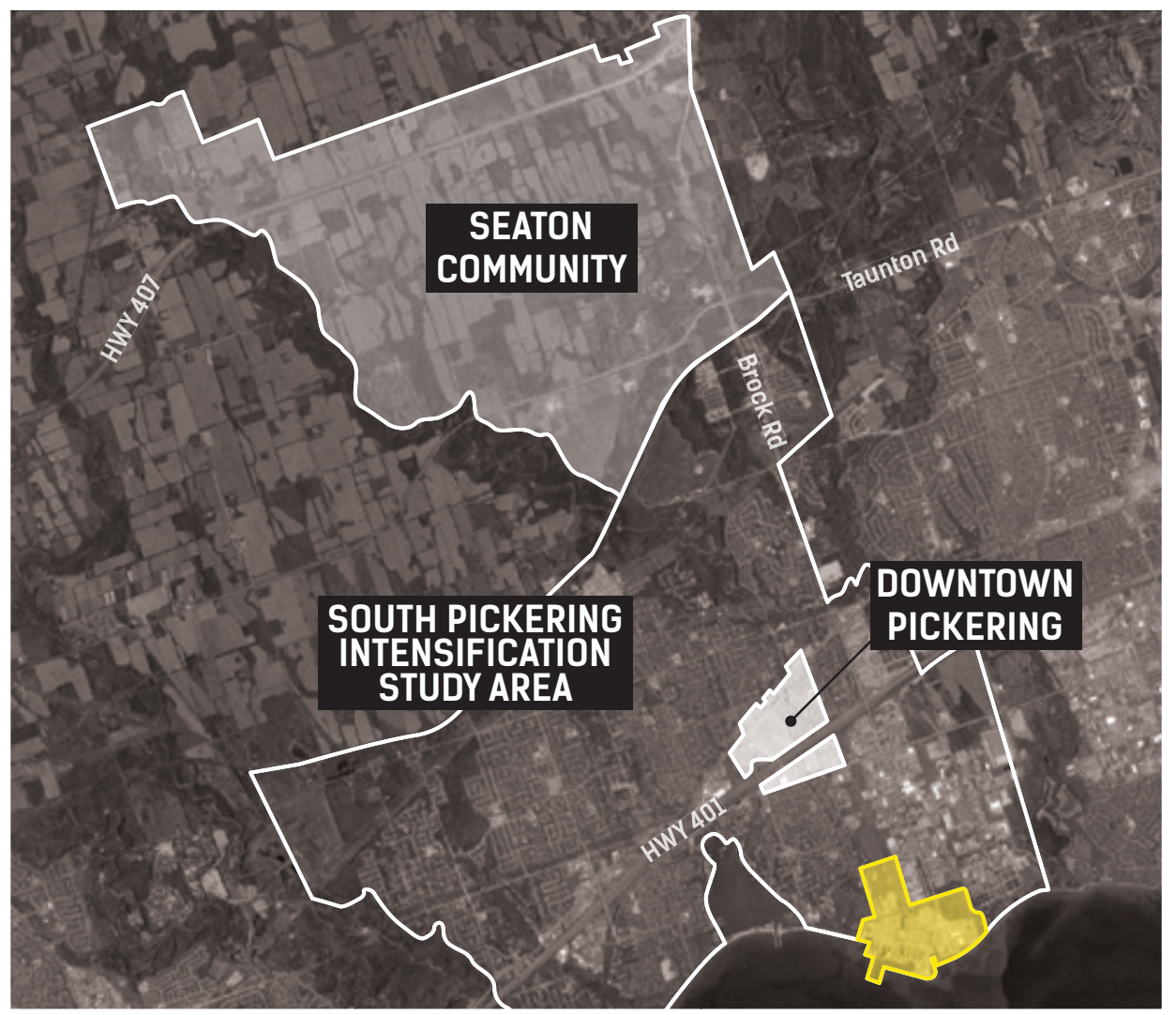

Figure 3: Areas targeted for growth around the study area 


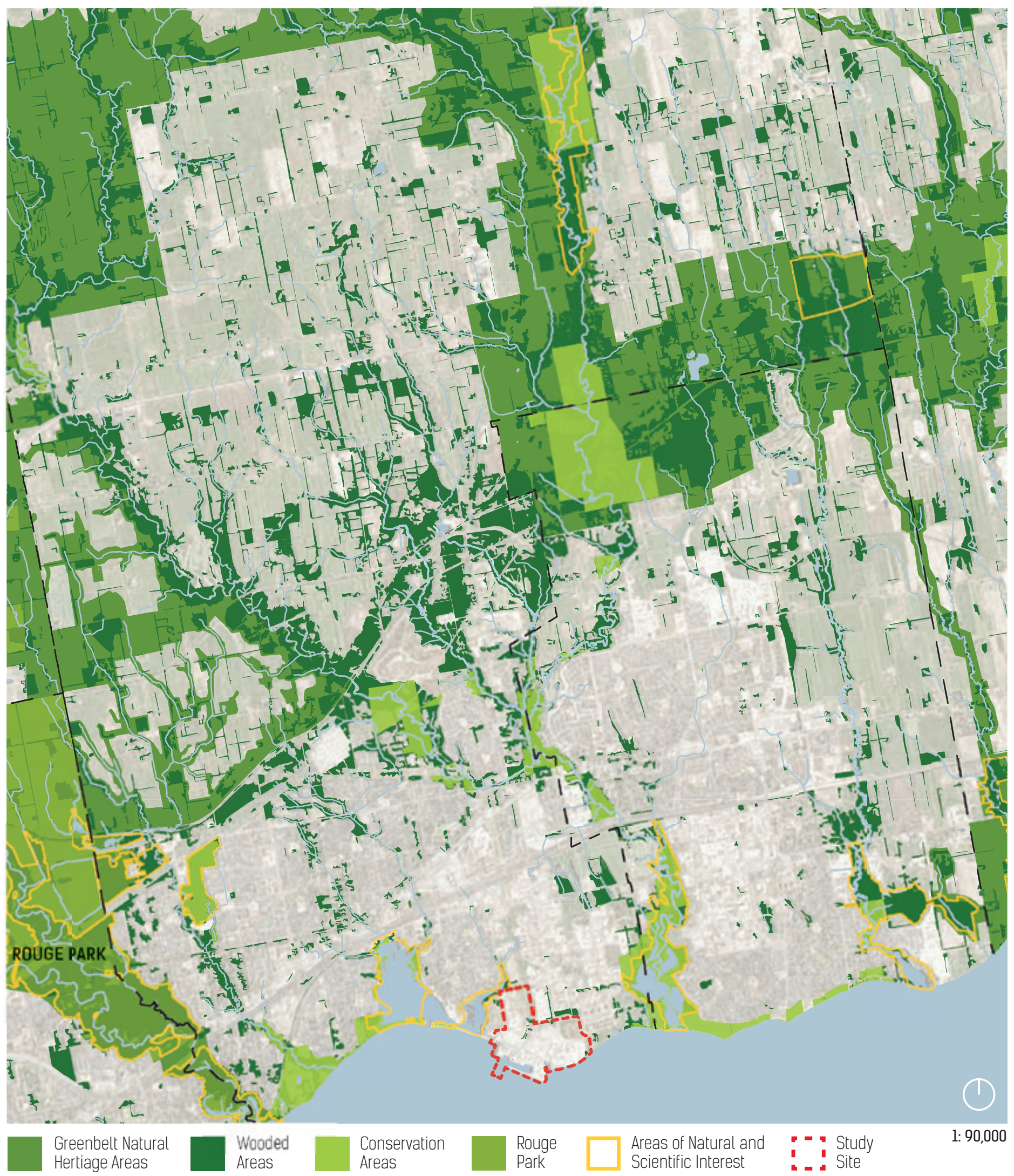

FIGURE 4: Natural features in Pickering, Ajax, and Rouge Park in Toronto

(Map data sources: Elections Canada (2014), Ontario Ministry of Natural Resources (2000, 2005, २006, 2008, 2011, 2012, 2013) 


\subsection{THE PICKERING WATERFRONT}

The Pickering Nuclear Generating Station is located in the Frenchman's Bay watershed along Lake Ontario. Frenchman's Bay is tied with the early history of the City of Pickering. By the 1800's the Frenchman's Bay port became a shipping hub exporting three million feet of lumber each year. The local shipping industry was also responsible for the local importation of grain, flour, salt, lime, and luxury items (TRCA, 2009). A combination of factors led to the decline in the importance of the harbour including increased industrialization and railroad expansion. Large-scale development on the barrier of the beaches that border the harbour entrance occurred in the 1940s with the construction of a lakefront residential community known as the Dumbarton Shores subdivision. Extensive flooding during the 1970s resulted in the purchase of these homes by the TRCA. In 1995, the City received 53 acres of the bay and marshlands and five acres for the development of a waterfront trail, and with that, the revitalization of the bay began (TRCA, 2009).

Frenchman's Bay is a shallow, provincially significant coastal lagoon, and is protected by a natural sand and gravel barrier beach. The four main tributaries that feed the Bay are Ambrlea, Dumbarton, Pine, and Krosno creeks (TRCA, 2009).

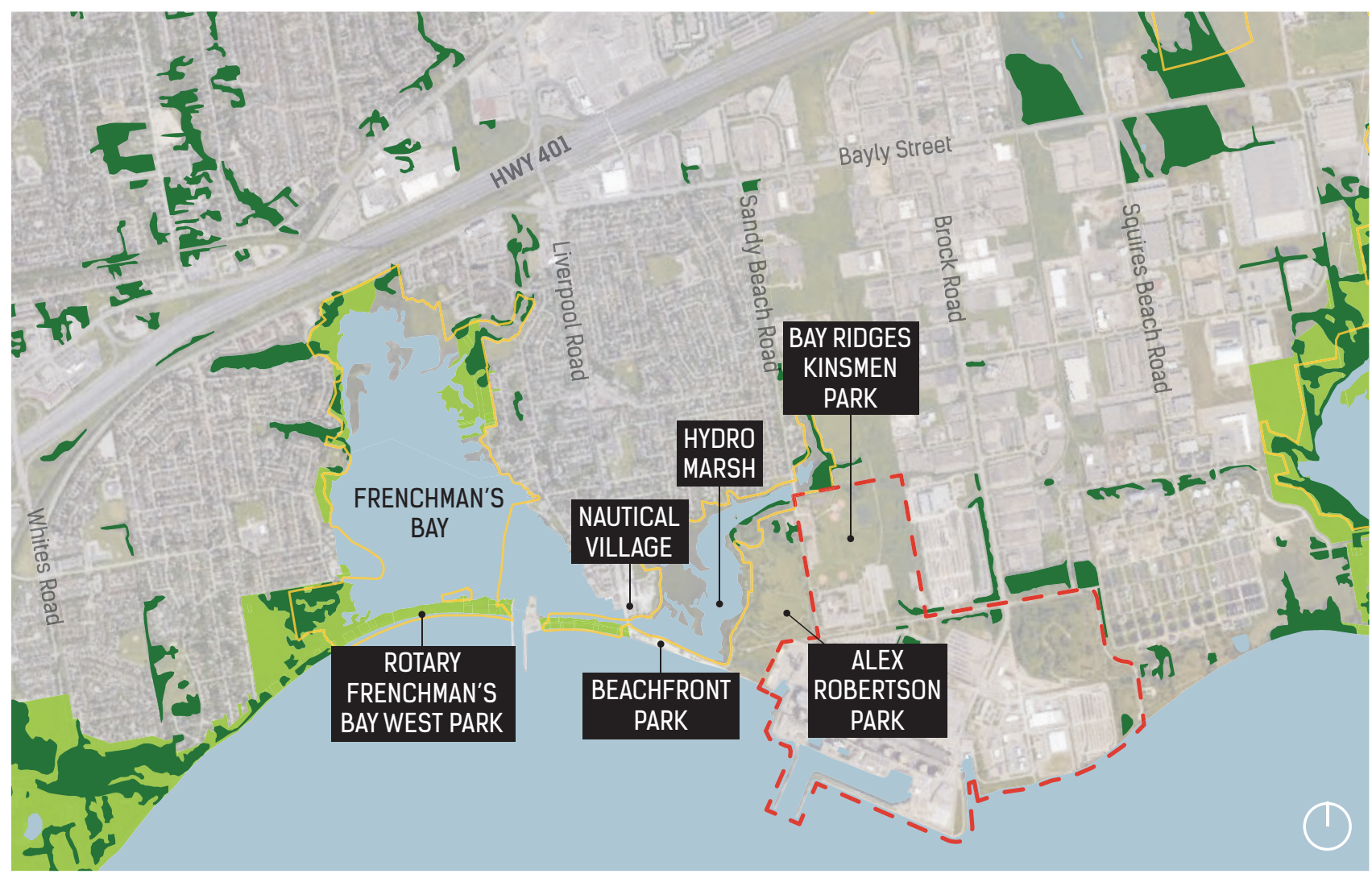

FIGURE 5: Pickering Waterfront and Frenchman's Bay area natural features

(Map data sources: Ontario Ministry of Natural Resources (2000, 2005, 2006, 2008, 2011, 2012, 2013) 
In 2003, the 'Great Lake Nautical Village' was built directly east of Frenchman's Bay. The Village is a new urbanist nautical-themed community with a mixed-use strip of shops, businesses, cafes and restaurants on its main thoroughfare, Liverpool Road. It also incorporates Millennium Square, a large public square. Adjacent to the square is the Beachfront Park with contains a beach, splash pad, beach volleyball courts, and children's play area (City of Pickering, 2016b].

The beach acts as a protecting barrier that separates the provincially significant coastland wetland - the Hydro Marsh - to the north, from Lake Ontario to the south. The 134-acre marsh provides bird watching and fishing opportunities with common sightings of herons, terns, and shorebirds. A boardwalk that leads to OPG's wind turbine accompanies the beach area.

The Beachfront Park, Millennium Square and Nautical Village have become a place for community events, and a popular and picturesque tourist destination in the summer.

The Pickering waterfront also contains a number of parks and pathways including:

Alex Robertson Park: The 48 acre park is located on the shore of the Hydro Marsh and includes a number of hiking and running trails, making it a destination for joggers and cyclist. The park is also a popular spot for community activities and has become a demonstration site for restoring open spaces to a more natural state as well as numerous stewardship activities. These activities include: naturalized plantings, viewing platforms, wood duck boxes,

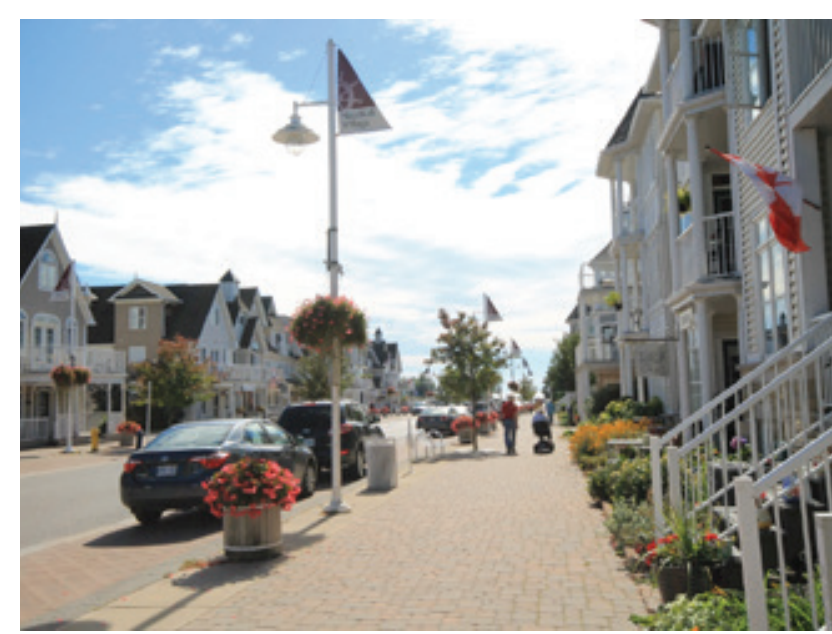

FIGURE 6: Nautical Village main street, Liverpool Road (Image source Taylor Marquis, 2015)

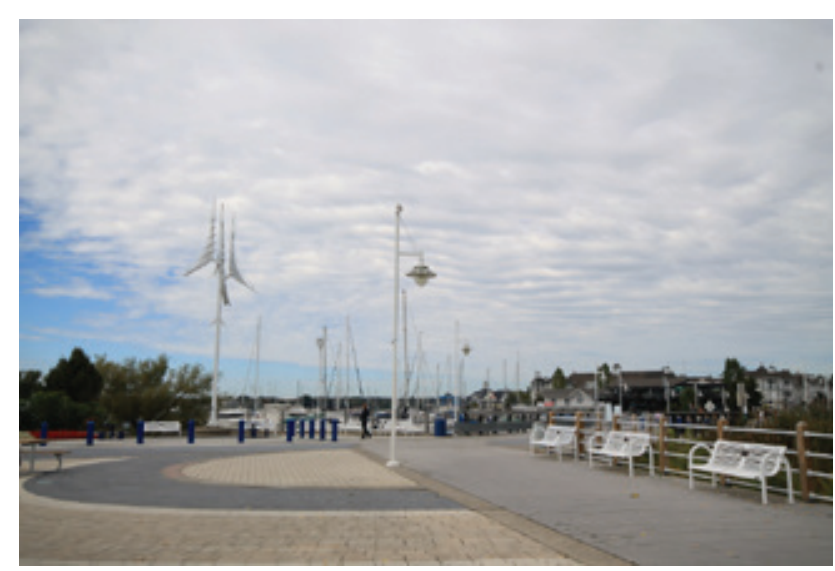

FIGURE 7: Millennium Square (Image source Taylor Marquis, 2015)

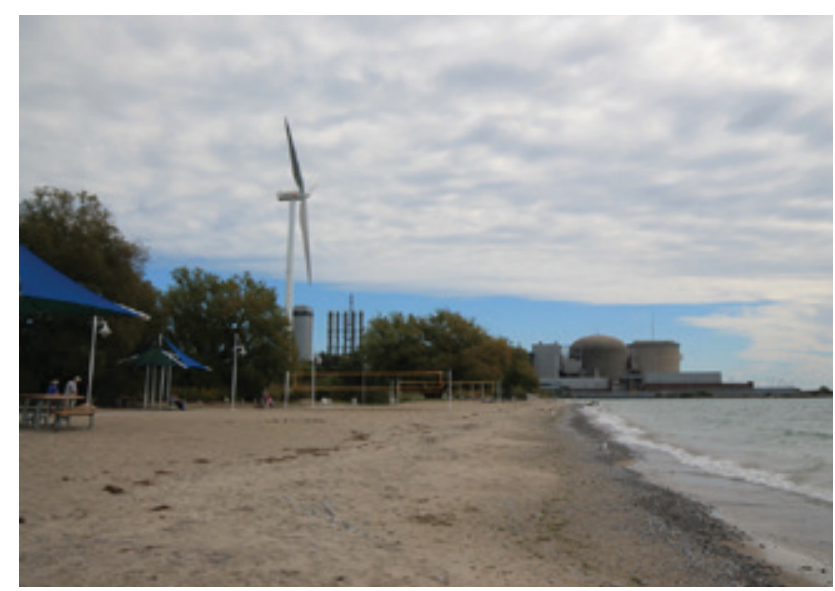

FIGURE 8: Beachfront Park

(Image source Taylor Marquis, 2015) 
snake hibernaculums, turtle basking logs, tern rafts, as well as a cricket pitch.

Rotary Frenchman's Bay West Park: The park is located on the southwest shore of Frenchman's Bay on Beachpoint Promenade off the south end of West Shore Drive. The Rotary Frenchman's Bay West Park has been designated as an Environmentally Sensitive Area by the Toronto Region Conservation Authority (TRCA) due to its diversity of vegetation and significant natural features. The park is characterized by a barrier beach, sand bar coastal wetlands, meadows, and climax forest (TRCA, 2009). The barrier beach is a dynamic beach and sand dune system that is a critically important and rare coastal ecological community that can be found in only a few locations within the Greater Toronto Area ITRCA, 2009). There is a shoreline and dune stabilization process being undertaken by the TRCA has helped establish and protect the coastal wetlands found in Frenchman's Bay.

Waterfront Trail: The Pickering Waterfront Trail is part of the 900 kilometre Great Lakes Waterfront Trail, a provincially and municipally funded trail that runs along the shores of Lake Ontario and the St. Lawrence River that creates a connected trail from Niagara-on-the-Lake to the Quebec border (Waterfront Regeneration Trust, 2013). The trail provides a direct connection to the Ajax, Whitby, and Oshawa waterfront parks to the east, and Rouge Park to the west.

Pickering's of the trail is divided into 3 sections:

- First Nations Trail $(3.5 \mathrm{~km}$ - from Rouge river to the west shore of Frenchman's Bay

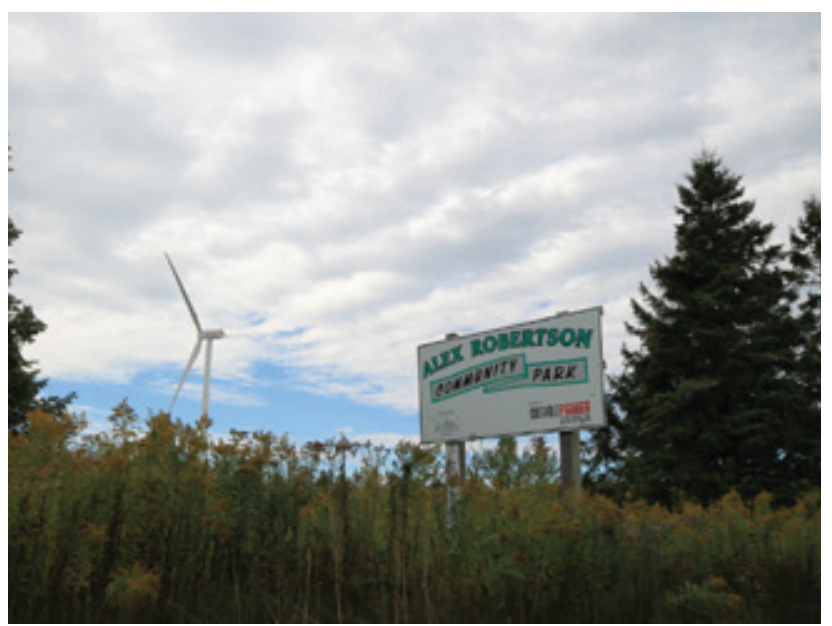

FIGURE 9: Alex Robertson Community Park (Image source Taylor Marquis, 2015)

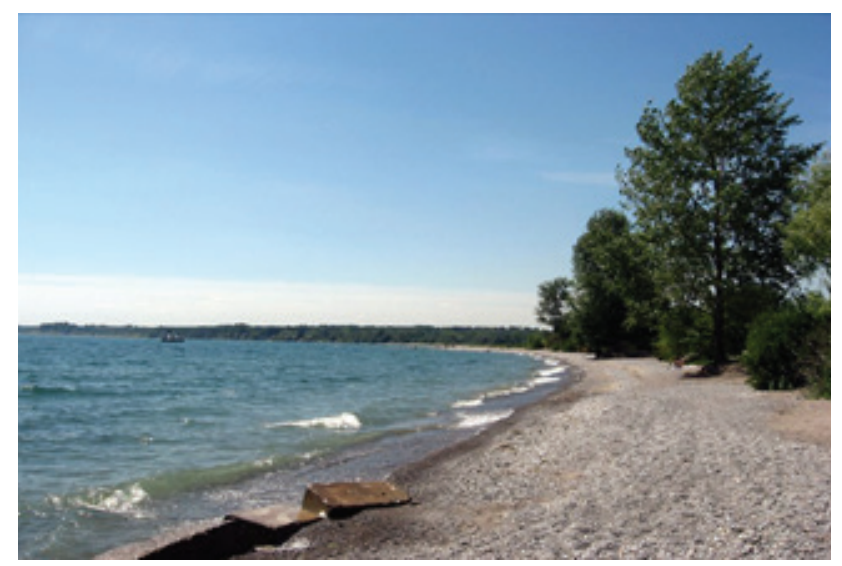

FIGURE 10: Rotary Frenchman's Bay West Park (Image source Jason Bragg, 2011) 
- Monarch Trail [4.7 km] - surrounds Frenchman's Bay and ends at Millennium Square

- Peak Trail $(4.2 \mathrm{~km}$ ) - from Millennium Square to the Ajax border

The Vision for the Mayor's Task Force on the Pickering Waterfront (Town of Pickering, 1998) states, "The Pickering waterfront should create a distinct sense of place". This sense must be nurtured by not only our heritage and unique natural setting, but also by what the waterfront represents to Pickering residents and visitors of all ages and abilities". The development of the Waterfront trail has become an integral component of this Vision. The trail has provided impetus for the further development of a tourist node in the Liverpool Road area (TRCA, 2009).

\section{Waterfront Wildlife Habitat}

Wildlife habitat is limited in the Frenchman's Bay watershed due to its densely urbanized and fragmented landscape (TRCA, 2009). However, the sites form a series of corridors and large patches that contribute to a network of wildlife habitat areas. The shoreline along Lake Ontario serves as a major habitat connection for wildlife and connects to core habitat areas located to the west at Petticoat Creek Conservation Area and the Rouge River mouth. The shore connection allows wildlife to move to larger intact habitat areas further inland, ensuring the survival of large mammals such as coyote and white-tailed deer. The Bay's tributaries also acts as linkages between habitat located north of Finch Avenue (TRCA, 2009). The woodland habitat within the surrounding area offers nesting, foraging, and shelter for resident and migratory bird species, as well as, small mammals, snakes, toads, and frogs.

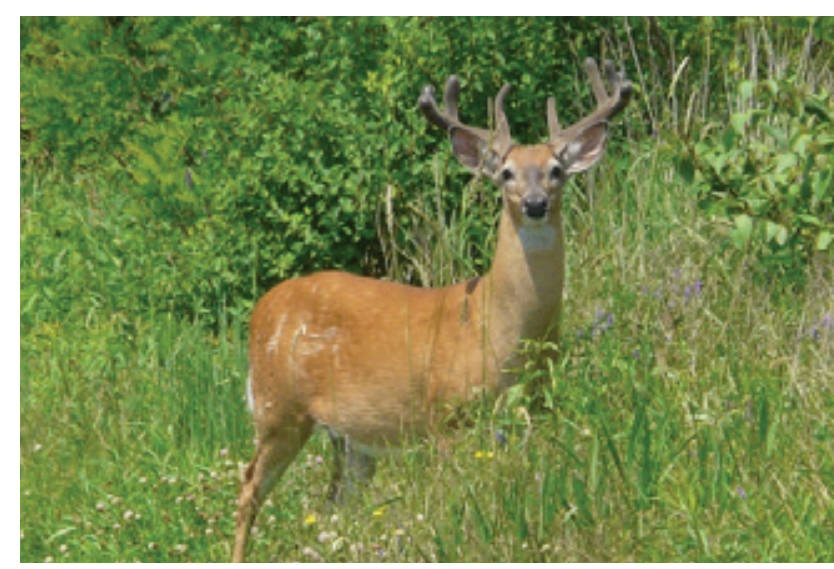

FIGURE 1l: White-tailed deer (IImage source Ken Sproule, 2010) 
Frenchman's Bay, Hydro Marsh, and the shoreline of Lake Ontario provide important habitat for reptiles, amphibians, mammals, and various migratory and resident, shore and water bird species, some of which are of conservation concern (TRCA, 2009). This portion of the waterfront is located within an important migratory zone, which encompasses both the Allantic and Mississippi flyways. Songbirds rely on the vegetated shorelines when in need of rest, food, or shelter during migration. Over २०० bird species have been recorded in this area (Senes, 2007], including rare and unusual birds have strayed from their migration route (TRCA, 2009).

The land/water interface is also a highly productive area, providing foraging opportunities for both aquatic and terrestrial species such as garter snakes, raccoons, and minks. It is also critical to the reproduction of amphibians, turtles, and numerous fish species (TRCA, 2009).

The managed parklands in the area also offer limited wildlife habitat. Trees and shrubs not only offer shelter for resident and migratory birds, these area providing foraging habitat (TRCA, 2009). Foraging swallows, sparrows, finch, nighthawks, swifts, and bats use open areas, while loading and foraging waterfowl utilize lawns (TRCA, 2009). Small mammals such as raccoons, opossums, eastern cottontail, and other rodents are also common in these areas, as are the red fox.

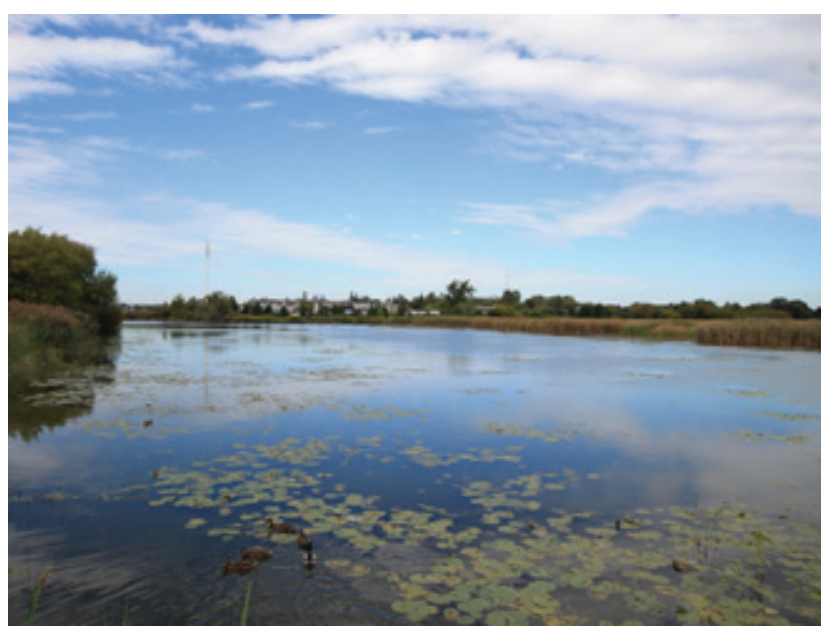

FIGURE 12: Hydro Marsh

(Image source Taylor Marquis, 2015)

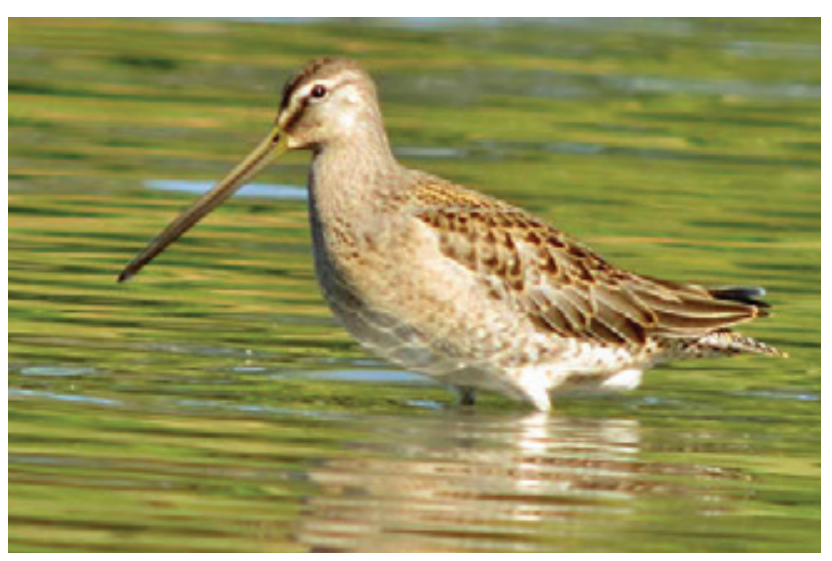

FIGURE 13: Juvenile long-billed Dowitcher at the Hydro Marsh (Image source Jean Iron, 2010) 


\subsection{PICKERING NUCLEAR GENERATION STATION}

According to the Durham Region Official Plan (Durham Region, 2013b), the land surrounding the Pickering Nuclear Generating Station are designated as Waterfront, and Employment Areas. Most of the surrounding area is a combination of both Living and Employment Areas, all of which are located within the urban or built-up areas of the City of Pickering. Lands along Lake Ontario are designated as Natural Areas, Active Recreational Areas, or Marina Areas, in the City of Pickering Official Plan [2010). The Nuclear Station site is designated as a Controlled Access Area in the Pickering Official Plan. The hydro corridor that extends north from the site is designated as a potential multi-use area.

The Pickering Nuclear site is surrounded by residential and recreational areas to the north-west, a hydro corridor the north, industrial and employment areas to the north-east and east. The Duffin Creek Water Pollution Control Plant is located to the east of the site and treats wastewater from both Durham and York Regions.

The Peak Trail section of the Waterfront Trail wraps around the around the Pickering Nuclear Generating Station, which occupies approximately 1.8 kilometres of the waterfront, and is currently not publicly accessible.

FIGURE 14:

Site boundary
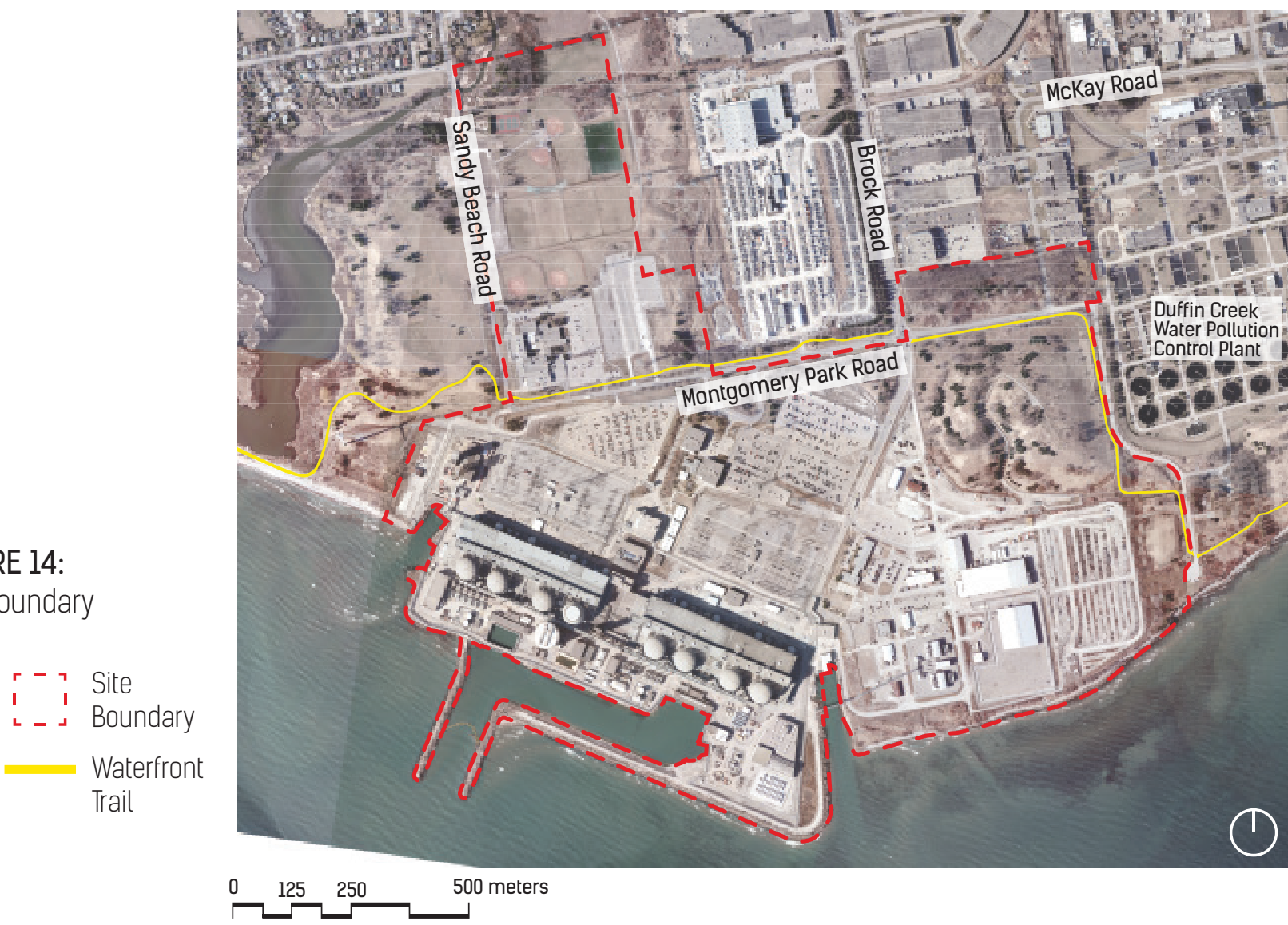
Ontario Power Generation owns approximately 500 acres of land around the Nuclear Power Station. The majority of the lands are a part of the station's exclusion zone, which is land on which there can be no permanent dwellings and which a licensee has the legal authority to exercise control (OPG, 2015).

All structures that contain radioactive materials are located within fenced and heavily secured areas that span the southern portion of the site. Directly north of this area are the switchyards that connect the station to the hydro corridor. These lands are owned by OPG but leased to Hydro One. Hydro One also leases the land on the north side of Montgomery Park Road as a storage area. Hydro One has a 999-year term land lease agreement with OPG (OPG, 2015).

Apart from the nuclear facilities, OPG owns and operates a wide range of other structures on the site, including a wind turbine, office buildings, training centres, a public information centre, and buildings for maintenance and storage. The western portions of the wide are licensed to the City of Pickering and are used for public and recreational uses. This includes the beach, Alex Robertson Park, and the Bay Ridges Kinsmen Park. Along the shoreline, south of the reactor units, is a water treatment facility for water used at the station [OPG, 2015).

The site is broken down into the following zones land are identified in Figure 25 below]:

FIGURE 15:

Planning zones defined for the Repurposing Pickering land use assessment

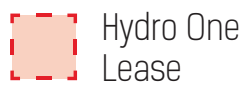

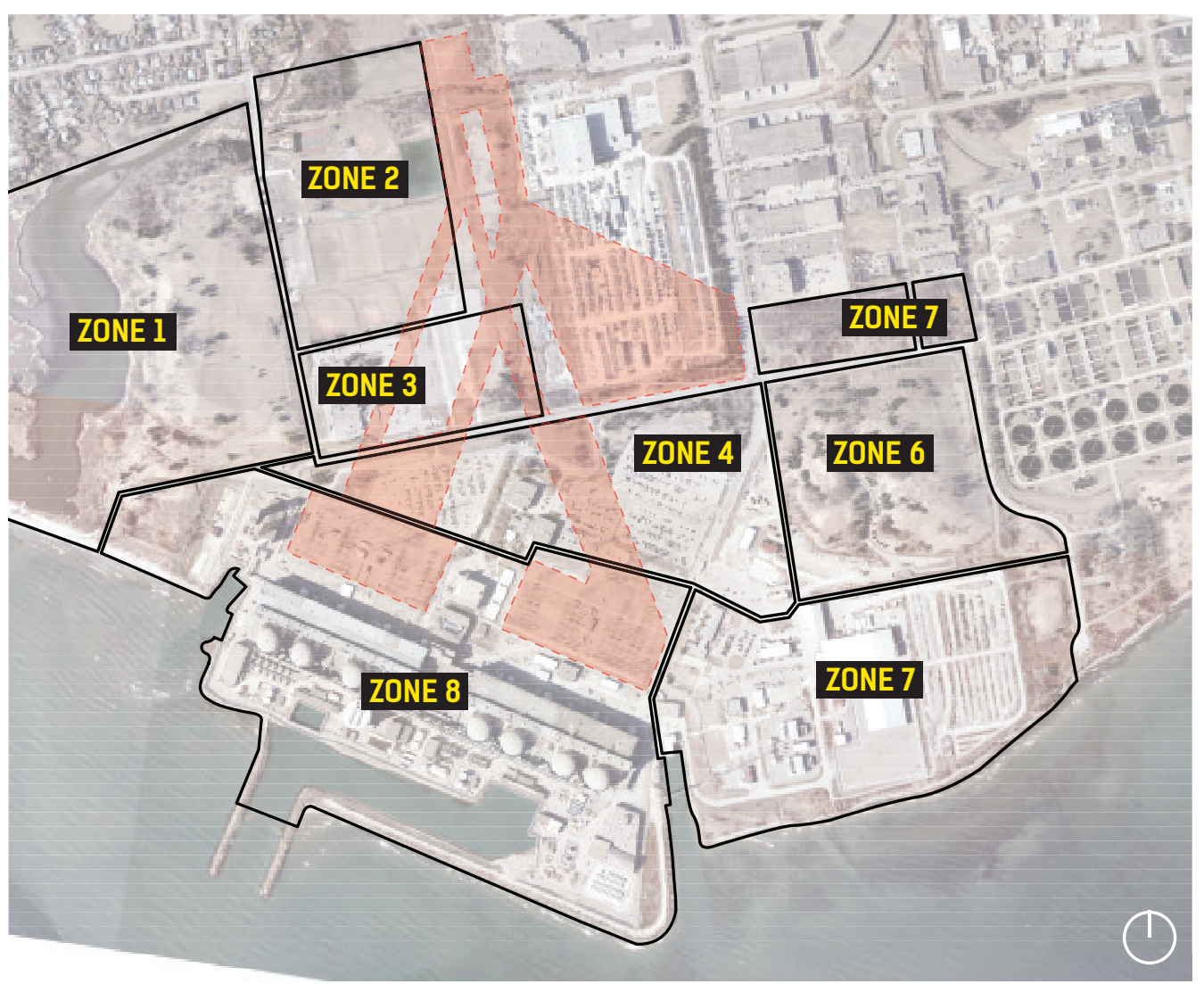

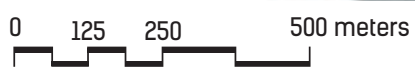


ZONE 1: Alex Robertson Park (101 acres): Contains environmentally sensitive lands and wetlands, a beach, and recreational trails.

ZONE 2: Kinsmen Park (38 acres): Contains a recreation area that is licensed to the City of Pickering and contains a number of sports fields.

ZONE 3: Pickering Learning Centre (23 acres): Contains education and transportation areas that include a training centre with Darlington and Pickering simulators.

ZONE 4: Administration/Parking Area (54 acres): An industrial and transportation area that includes offices (Engineering Service Buildings) and parking areas.

ZONE 5: General Employment (11 acres): Undeveloped, heavily vegetated area that is immediately beside the wastewater treatment plant.

ZONE 6: Landfill (39 acres): The landfill area from the construction of the Pickering Nuclear station. It is heavily vegetated and is no longer in use.

ZONE 7: Nuclear Waste/Controlled Area (72 acres): Contains the waste storage area for the used fuel, workshops, machine shops and offices.

ZONE 8: Power Block (134 acres): Contains the Power Generation Station, waste and storage, and industrial areas. The area also includes used fuel stroll, switchyards, turbine buildings, a wind turbine and a small, overgrown landfill (that is no longer in use).

FIGURE 16: Repurposing potential over time during the decommissioning process (Adapted from Ontario Power Generation 2016)

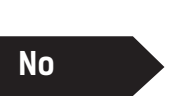

Implementation of reuses or new uses is not deemed possible due to the very high level of constraints imposed by the activities within or adjacent to the planning zone.

Medium

New uses may be possible to implement also on a larger scale, subject to applicable constraints and uncertainties.

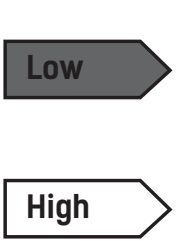

Certain types of complementary uses would be possible to implement, although significant constraints are anticipated. Changes on a smaller scale may be particularly conducive

Complete change in use within all or most of the zone may be possible.

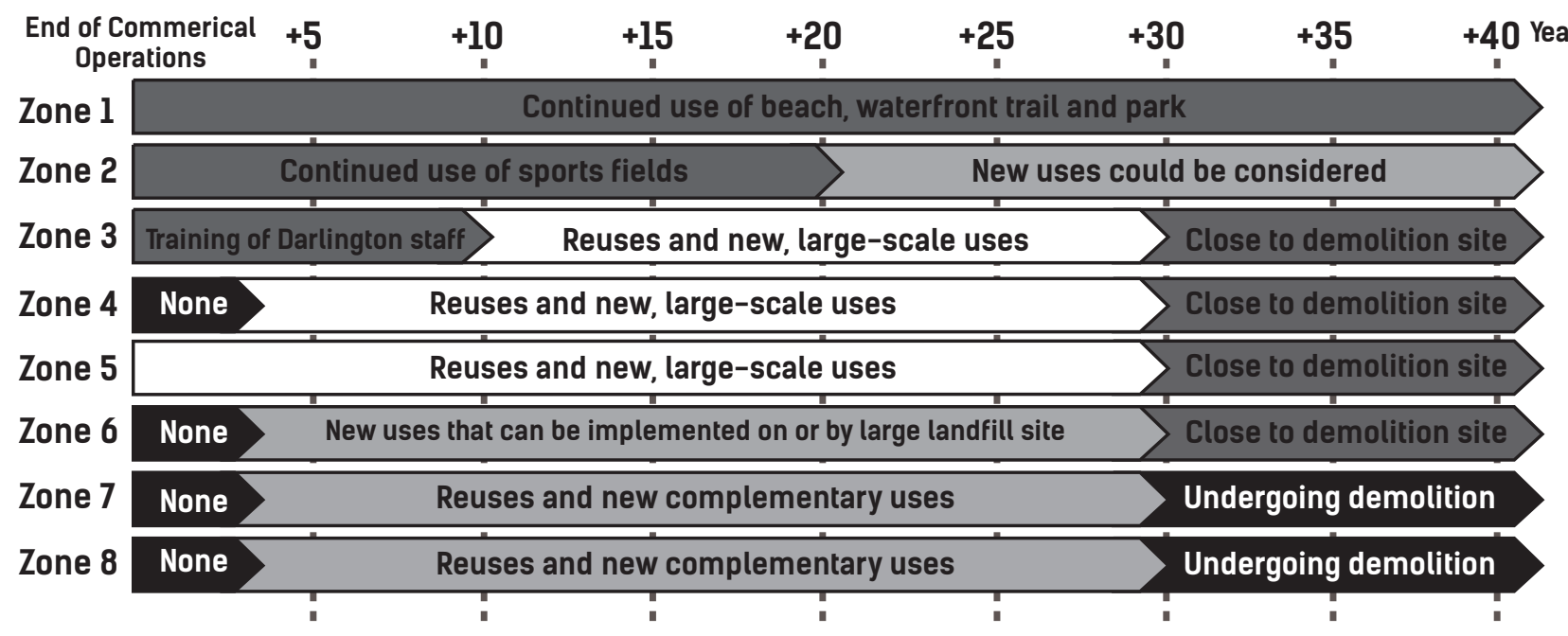


Once commercial operations have ceased, nuclear-related operations will continue for another four decades with respect to used fuel storage, decommissioning and waste management [OPG, 2015]. New uses should take into account constraints associated with those activities, and the OPG has provided information on the repurposing potential of the site during the decommissioning period (see Figure 16).

\section{Site Natural Environment}

During the construction of the station, the ground surface of the site was extensively modified. According to the preliminary assessment of the site by OPG, some of the key existing natural features of the site include:

Shoreline: The site's shoreline frontage along Lake Ontario is approximately 2,260 meters. The shoreline was extensively modified during construction and no natural shoreline remains within the site's boundaries [OPG, 2015].

Soils: The original soil complex of the site was significantly disturbed during construction. The upper soils were removed and filled with sandy and silty fill material. In areas where original soil remains, it is composed of clayey glacial till overlying bedrock (OPG, 2015).

Vegetation: The protected areas in the southern portion of the site do not contain any vegetated areas of significance. Areas outside of the protected zones are a host to a variety of vegetation including grasses or shrub bush, and treed areas along the east of the site [OPG, 2015].

Wildlife habitat: Areas of the site that are not routinely used, the vegetated areas, have become habitat $f$ or wildlife. A variety of species of mammals, birds, reptiles and amphibians have been observed in the area [OPG, 2015].

\section{"Repurposing Pickering"}

In planning for the end of commercial operations at the Pickering Nuclear Generating Station, OPG is presently undertaking a study to explore future uses of the site. Their goal is to ensure that the site will continue to be put to productive uses that benefit the community during and after the decommissioning of the Pickering station. OPG aims to protect the site's long-term potential for the site once it has been released from regulatory control.

In OPG's preliminary assessment report [2015], which incorporated feedback from the public and stakeholders during consultations and input from a contracted consulting team, determined that the following types of land use categories are most suitable during the decommissioning period: power, industrial, institutional and recreational uses. These land uses have been recommended for future study. 
Once the plant is released from regulatory control in 2064, the population of the City of Pickering is expected to double to over 200,000 people. As the City intensifies, there will a growing importance put on natural areas for both recreation opportunities, and natural connections and habitats. This site is the last site of this scale ( 400 acres) along the waterfront that could be dedicated to these uses.

There is a rich natural heritage in the immediate surroundings of the site, Rouge Park to the west, and the Greenbelt further north. Restoring the site into a natural environment can play an important role in fostering important green connections, natural corridors for flora and fauna, and building greater environmental resiliency.

Additionally, parks do not only provide recreational opportunities, but can also create a civic identity. In the case of this site, the nuclear station is closely associated with the identity the City of Pickering. Transforming this landmark into an open and publicly accessible park and recreation area can create a new identity for the City of Pickering. The site also provides an opportunity to improve the Waterfront Trail connection. This improves the connection to additional waterfront parks and areas along Lake Ontario.

Repurposing Pickering: OPG wants to maintain ownership of the site and are entertaining a wide range of new uses on the site. Uses that currently rank high with OPG include: Industrial (film studios, food production, manufacturing, outdoor storage); Institutional (Public tours, Public information centre and/or museum, Higher education); Recreational (Community activities, parkland). These uses are constrained by their current decommissioning and site release schedule and the strict legal restrictions imposed on them. However, redeveloping the site into parkland appears to be feasible and within the realm of possibility.

Hydro One also has a 999-year land lease on the site and could potentially be interested in continuing energy production on site. Potential Hydro One use: Solar Power? The site is large enough to accommodate this use and the existing hydro corridor, leased by Hydro One, can be updated to make the necessary improvements to support this form of energy production

Because the site will not be completely open until 2064, phasing will be a key component on site. It is important that the redevelopment is phased over time to allow residents/visitors to interact with the site (and stay interested and invested) as it is slowly opened up. It will also take decades to establish a natural ecosystem on the site and should begin shortly after the station is closed. The park should remain flexible and adaptable when it comes to programming as the needs of the community and the City can be expected to change. 


\subsection{NUCLEAR POWER IN CANADA AND THE PICKERING NUCLEAR POWER GENERATING STATION}

The Pickering Nuclear Power Generating Station was the world's first, and once largest, commercial Canadian Deuterium Uranium reactor (CANDU) power station. The CANDU technology and reactor was developed exclusively in Canada, and was designed specifically for the production of electricity (candu.com).

The commercial use of nuclear power has only been around for 60 years², and only five stations across the world have completed the decommissioning process and been completely dismantled ${ }^{3}$. There are a number of stations that have been closed, but are still in the process of decommissioning. Nuclear plants in Canada and the United States were designed for a 30-40 year lifespan, and undergo a lengthy and phased regulated decommissioning process that can take up to 50 years before they can be demolished and released from regulatory control (Canadian Nuclear Safety Commission, 2016).

While the decommissioning process of these stations has been heavily researched, there is limited research on the reuse potential of the sites both throughout, and once it has completed. Existing literature and regulation dictates that sites should be returned to their green field state, and do not discuss any reuse opportunities during or after decommissioning. However, the International Atomic Energy Association (IAEA) is starting to explore alternate redevelopment options of the sites, which leads to the "Repurposing Pickering" project that is currently been undertaken by the Ontario Power Generation at the Pickering Nuclear Power Generating Station site.

This section will review the history of nuclear power in Canada, provide a brief explanation of how the CANDU reactor works, how nuclear plants are decommissioned, the current discussion within the industry on the redevelopment potential of these sites, and the existing decommissioning plan for the Pickering Station.

\footnotetext{
${ }^{2}$ The first commercial nuclear power station in the world was Clader Hall in Windscale, England, and was opened in 1956 (Kragh, 1999]. The first commercial nuclear generator in the United States was the Shippingport Atomic Power Station in Pennsylvania in 1957 (Nuclear Regulatory Committee, 2007)

${ }^{3}$ These plants include the Shippingport Atomic Power Station in 1985 (Pennsylvania, USA), Maine Yankee Power Plant in 2005 (Maine, USA), Connecticut Yankee Nuclear Power Plant in 2006 (Connecticut, USA), the Yankee Rowe Nuclear Power Station in 2007 (Massachusetts, USA), and Chooz A in 1991 (Chooz B-1 and B2 are still in operation) (Ardennes, France).
} 


\subsection{HISTORY OF NUCLEAR POWER IN CANADA AND THE PICKERING NUCLEAR POWER GENERATING STATION}

[Adapted from the Canadian Nuclear Association 2015, and World Nuclear 2016]

The nuclear industry in Canada began in 1944 when Canada began developing its own line of power reactors. An engineering team was bought together in Montreal, Quebec, under the administration of the National Research Council (NRC), to develop a heavy water moderated nuclear reactor. This led to the construction of a research facility in Chalk River, Ontario.

In 1945, approval was given to proceed with the construction of the Zero Energy Experimental Pile (ZEEP) test reactor at Chalk River. In September 1945, the ZEEP became the Canada's first nuclear reactor, and the second successful nuclear reactor outside of the United States. ZEEP was also one of the first heavy water reactors in the world and was instrumental in the development of the National Research Experimental Reactor (NRX) in 1947.

The Canadian government established the Atomic Energy of Canada Ltd (AECL) as a crown corporation in 1952, with the mandate to develop peaceful use of nuclear energy. AECL took over the operation of Chalk River from the NRC, and in the early 1950s, collaborated with Wilfrid B. Lewis, Ontario Hydro, and Canadian General Electric to begin the development of the CANDU reactor. The first electricity-producing reactor, and the prototype for

Figure 17: Canadian Nuclear History Timeline

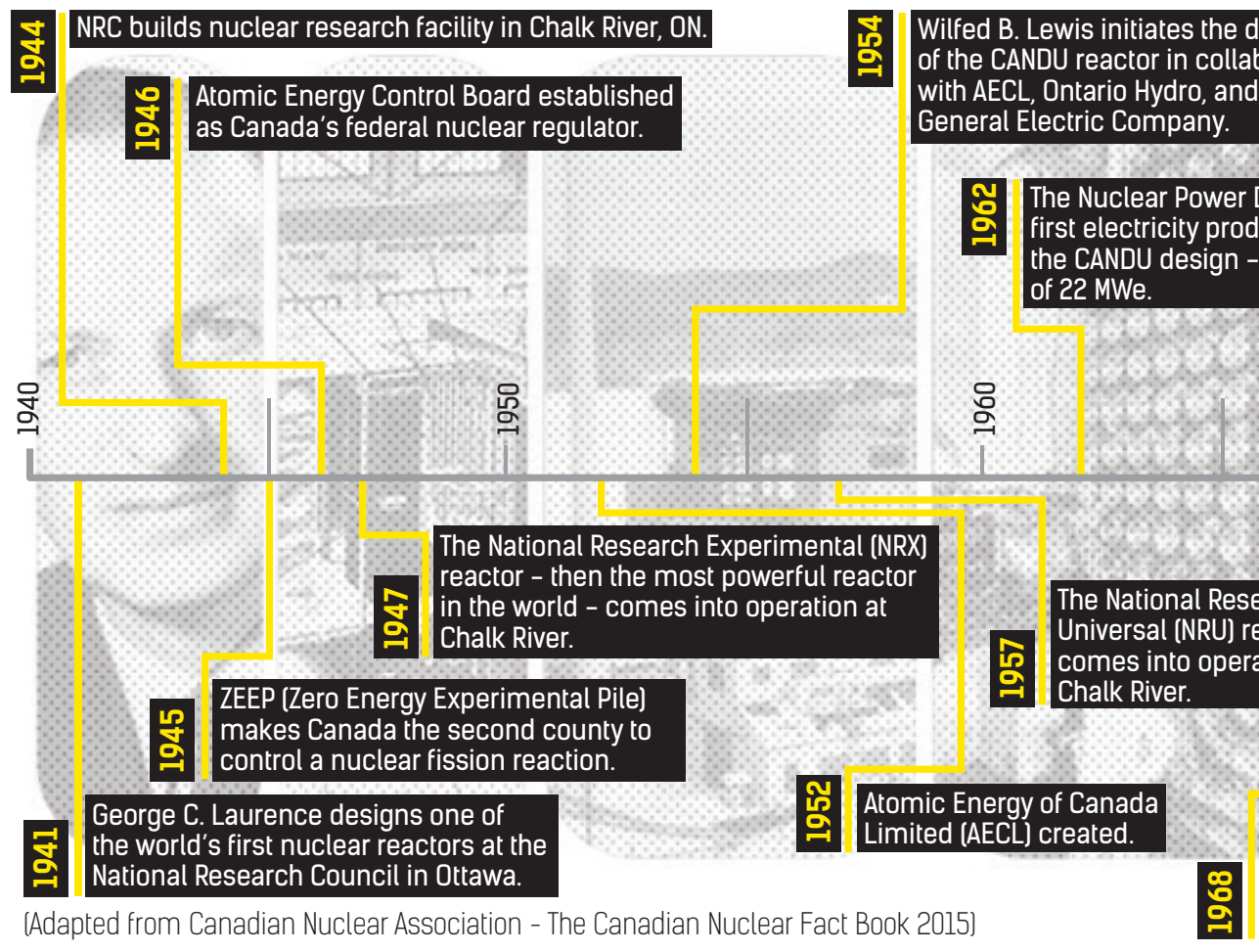

control a nuclear fission reaction. full-scale power reactor - comes

online in Kincardine, producing २2० MWe. 
the CANDU design, was the Nuclear Power Demonstration [NPD], which was built in 1962. Its success led to the construction of the first full-scale reactor at Douglas Point in 1968. The first commercial CANDU reactor began operations in Pickering, Ontario, in 1971.

In 2011, Candu Energy acquired AECL's commercial operations. AECL retained the intellectual property rights for the CANDU reactor and still operates as a federal Crown Corporation. They are now responsible for the longterm contractual arrangement with the Canadian National Energy Alliance [CNEA] for the management and operation of Canadian Nuclear Laboratories (CNL) (Atomic Energy of Canada Limited, 2015). They also manage Canada's radioactive waste and decommissioning responsibilities.

Currently, there are 19 power reactors operating at four nuclear power generating stations in Canada (Canadian Nuclear Association, 2014). Three plants (Bruce, Darlington, and Pickering) are located in Ontario, and one in New Brunswick (Point Lepreau). In 2014, Nuclear power accounted for 16\% of electricity generated in Canada [Canadian Nuclear Association, 2014].

CANDU reactors are not only used within Canada, and as of 2015, there are 28 CANDU, and CANDU-derived reactors used worldwide, which account for $11 \%$ of nuclear reactors worldwide (Canadian Nuclear Association, 2014).

Bertram N. Brockhouse awarded

Nobel Prize for neutron scattering research conducted at Chalk River. (NWMO). In 2007, the federal government approved the NWMO's Adaptive Phased Management approach for the long-term storage of spent nuclear fuel.

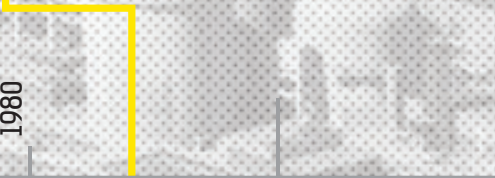

All four units at Pickering $A$ come online at $2060 \mathrm{MWe}$

AECL's Commerical operations acquired by Candu Energy. AECL remains a federal crown corporation.
Refurbishments to Bruce A

complete, making the Bruce

Power facility the largest nuclear generating station in the world. 


\section{Pickering Power Generating Station}

When the Pickering nuclear generating station was first completed in 1973, it contained four reactor units, which are known as Pickering A(1-4). Four additional units (Pickering B) were constructed in the 1980s, with the last unit completed in 1986. Pickering units Al and A4 were refurbished in 2004-2005, extending their life expectancy to 2020 and 2018. However, due to cost overruns (which were twice than the original estimate), its owner and operator, Ontario Power Generation [OPG], decided not to refurbish units A2 \& 3 and retire them in २००५ (World Nuclear, 2016).

In 2010, OPG decided against a full refurbishment of the remaining units in the station, and decided to spend \$200 million on a fuel channel life management project that would extent the station's life expectancy by ten years before decommissioning the plant in 2020. The Canadian Nuclear Safety Commission (CNSC) renewed the single operating license of the remaining six reactors in 2013, and in November 2015, a study was released assessing the potential running of the six reactors until 2024. In January 2016, the government approved this study, and two of the reactors will be shutting down in 2022, and the remaining four in 2024. OPG is currently preparing a license application accordingly. The station is currently the largest single employer in the City of Pickering with 3,000 employees and has a total output of 3,100 megawatts (MW). The station currently produces $14 \%$ of Ontario's power (OPG, 2015).

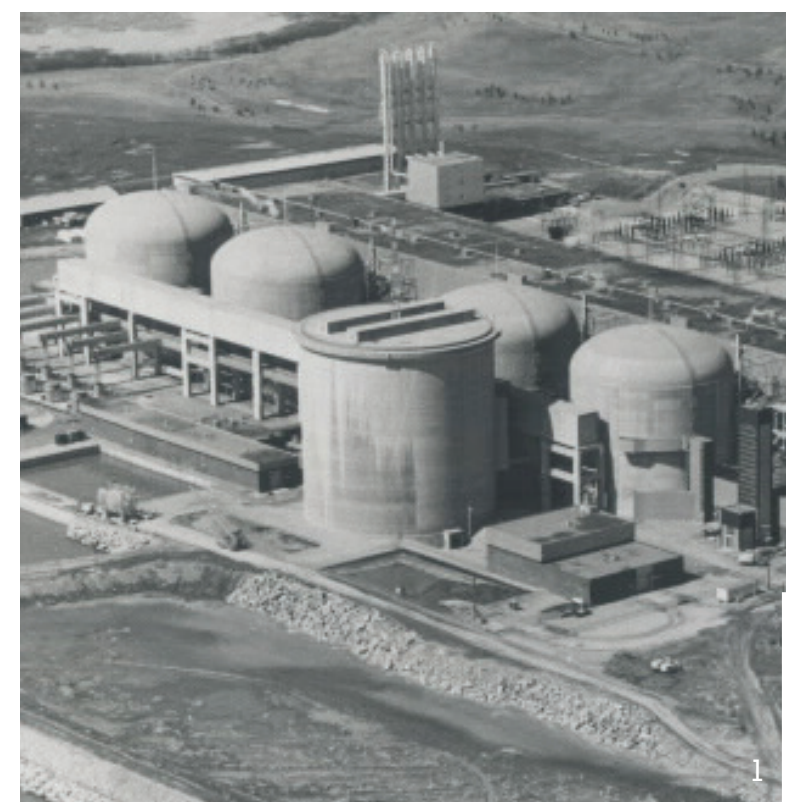

Figure 18: Pickering Nuclear Generating Station under construction in 1972, and in 1975 once completed. (Image source: (1) Toronto Star Archives, 1975, (2) Pickering-Ajax Digital Archives, 1972]

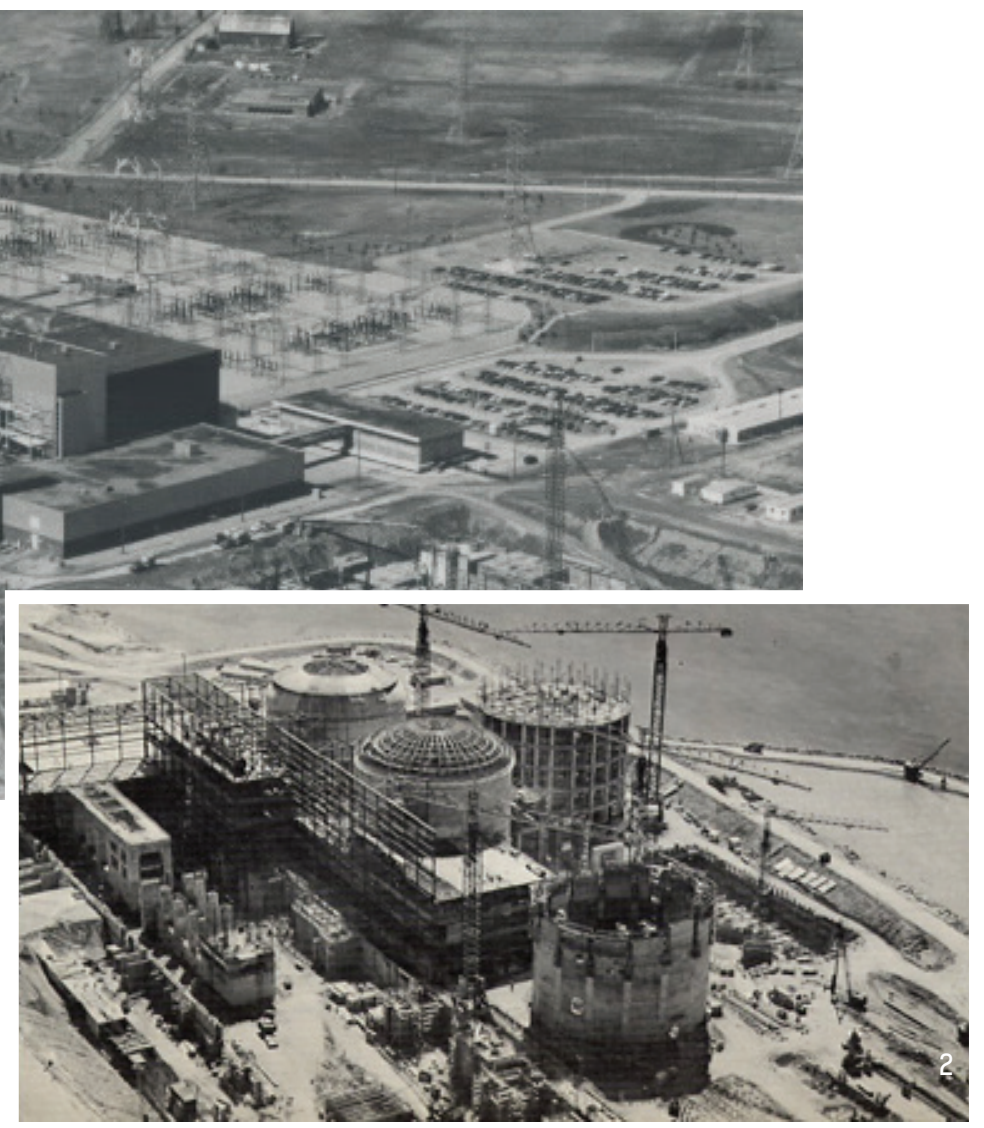




\subsection{HOW THE CANDU PLANT WORKS}

Nuclear energy begins with uranium, a heavy metal that is mined in Canada. Natural uranium has three or more "isotopes," with slightly different weights (Canadian Nuclear Association, 2016). One variety, uranium-235, naturally wants to split, or fission, into two lighter elements. During the fission process, a tremendous amount of heat is generated, which can be converted into electricity. However, naturally occurring fission events occur infrequently, and in order to produce a useful amount of heat, the rate of fissioning must be drastically increased. A nuclear reactor is a device in which uranium can be caused to fission at a higher rate, and that the heat released is harnessed to generate steam to spin a turbine that powers a generator [Steed, 2007). In order to ensure that the rate of fissioning does not increase beyond the capacity of the power station to use the heat generated, it is essential to control the fission process at all times to control the desired amount of heat being produced. Control mechanisms such as control rods are installed to move in and out of the reactor core to slow down or stop the fissioning process.

To ensure that the reactor does not overheat, it is placed in a tank that contains heavy water as a moderator. Heavy water coolant circulates through the reactor core to cool the fuel bundles (which contain the fissioning uranium], down. As the heavy water coolant is pumped through the fuel bundles, the hot coolant is pumped into the steam generator, or boiler, where the heat in the heavy water boils feedwater (ordinary water) into steam. This

Figure 19: Schematic diagram of CANDU reactor

(Adapted from Canadian Nuclear Association 2015, Steed 2007)

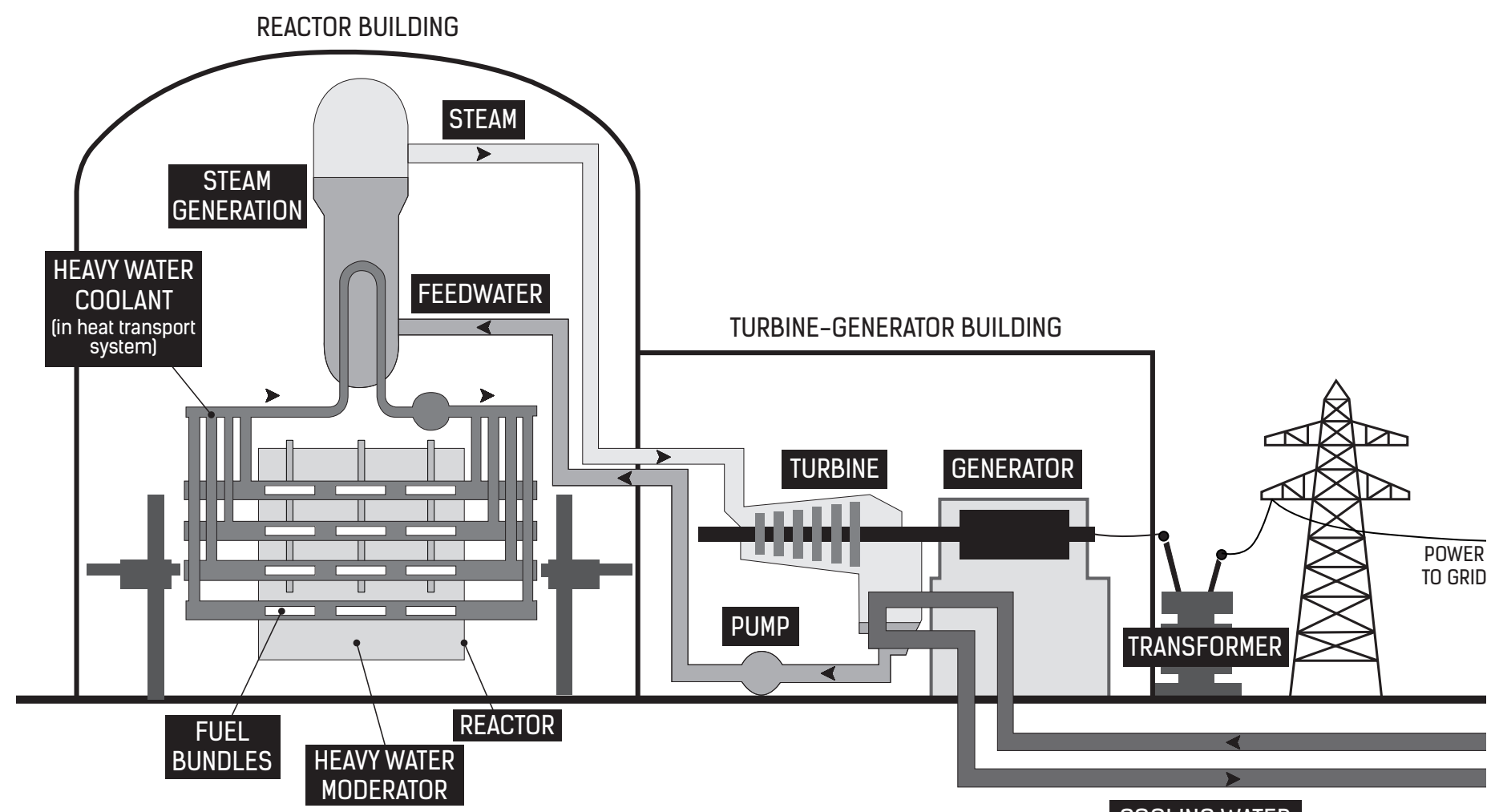


steam is then pumped into the turbine hall to spin the turbine, which drives the generator to produce energy [Steed 2007, Canadian Nuclear Association 2016].

Once the steam cools down, it is then condensed back into water and is then pumped back into the steam generator to pick up heat from the hot heavy water coolant all over again. The hot heavy water coolant follows the same process as it cools down. The coolant is pumped back through the reactor to heat up again (Steed, 2007]. A dump tank is located underneath the reactor where the heavy water moderator may be dumped into in order to shut down the reactor.

Each reactor is housed in its own reactor building, and is separate from the turbine and generator, which are located in the turbine building. The reactor buildings are large reinforced concrete buildings: their internal diameter is 140 feet, their walls are 4 feet thick, and their height is 152 feet, 9 inches (Steed, 2007). The eight reactor buildings at the Pickering station are connected by a vacuum duct to a single vacuum building. The vacuum building rapidly draws in and uses a water spray to condense any steam from a loss-of-coolant accident of any of the reactors of the station. This allows the reactor building pressure to return to subatmospheric conditions and minimizes any leakage from the reactor building.

\section{Nuclear Waste and Radioactivity}

The principle waste from a nuclear power station is irradiated, or spent nuclear fuel. This waste is considered to be high-level waste. When used fuel is removed from a reactor core, it is hot, radioactive, and highly dangerous to unshielded workers. In Canada, spent fuel bundles are stored in fuel bays onsite, which are essentially pools filled with water, for five to ten years to cool down. Once safe, the bundled are then stored in dry fuel storage concrete canisters, which are stored onsite until they are ready to be transported off-site at a later date.

The remaining waste on site is either considered intermediate-level waste, or low-level waste. Intermediatelevel waste includes reactor parts that have been in direct contact with radioactive material. After use, these items are held in containers made of materials that block radiation (lead, for example). The waste is stored in long-term facilities where the items slowly lose most of their radioactivity over time. Low-level waste includes items such as cleaning tools and protective clothing that are used in nuclear facilities. These items rarely touch radioactive material and can be handled like regular garbage but are sometimes placed in long-term storage for safety concerns].

Some areas of a nuclear power station have quite intense radiation levels while the reactor is operating at high power, and so access to these areas are restricted by locked doors. Other areas are accessible at all times. Canadian nuclear power stations are divided into zones to control the spread of radioactive contamination [Steed, 2007). 


\subsection{PLANT DECOMMISSIONING PROCESS}

International Atomic Energy Agency (IAEA) publications refer to three primary strategies that are to be used when decommissioning a facility or site. These primary options are immediate dismantling, deferred dismantling and entombment (IAEA, 2006). The strategy most commonly used, and that will be used to decommission the Pickering Nuclear Power Generating Station, is the deferred dismantling process. Deferred dismantling, also called safe storage or safe enclosure, is the strategy in which parts of a nuclear facility containing radioactive contaminants are brought into a conditions where they can safely be stored and maintained on site until they can be subsequently decontaminated and/or dismantled (IAEA, 2006).

Decommissioning and dismantling a nuclear power station is a more difficult and expensive task than for a conventional oil- or coal-fired station. This is largely attributed to the highly radioactive fuel and materials that must be handled remotely and requires special tools to limit the exposure to radio for the workers dismantling the plant (Steed, 2007). The process for decommissioning a CANDU facility is as follows:

The first step in the decommissioning process is to remove all the fuel from the reactor and deposit it in the spent fuel bay. Here the fuel will be allowed to cool for at least six or seven years, until it can be safely transferred into dry storage containers. Once the fuel has been removed from the reactor, a process that takes about four to six months, the heavy water will be drained from the moderator and heat transport systems, and will be shipped to Ontario Power Generation's Darlington Tritium Removal Facility for de-tritiation. The detritiated heavy water will be available for use in another CANDU reactor

Once the water and fuel have been removed, a radioactive "crud" will remain on the insides of the feeder pipes, headers, and boilers. A special solvent is run through the boils, reactor, and piping to decontaminate these surfaces [Steed, 2007]. While the reactor and associated piping will be much less contaminated, the reactor internals will remain fairly radioactive and will require special handling and storage at a radioactive waste site.

At this point, a decision will be made to either start dismantling the reactor, boilers, and piping, or wait to as much as fifty years for the radioactivity to decay quite considerably. Unlike certain dangerous materials, radioactivity diminishes with the passage of time. Allowing the radioactivity to diminish protects those who are involved in dismantling the site for they will be exposed to less radiation (Steed 2007). This applies to the reactor building on the site, and to the areas that may have come in contact with radioactive materials. Because the turbine and associated administrative buildings have never come into contact with radioactive materials, they do not require a special decommissioning or dismantling process.

At some point, the nuclear fuel will likely be transported a central fuel repository, a facility that Canada is currently in the process of establishing. While the fuel will remain radioactive for thousands of years, the 
intensity will have greatly decreased. In approximately 500 years, the fuel will emit that same radiation as newly mined uranium (Steed, 2007). Such radiation intensities are still significant, but far from lethal. As this is a wellunderstood process, there are no unsolved technical problems in managing this fuel.

\section{Pickering Nuclear Generating Station Decommissioning Process}

The following diagram (Figure 20) outlines the assumed decommissioning timeline provided by OPG. It is estimated that the process will be completed by 2064.

Figure 20: Main timeline assumed for purpose of the 'Repurposing Pickering' assessment

\section{Approximately}

2024

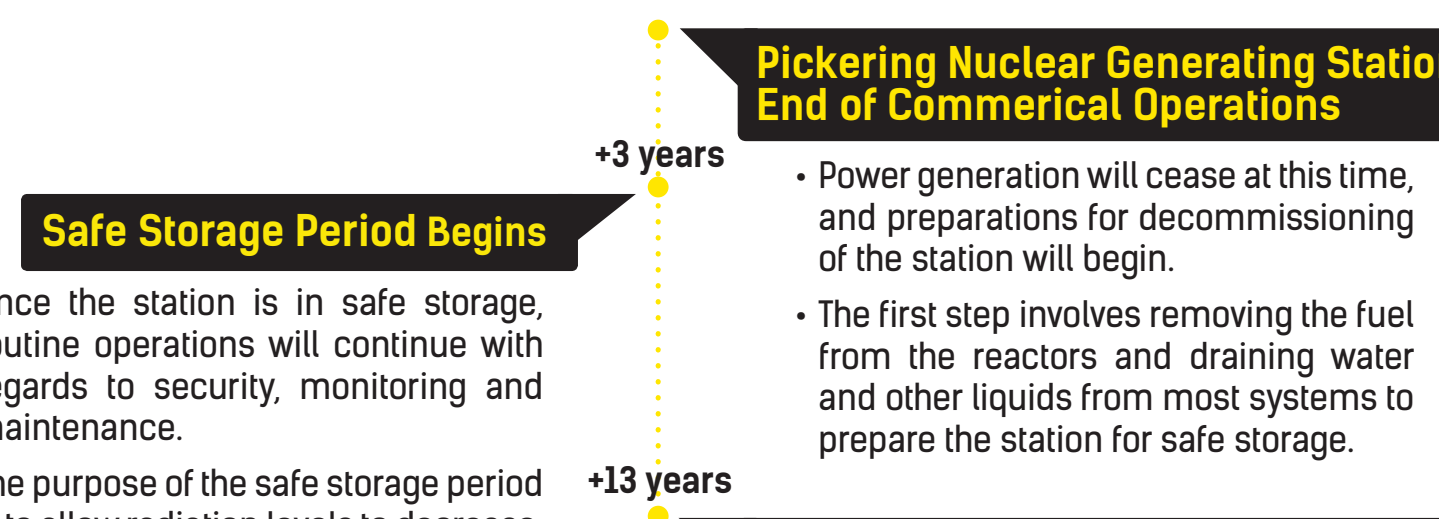
is to allow radiation levels to decrease.

- Potential repurposing options that are compatible with decommissioning operations may be implemented.

\section{+13 years}

\section{Used Fuel Transferred to Dry Storage}

- During the first 10 years of safe storage, used fuel will continue to be transferred into dry stroage containers and moved to the adjacent

+30 years waste management facility.

\section{Used Fuel Transported Off-site}

- After the safe storage period, it is expected that the used fuel will be transported off site.

- At this time, the physical demolition of remaining structures will begin.

- Once used fuel has been removed from the site, restrictions on potential new uses will be reduced further.
- The process and equipment needed for this transfer are already in place, and the site can easily accommodate all used fuel from the Pickering station.

+40 years

\section{End of Decommissioning}

- At this point, the decommissioning of the nuclear facilities will be complete and the site can be released from regulatory control.

- The remainer of the lands will then be available for repurposing. 


\subsection{NUCLEAR SITE REDEVELOPMENT}

The first International Atomic Energy Association publication on the decommissioning of nuclear facilities was issued in 1976. Since then, over 40 technical documents, conference proceedings, technical reports, and Safety Series and Safety Standards publications have been issued covering specific aspects of the decommissioning process. This includes technological aspects, safety and environmental protects, national policies and regulations, monitoring programs, characterization of shut down facilities, and design and construction features to facilitate future facility decommissioning (IAEA, 2006).

For a long time, the final goal of decommissioning was to reach the unrestricted release of the site and restoring it to its previous natural condition - to a green field state. However, more experience in the decommissioning process has become available over the last 15 years, and has altered the way the industry see this process [IAEA, 2006]. Recent experience has shown that once a site has been decommissioned, there is a desire to immediate re-use of the site or buildings in a productive application (Laraia, 2011). Some of these facilities were originally constructed on the edge of a growing metropolitan area, often along a waterfront, but are now located in the centre of an urban area and are engulfed by city sprawl. These sites now occupy prime and desirable land within these growing communities (IAEA, 2011). Laraia (2011) also claims that most facilities benefit from a flat topography, good access to utilities transport and other communication links, as well as a skilled labour force, all of which are conducive the rapid redevelopment (Laraia, 2011).

This has impacted the way the nuclear industry and the IAEA think about the end goals of the decommissioning process. The IAEA have recently released a number of technical reports that explore the redevelopment potential of these sites, as well as a number of case studies and lessons learned from both the nuclear and non-nuclear industry.

The industry is encouraging that a closed life cycle approach should no longer be the only option for these sites (IAEA, 2011), and that decommissioning should provide an opportunity for redevelopment and ruse. They claim that various redevelopment and reuse options should be explored and incorporated into the decommissioning strategy. Exploring and identifying these options early in the process, new technology (such as clean up techniques) or the development of new infrastructure (waste disposal facilities) can be implemented to increase the redevelopment opportunities (Laraia, 2011). The opportunity to reuse these obsolete facilities, that are now found within the urban core, supports sustainability and smart growth initiatives that focus redevelopment to inner cities in an effort to decrease urban sprawl and in improving the quality of life of its residents (IAEA, 2011). 
The site played an important role in nuclear power in Canada and the development land global distribution) of the CANDU reactor and nuclear technology. With our new understanding of cultural heritage, the site is worthy of some sort of commemoration or preservation. However it should be done in a manner that acknowledges the polarizing opinions about the industry, but also creates a place that can inform and facilitate a conversation that allows individuals to form their own conclusions. This process could be improved by allowing people to interact with the buildings, which would allow them to understand how they work, and the lengthy and complex process of dismantling once they have reached the end of their productive life cycle.

The dangerous levels of radioactivity are well contained on site, and are restricted to the reactor building and fuel management facility. This creates a safe opportunity for people to interact with the rest of the site during decommissioning, allowing for the remaining structures on site to be demolished early in the process, and for the lands to begin ecological restoration. Once the used fuel, coolants, reactor and associated radioactive material is removed from the reactor buildings, and the radioactivity is given time to diminish, an opportunity exists to open the buildings to the public and to use them as an educational tool. Some of the fear that exists around nuclear energy and its perceived dangers are not always rational, and reusing the buildings, or even allowing the public to tour them during the decommissioning process, can use existing skepticism as an educational tool, and inform the public perception of risk. Pickering units A2 \& A3 have been closed the longest and could potentially be the safest units to use.

The decommissioning process and repurposing of the site will be the first within Canada and can set a precedent for other nuclear facilities around the world. It presents not only an educational opportunity for individuals in the nuclear sector, but for the public at large. What is proposed should be outside of the status quo, while being reflective of what is both possible and appropriate for the site and the greater community. 


\subsection{PRECEDENT STUDIES}

This new understanding of post-industrial landscapes and disturbed sites, has not only been redefined by Meyer (2007) and Braae (2015), but also through a number of recent park projects on former industrial sites. These projects have employed design strategies that integrate multifunctional long-term solutions that focus on the sustainability, quality and multi-functionality of the space, while paying special attention to their historical significance, and socioeconomic and cultural aspects. This section will explore two of these projects: Landschaftspark Duisburg-Nord, and Fresh Kills Park. These projects were chosen due to their different approaches undertaken in regards to their design and theoretical approaches, their applicability to the site, and due to the fact that they are often referred to as revolutionary projects that have transformed our understanding of industrial and 'disturbed' landscapes. 


\subsection{LANDSCHAFTSPARK, DUISBURG-NORD, GERMANY}

LOCATION: Duisburg, Germany

DESIGN: Latz + Partners

PROJECT DATES: 1990-2002

SIZE: 586 acres (237 ha)

In 1990, Latz + Partners won the international competition for the design of the former Thyssen Stahl iron and steel works. The conversion of the disused mining zone and iron and steel works into a park was an innovative design approach which has led the park to become one of the richest references for transforming ruinous industrial landscape (Braae, 2015).

The site is comprised of a surface fragmented by motorways, roads, railway lines, and industrial facilities, making it impossible to recognize the original landscape. Latz + Partners took this existing landscape and attempted to reveal the unique qualities of this place and open it up to new uses. The complex historical layers of use, which had left their mark on the landscape, were used for their creative potential, rather than being erased or camouflaged.

The park is often described as having three distinct zones (Hargreaves, 2007). Two zones respond to the industrial past. In the first zone, the industrial machinery has been opened to the public for access, interpretation, and adaptive reuse such as diving in the gastrometer and wall climbing in the ore bunkers. The second area is the wilderness area, and features a potpourri of plants form around the world that arrived as seeds via

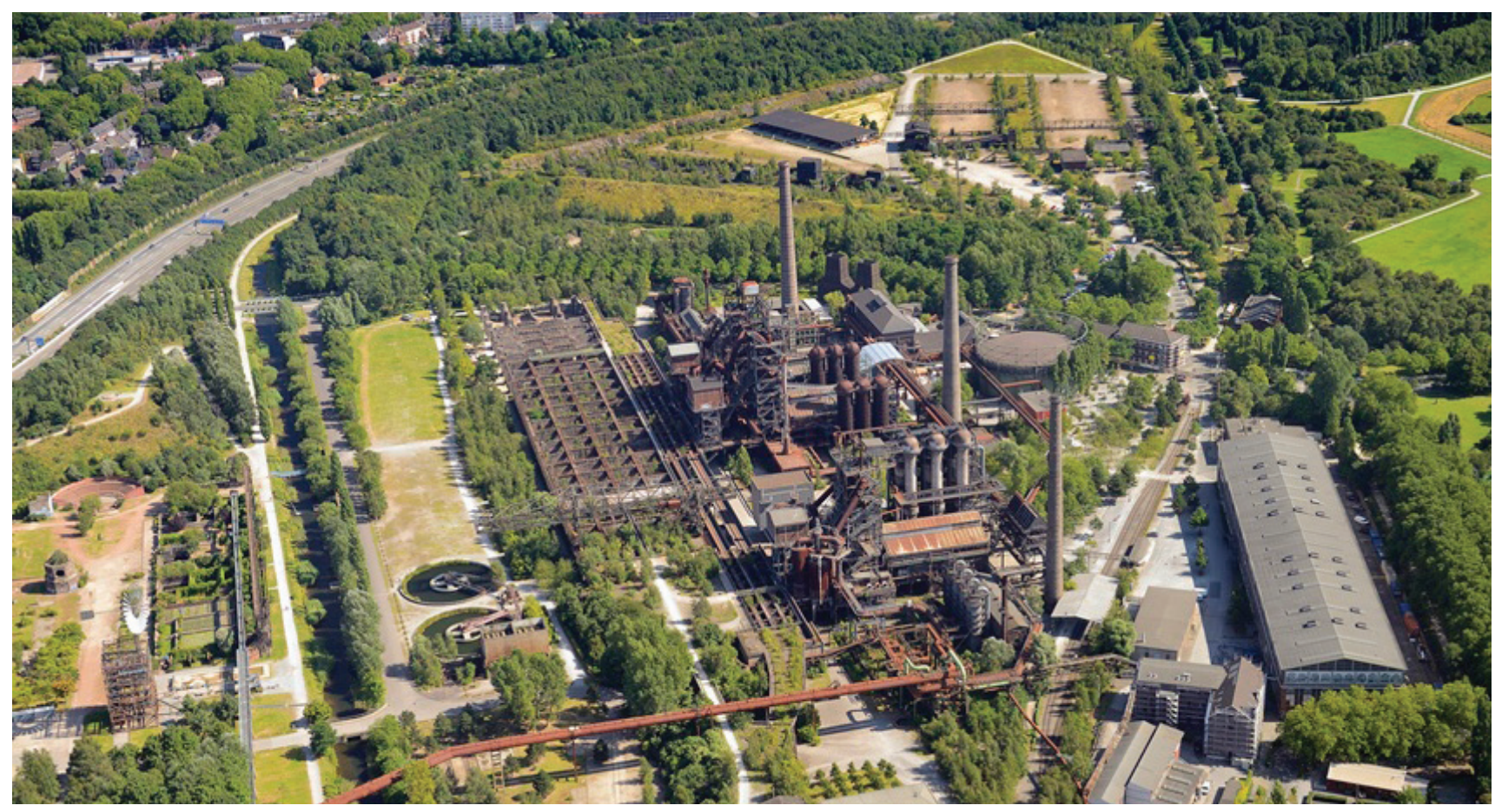

FIGURE 2l: An aerial photograph of Landschaftspark.

(Image source: Udo Becker) 
rail cars over the life of industrial use on site. The third zone is derived from the immediate context where gardens, playgrounds, a community centre, a farm, and recreation fields abut the residential neighbourhood (Hargreaves, 2007). The variety of uses and activities that occur within the park were largely unchoreographed and emerged over time. Many of these activities were originally considered transgressive, and became officially sanctioned over the years (Langhost, 2014).

In addition to preserving the site's industrial history, principles of ecology and sustainability guided the design of the site. The overgrown property turned out to contain a wide diversity of flora and fauna, including a number of threatened species, which had adapted to the polluted soils. Some of these features were maintained and integrated into the design of the site. A number of different interventions were carried out to clean the land, according to the type of pollutant materials. This means that there are areas where the land has been covered with new layers, but there are other areas that have been closed off and will be unable to be used as they are cleaned through phytoremediation - these are disused tanks that contain closed gardens where a variety of plant species grow. A walkway linking the different areas of the park enables you to view these gardens. In keeping with the theme of sustainability, materials that could not be reused were recycled and turned into steps and pathways within the park.
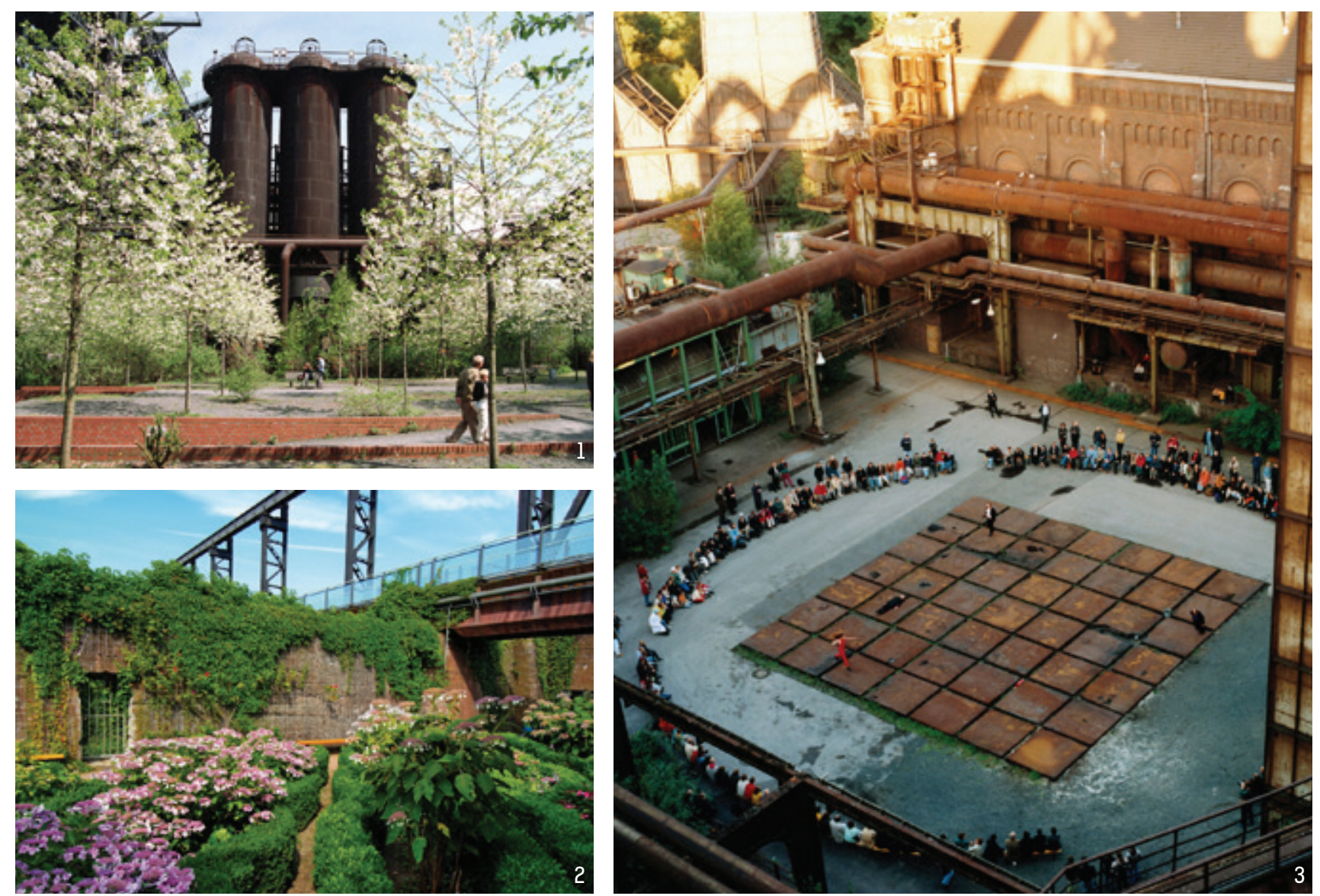

FIGURE 22: Photographs of some of the key design elements in the park. Image 2 is a garden that is created in a disused tank. Image 3 is the Metallic Square which was built in the unoccupied space between furnace buildings. Image sources: (1) Latz+Partner, (2) Mark Wohlrab, (3) Latz+Partner) 
Running through the entire site is the old Emscher channel. It was formerly used as an above ground wastewater disposer that took away the domestic and industrial wastewater from the Rhur District. Now, the wastewater flows through an underground pipe, and the channel, now called the Clear Water Canal, is exclusively filled by ground and rainwater. Over the years with some help, the channel was regenerated.

In commenting on the park, James Corner (1999) revealed that it is absolutely critical to understand that Duisburg-Nord is not about "ecological restoration" - it is about creating "new and interactive alliances" between human and non-human systems. The park has also been referred to a new and hybrid socioecological assemblage (Kaika, 2009, Swyngedouw, 2010). This assemblage prefers neither the natural nor the human systems, and "softens" or alleviates any "environmental and social inequities based in the segregated functionalism and efficiency of modernist-capitalist landscapes of production" (Langhost, 2014, p. 1119).

Despite its structural complexity and programmatic density, the park does not feel over-programmed (Langhost, 2014). Flexible and imaginative uses are tolerated and spatial conditions might be adapted to accommodate them. As a result, very few areas are off limits - access onto the industrial structures is made possible by applying a commonsensical approach to safety and risk management (Langhost, 2014). Graffiti is not removed and form a palimpsest that renders a wide range of assertion of identity, territoriality and protest. Visitors and users become active agents in the ongoing change of the site and their experience is an immersive and interactive one - "and their impact on the plants and other materials makes them co-authors of the place they occupy" (Langhost, 2014, p. 1120).

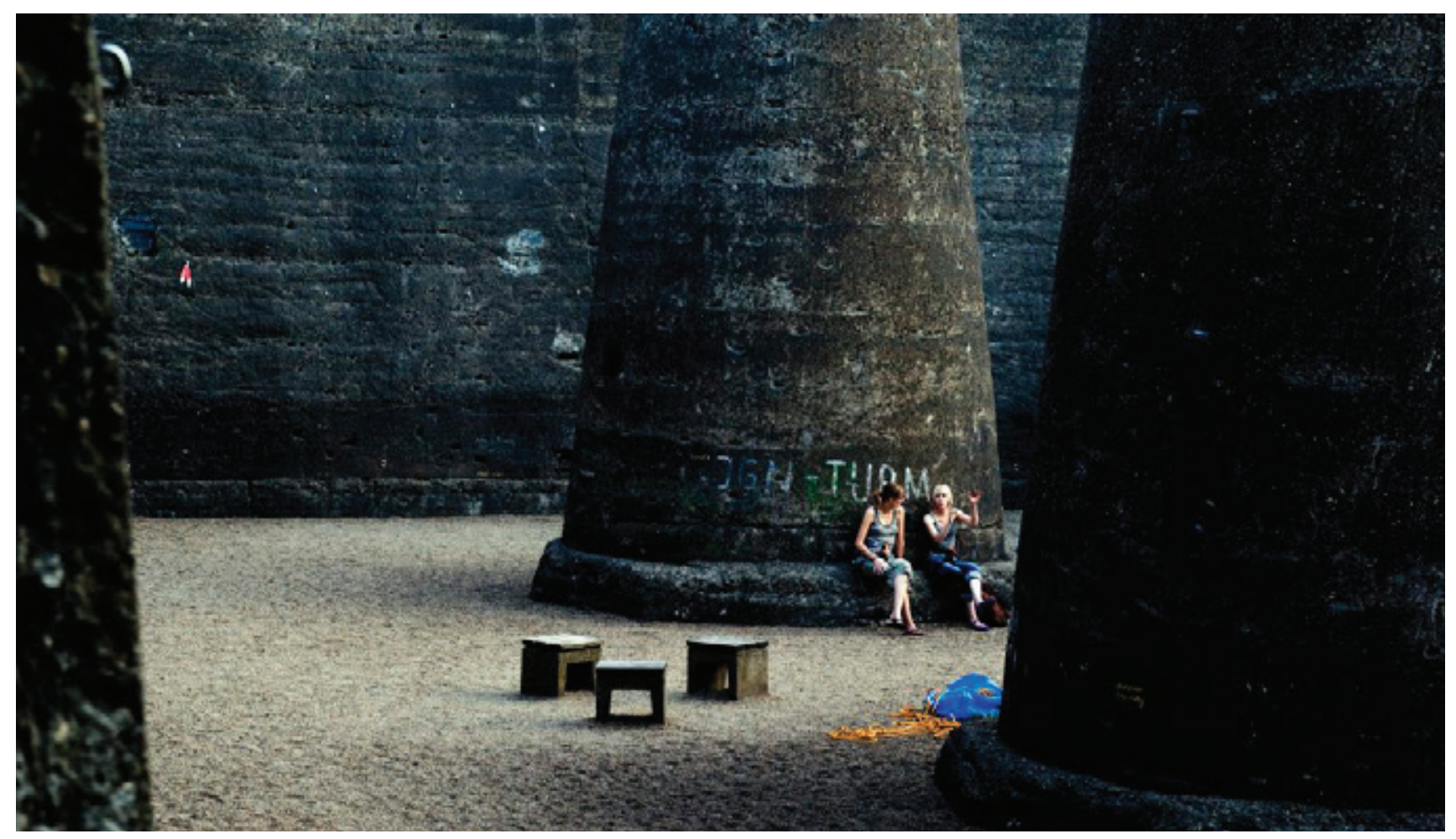

FIGURE 23: Former ore bunkers are transformed into new public spaces. (Image source: Michiel Wijnbergh) 
The transformation of the former industrial site into a park also fulfills a critically important function for the surrounding neighbourhoods. Due to its complexity, diversity of conditions and sheer scale, the park facilitates a wide range of opportunities for residents to encounter a wide range of "urban natures" (Langhost, 2014). It also allows them to actively participate in the making of the landscape and allows them to transform it into a place of their own.

In his review of the park, Langhost comments that the park's inclusion of both human and non-human components creates a productive "heterotopia" that continuously produces new interactions between "nature" and "culture". He claims that this interaction creates continuously changing conditions and experiences and invites an ongoing critical reflection of the landscape. This also posits the human experience as an involvement in this change, facilitating and encouraging a much more active, immersive and participatory experience beyond the passive (and voyeuristic) practice of looking (Langhost, 2014).

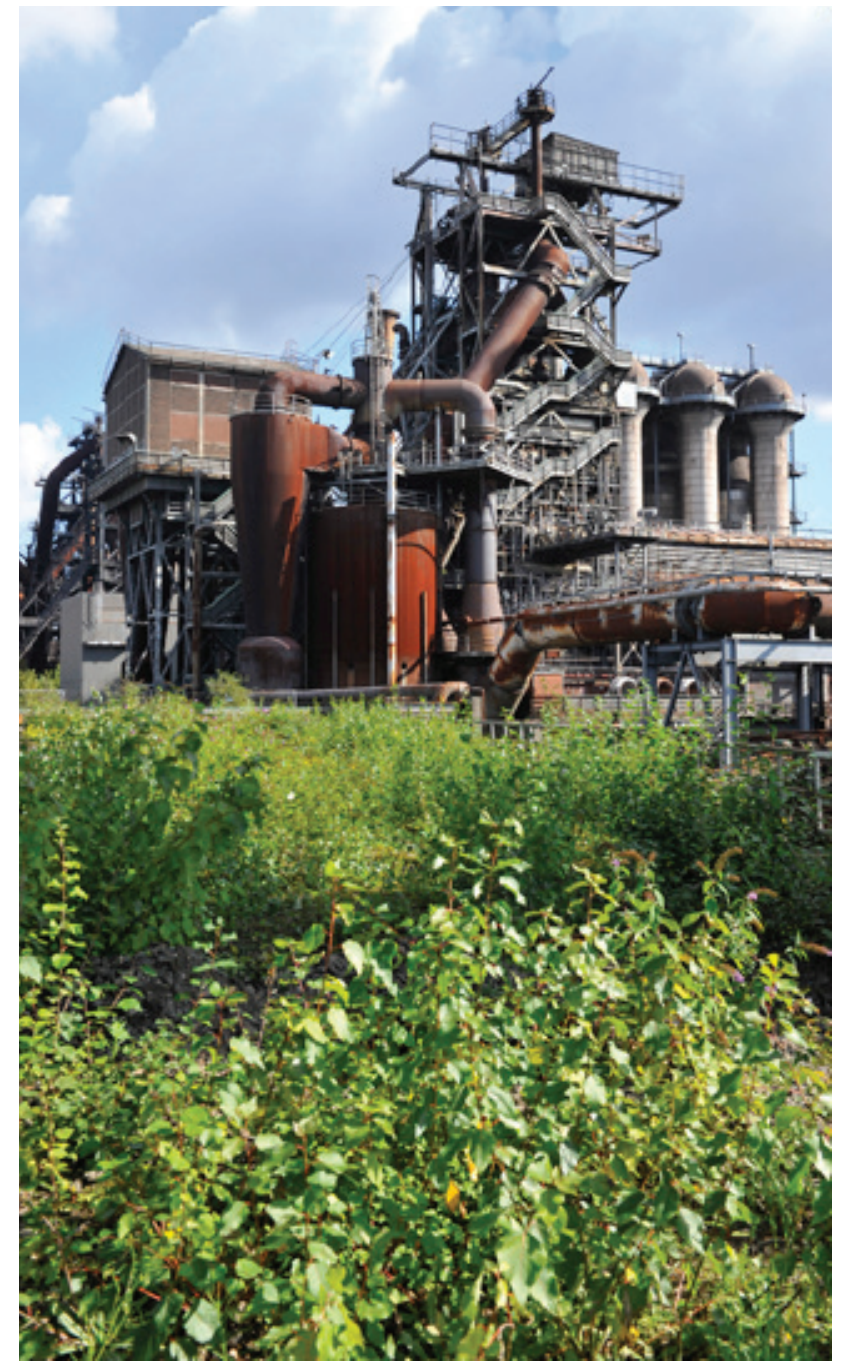

FIGURE 24: The blast furnace was repurposed as a viewing platform and offers a view of the entire site.

(Image source: Thomas Berns)
"Destroying and polluting the environment is certainly still the first thing we associate with the concept of heavy industry and landscape architects tried to combat the pollution with green spaces and strips of green. So that means dismantling, removing residual pollution and using natural soil to bury all the remains under a stretch of green in the tradition of the English garden [...]. But acquiring knowledge about production could be fascinating and it could be possible to discover a new aesthetic perception of the gigantic production machines, described as an identification item, 'landmark' or mythological dragon."

(Peter Latz, 2003, p. 64) 


\subsection{FRESH KILLS PARK - LIFESCAPE, NEW YORK, USA}

LOCATION: Staten Island, New York

DESIGN: James Corner Field Operations

PROJECT DATES: 2012-2035 (expected)

SIZE: 2,200 acres (898 ha)

In 2003, Field Operations was selected as the winner of an international design held by the New York City Department of City Planning competition for the design of the Fresh Kills Landfill in New York's Staten Island. Once the world's largest sanitary waste landfill, the site will be transformed into 2,200 acres of public parkland. The park will feature extensive tidal marshes and creeks, over 40 miles of trails and pathways, and significant recreational, cultural and educational amenities. The park will also feature an earthwork monument to honour the September 11 recover effort undertaken at Fresh Kills after the debris resulting from the World Trade Center was deposited at the landfill. This 30-year plan involves the restoration of a large landscape and includes the reclamation of the toxic wetlands that surround and penetrate the former landfill (Stiener, 2011).

Lifescape as a process is ecological in its deepest sense - it is "a process of environmental reclamation and renewal on a vast scale, recovering not only the health and biodiversity of the ecosystems across the site, but also the spirit and imagination of people who will use the park as parkland" (Corner 2005, p 15). Corner claims

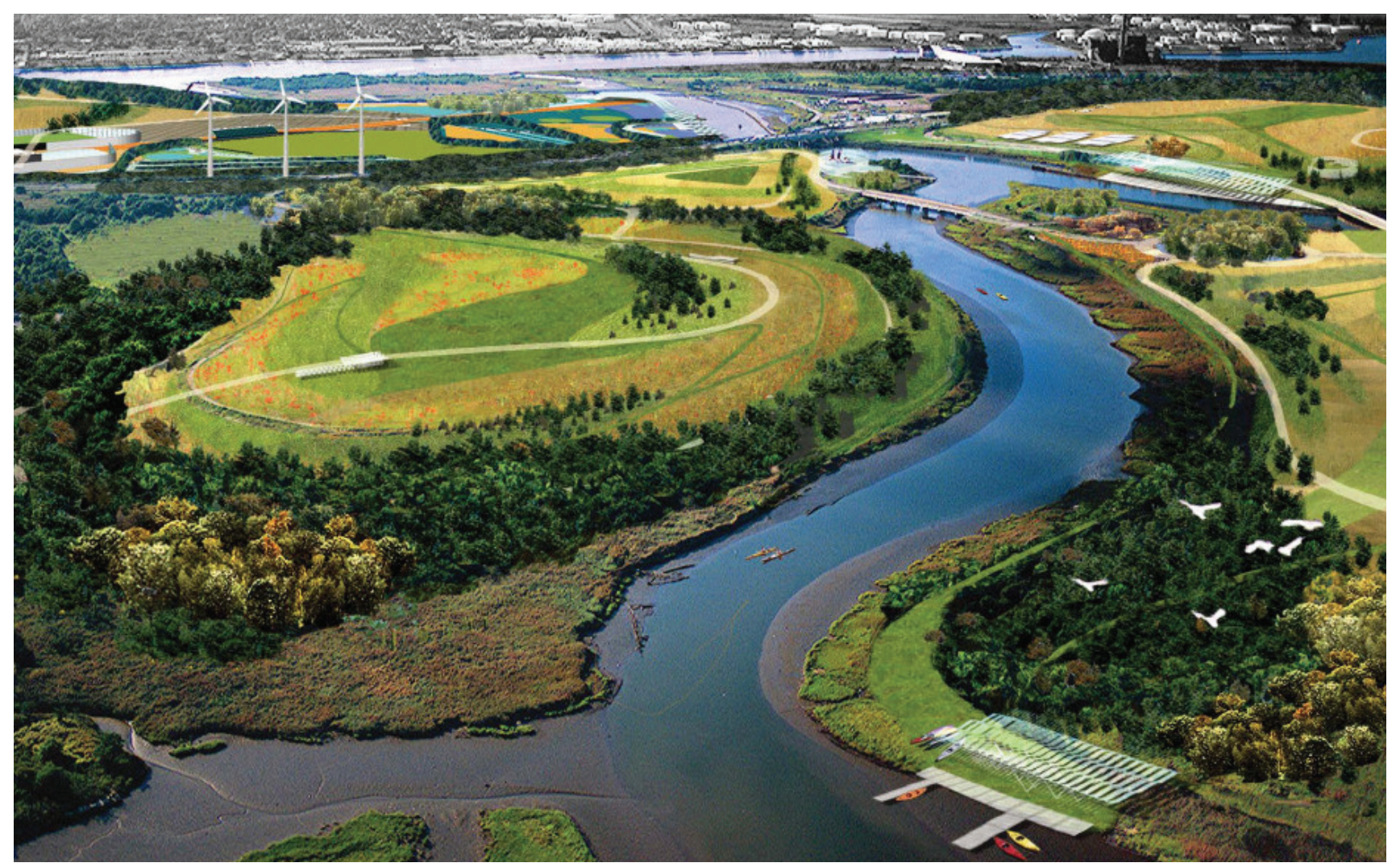

FIGURE 25: The Lifescape project aims to create a diverse range of parkland for wildlife, cultural and social activities, and recreation opportunities.

(Image source: New York City Department of Parks and Recreation - Draft Master Plan) 
that understanding Lifescape as a process is central to the project. Due to the site's scale and complexity, Corner claims that the site cannot be "designed" in total, nor constructed overnight. "Rather, it must be "grown", as in seeding, cultivating, propagating and evolving" (Corner 2005, p 15). As a result, the master plan comprises of a thirty-year program, built-up from six phases, each with a number of discrete stages. Thus, "design at Fresh Kills is as much about the design of a method and process of transformation as it is about the design of specific places" (Corner 2005, p 15).

The development plan will be implemented in the following stages lalso see Figure 7):

Today: Mound-scape I engineering ground

3 Years: Field-scape I manufacturing soil and habitat

6 Years: Open-scape I initiating access and activity

10 Years: Place-scape | building spaces

20 Years: Event-scape I diversifying ecologies and uses

30 Years: Lifescape I growing new life

Due to the scale of the site and its former use as a landfill, soil strategies form the fundamental challenge to the site's conversion as soil affects the potential of establishing the landscape and creating a natural and functioning ecosystem. The strategy that Field Operations proposed involves an in situ "strip cropping" approach to soil renovation as an alternative to laying new topsoil. This agriculture practice involves seeding three carefully selected crops per year and roto-tilling them into the soil to build organic material. Crops are planted on alternating strips that follow the contour of the land, and help control erosion. In addition to its productive effects, the distinctive visual and spatial qualities of large-scale strip cropping "are beautiful and experimentally interesting - emblematic of large-scale environmental removal and renewal for the site for new uses" (Corner 2005, p 18).

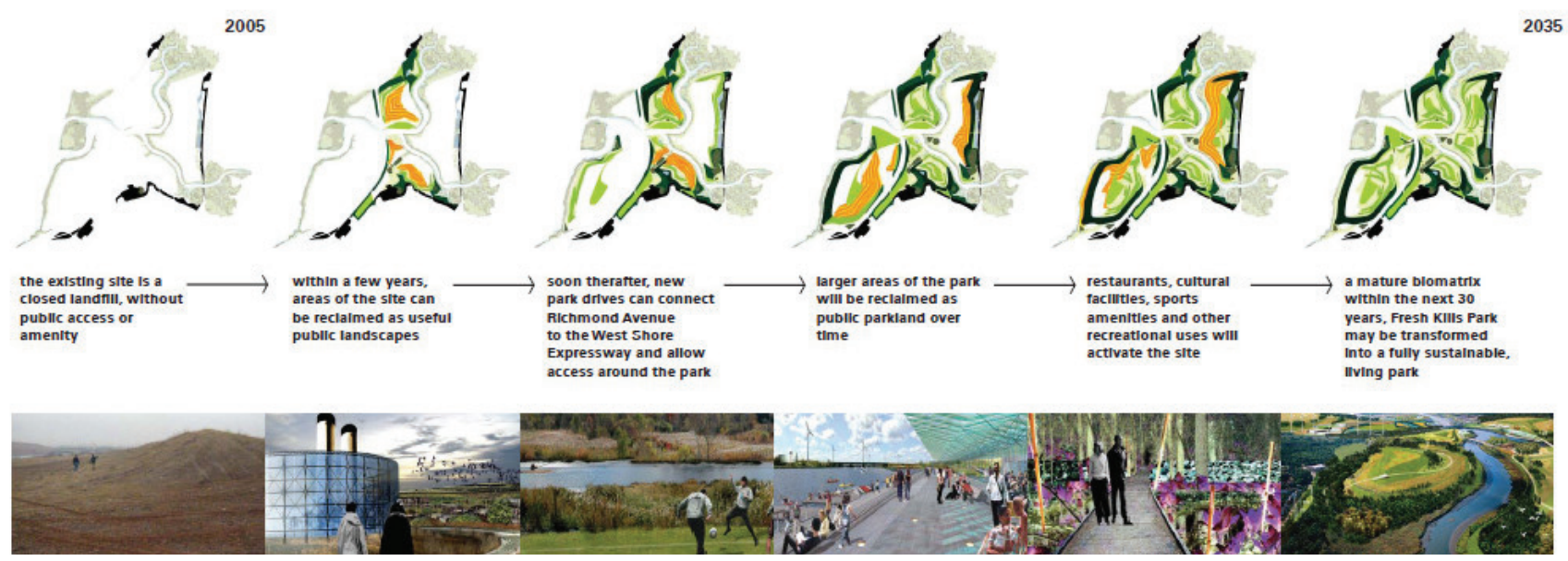

FIGURE 26: The development plan for the site will be implemented in six stages over thirty years.

(Image source: New York City Department of Parks and Recreation - Draft Master Plan) 
Once the soils are improved, the propagation of plan communities will begin. At this point, the landscape will be built largely from plants native to Staten Island. Native species are adapted to the island's unique climate and geomorphology, and will require less ongoing maintenance once established. Native plant communities will also "provide habitat for the resident microorganisms and wildlife that have coevolved with them" (Corner 2005,18-19].

To define the threshold of the parkland, while preserving a sense of scale of the unusually large site, dense woodland is concentrated in a rim around the edge of the parkland. At a more detailed scale, the woodland will contain a diversity of species. The rim will preserve the openness of the interior of the site (rather than cutting it into small compartments), and also provides a continuous ecological corridor for animals (Corner, 2005).

The design elements of the park are all based around the creation of "landscape atmospheres". Where possible, grading and manipulation of the ground plan will be used to create enclosures or landform buildings that will support the park program. The most dramatic landform will be the September 11 earthwork monument to be located on the west mount at Fresh Kills. For nearly a year, investigators and recovery workers sorted through 1.46 million of debris from the World Trade Centre to search or traces of those who were missing. To honour those who were lost on September 11, and the extraordinary recovery efforts, an earthwork monument will mark the recovery area. Two earthforms will mirror the exact width and height of the towers. A second incline will be on axis with the location of where the towers once stood, and providing a clear vista to lower Manhattan. "This slow,

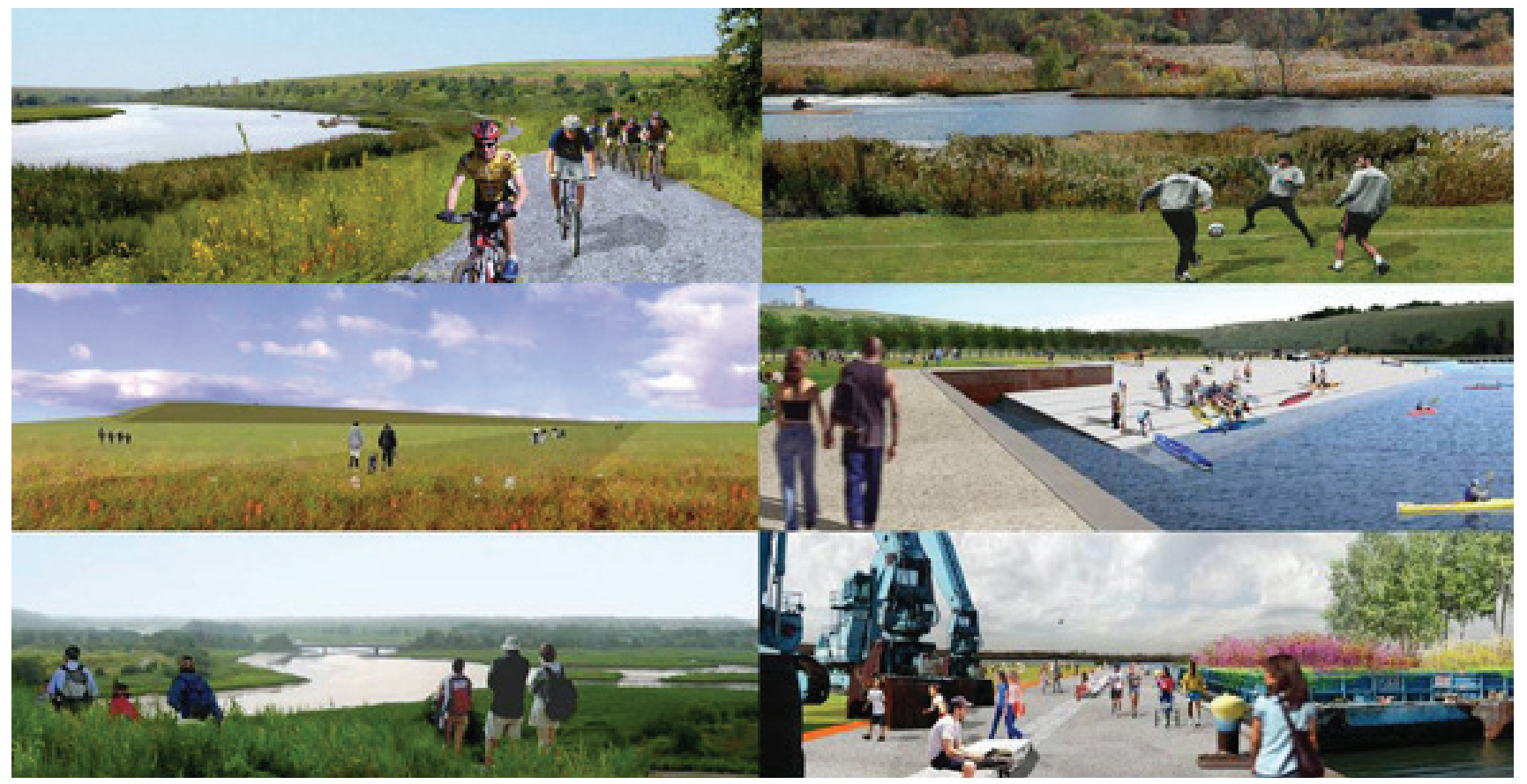

FIGURE 27: Renderings of key features and proposed uses of the park. (IImage source: New York City Department of Parks and Recreation - Draft Master Plan) 
simple duration experience of ascending the incline, open the sky and vast prairie horizon will allow people to reflect on the magnitude of loss." (Corner 2005, p 20).

The soil making, successional planting, and landform manipulation are the three primary large-scale landscape architectural gestures form the "medium" of the park and help produce the "lifescape matrix". Within this matrix, there are three coordinated systems - habitat (landscapes, program (event areas and facilities) and circulation (roads and paths). These layers create a framework that is coherent and flexible for the park's future development, but is flexible enough to adapt to change. Over time, it is the goal that the initial framework of inter-related habitat, program, and circulation elements will spread and evolve into a layered and fully integrated park matrix (Corner, 2005).

"Rather than erasing the past (landfill), on the one hand, or recreating a long-lost environment (nature), on the other hand, Lifescape instead proposes a growth emergence from past and present conditions toward a new and unique future. The result will be a synthetic, integrative nature, simultaneously wild and cultivated, emergent and engineered. In this way, the plan seeks to change how we experience reclaimed landscape in the city and demonstrate new potential for closed landfills and other post-industrial sites around the world." (Corner 2005 , p 21)

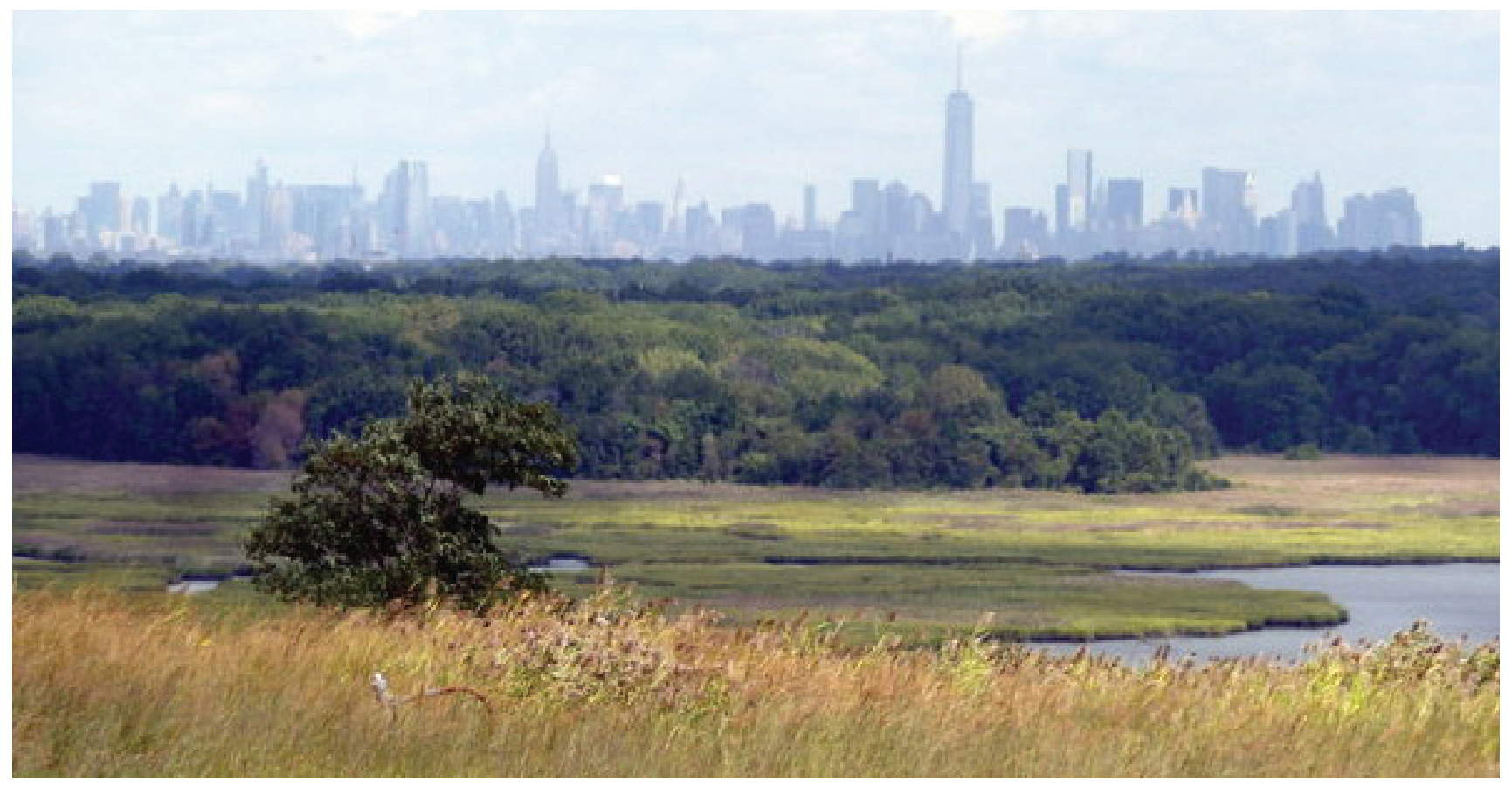

FIGURE 28: A view of Manhattan from restored marshlands on the site.

(Image source: Advance Photo) 


\section{LANDSCHAFTSPARK:}

This park retains all of the existing buildings on site, and allows them to be used and interacted with in new ways (ways that would not considered to be $100 \%$ 'safe' for North American standards - but it is time to push the envelope). However, some structures are used as landmarks and reminders of the industry that once occupied the site and the role it played within the community.

Could the reactor buildings on the Pickering site be used in new ways? While they contain highly radioactive materials, all of the most dangerous components will be removed and any remaining radioactivity will decrease over time. Pickering Units A2 \& A3 were closed in 2003, allowing the radioactivity to decay over the past 13 years, and are the units that could be the most appropriate for reuse. This presents an opportunity to reuse the structures. However, should they be used as landmarks, or should they be repurposed for a new use - a centre for research into renewable sources of energy? The structures on site are sublime and dominate the Pickering 'skyline' and are a strong reminder of its former use, but repurposing the structures can help bridge the gap between its history and the future.

\section{FRESHKILLS PARK:}

The primary focus of this park is about the process of reclaiming and re-naturalizing this heavily polluted and abused site. It is acknowledged that the site is too large and complex to attempt to fix all at once, and a phased approach should be undertaken to re-naturalize the site, with an emphasis on developing a foundation for future use and programming.

The Pickering Station site is very large, and its decommissioning process and release is also relatively complex, with a predicted release date forty years from now. Using a long-term phasing approach, in partner with the release of the site would be most appropriate. Due to the timeline, it will also be difficult to determine detailed programming for the site, as it is likely to change over the next forty years. However, the proposed plan should establish a foundation for a wide range of possible programs and uses.

Freshkills Park employed a wide range of strategies to restore the ecology of the site. While the Pickering Station site did not contain any prior natural features to restore, it could be the site for the use of new ecological restoration technologies to establish a new ecosystem on the site. It would be an impactful juxtaposition to the site's history, and would allow the site to further continue to contribute to the advancement of technology. 


\subsection{PICKERING NUCLEAR PARK}

Informed by the research presented, a vision and design principles was developed to guide the transformation of the site into 400 acres of new parkland in the City of Pickering. As the City's population is expected to double within the next 40 years, and this site provides a unique opportunity, one that only comes once in a generation, to secure a single property of this scale along the waterfront. It also presents the City of Pickering the chance to create not only a public park, but restore a key node within the region's natural system.

It is important to note that a number of creative liberties were taken in the development of the phasing process. This was due to the intention of proposing a vision and future usages that would be outside the status quo, and to the supporting research that claims that decommissioning processes can changed and adapted to through new technology to accommodate predetermined end uses and plans, as long as it is established before the process begins (Laraia, 2011].

Additionally, likely due to security reasons, there is a gap of addtional information related to detailed plans and site information. This has also led to a number of assumptions taken about what can physically be done with the site and associated structures. 


\subsection{THE VISION}

In 40 years, the Pickering Nuclear Generating Station will be reopened to the public and transformed into an expansive 400-acre park. The park will be dedicated to active and passive recreation uses, historical and cultural commemoration, and education and advancements in sustainable energy production. Improved connections will allow users (both human and wildlife) to reconnect with the site, while ensuring the waterfront remains a natural haven and a key destination in the intensifying and rapidly evolving city.

The objective is to re-imagine the potential and future use of nuclear sites once they have reached the end of their life cycle, while facilitating a conversation about nuclear power and energy production, and understanding its impact on the planet.

The vision and design principles are intended to create a space where this interaction can take place while allowing the site to evolve and be opened to new uses over time and play a new and lasting role within the community.

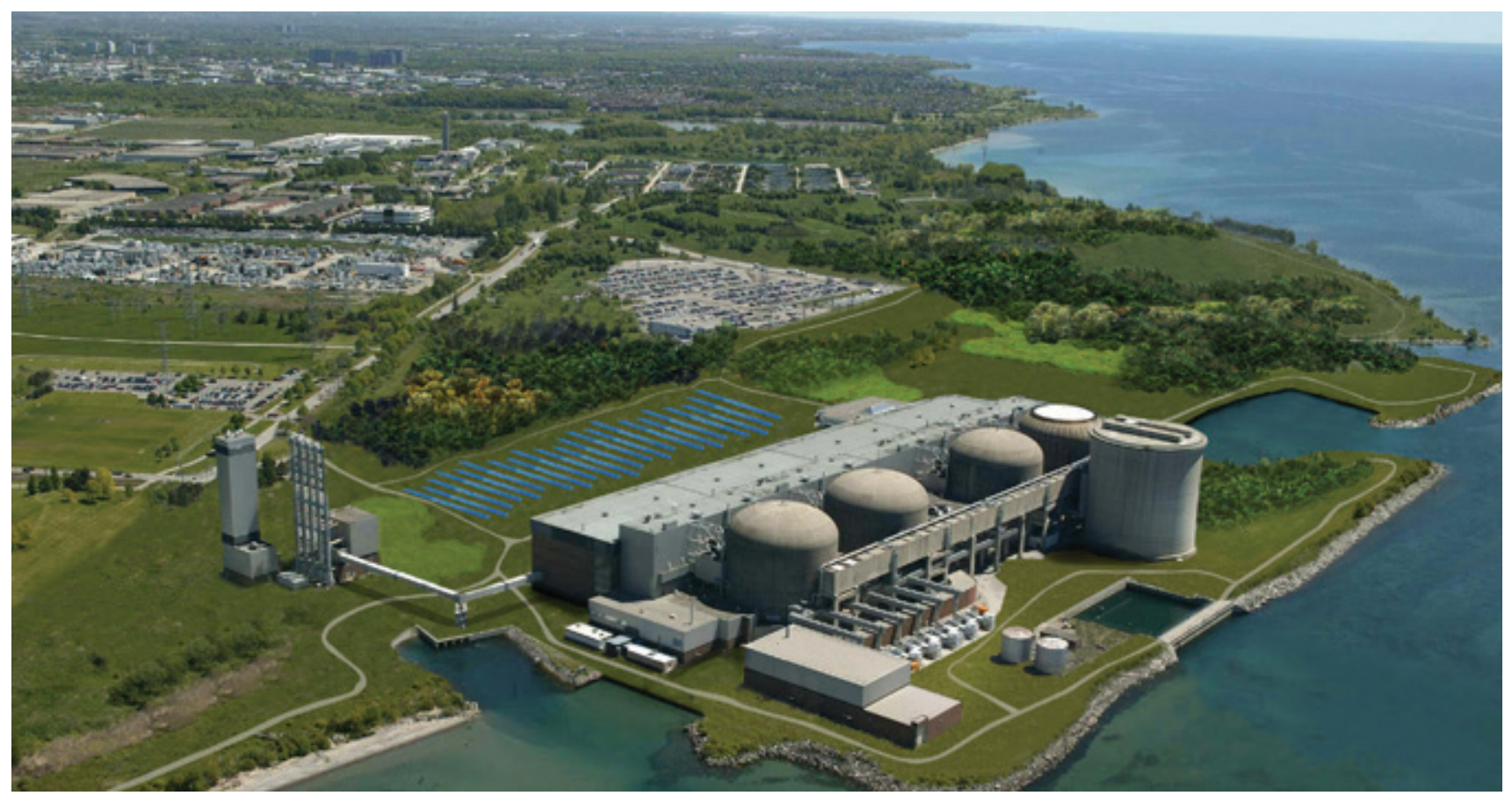

Figure 29: Proposed vision for the Pickering Nuclear Generating Station site 
Figure 30: Site Plan
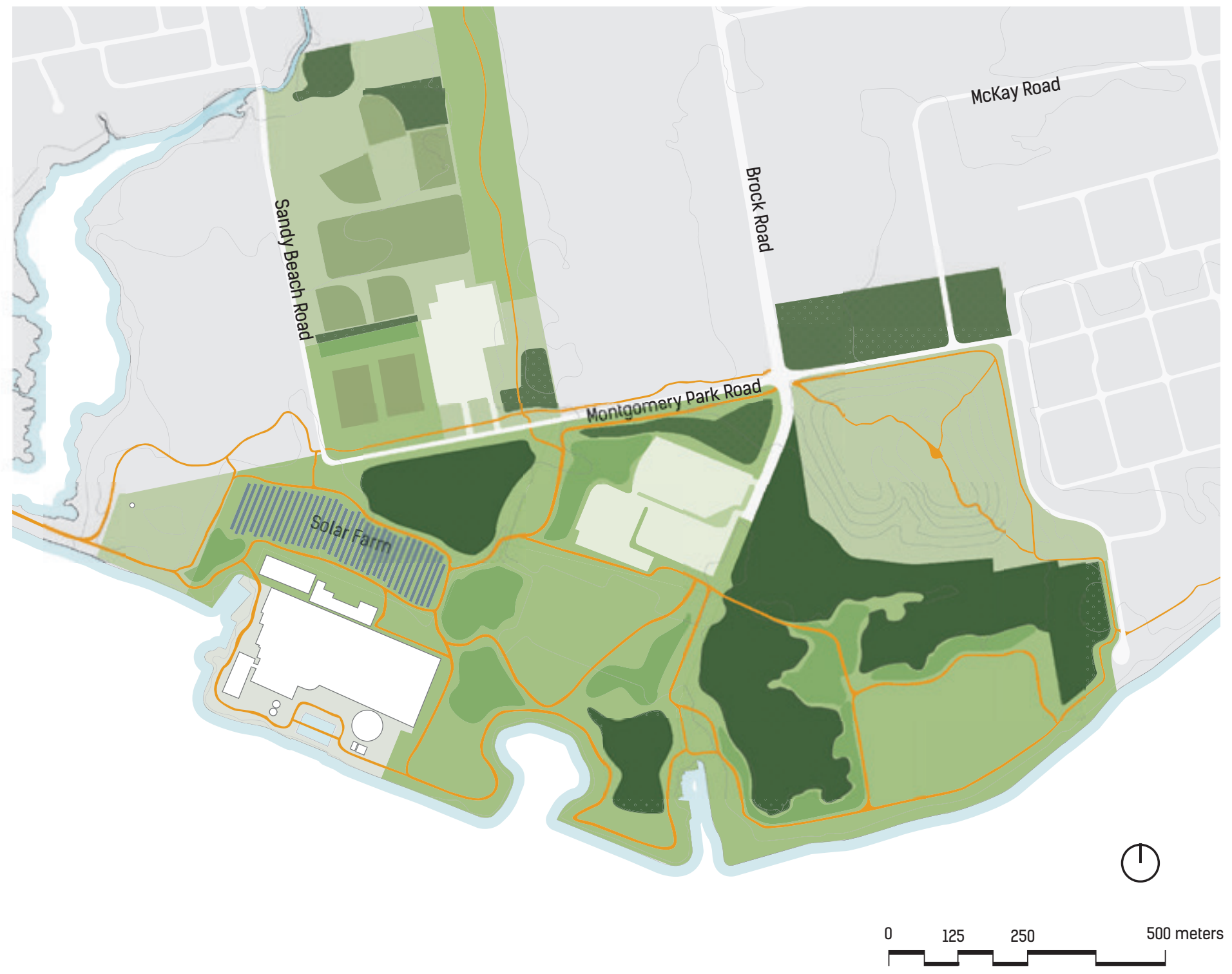

Existing Green Space

Existing Wooded Areas
New Parkland and Green Space

Meadows
New Wooded Areas

Parking Lot
Sport Fields

New and Existing

Structures 


\subsection{DESIGN PRINCIPLES}

\section{ENGAGING ECOLOGY}

Any of the pre-existing natural systems on the site has been significantly altered and redeveloped beyond recognition. Taking advantage of the site's strategic location within a rich natural heritage system, its reuse should allow nature to reclaim it. The soils on site should be restored to support a variety of native flora species to create diverse natural habitats and ecosystems for wildlife to be reintroduced into the area. Additionally, manicured and programmed areas should be integrated for both passive and recreational human use. The retention of the site for a natural refuge will not only positively impact the health of residents, but the increased natural green space has further potential to improve air quality, reduce C02 emissions, and build greater environmental resiliency.

\section{HIGHLIGHTING HERITAGE AND CULTURE}

Nuclear energy represents a significant and unique period in Canadian history and the development of 'sustainable' sources of energy in the world. It also represents an industry that faces increasing challenges and tensions towards its use as a 'sustainable' form of energy production due to its inherent safety risk to the surrounding community, and its role in future energy production as our consumption of energy continues to increase. The site and its structures are the manifestation of this tension and should be used to educate the public, and to ensure that its contributions do not get 'swept under the rug' and forgotten.

\section{MAKING CONNECTIONS}

The site, which has been inaccessible to the public for over 40 years, should be reintegrated into the city and new connections should be made between the site and it surroundings. This includes the integration of new pathways into the site during the decommissioning process, the continuation of the waterfront trail along the waterfront, and a new connection north to the proposed 'Downtown Pickering' along the hydro corridor. These connections should also support and improve ecological linkages connections through the site.

\section{LINKING ENERGY AND EDUCATION}

This project presents the first large-scale example of the decommissioning, dismantling, and repurposing of a commercial nuclear station in Canada and provides a learning experience for both those within the nuclear industry, and the public at large. It is important that the decommissioning process is used as an educational opportunity that allows the public to interact with the site. Due to the perverse history of nuclear energy, the retirement of the station presents an opportunity for the site to be used for new and experimental methods of energy production, and in ecological restoration technology and techniques, beginning a new chapter in the search for sustainable energy production for the future, and restoring sites that have been damaged in the process. 


\subsection{PHASING}

Due to the lengthy decommissioning process and timeline, the vision is largely focused on the phasing and release of the site during the decommissioning process. It is primarily concerned with establishing a foundation that is flexible and allows for a wide range of programmable areas to support a variety of uses that are expected to evolve over time. The phasing of the project closely matches the expected release of the site as indicated by OPG, but provides some alternatives process that reintroduces the public to the site throughout the decommissioning process, and to support its re-naturalization.

Figure 31: Phasing Diagram
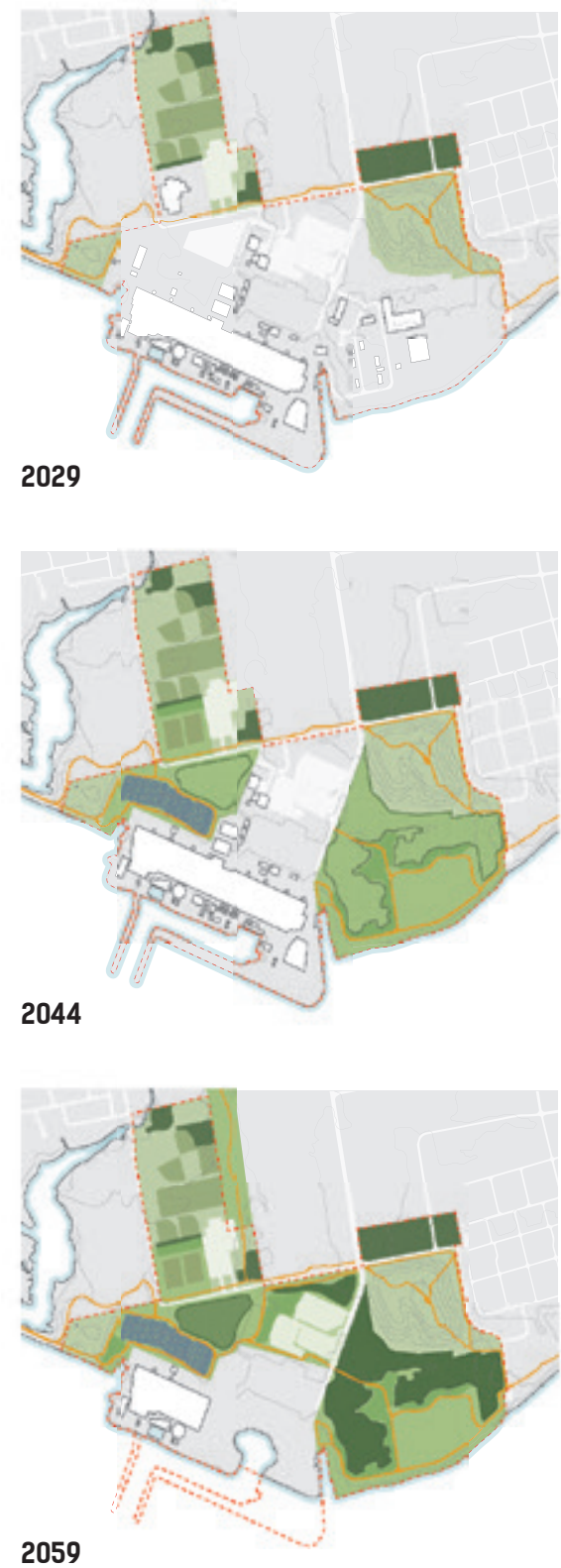
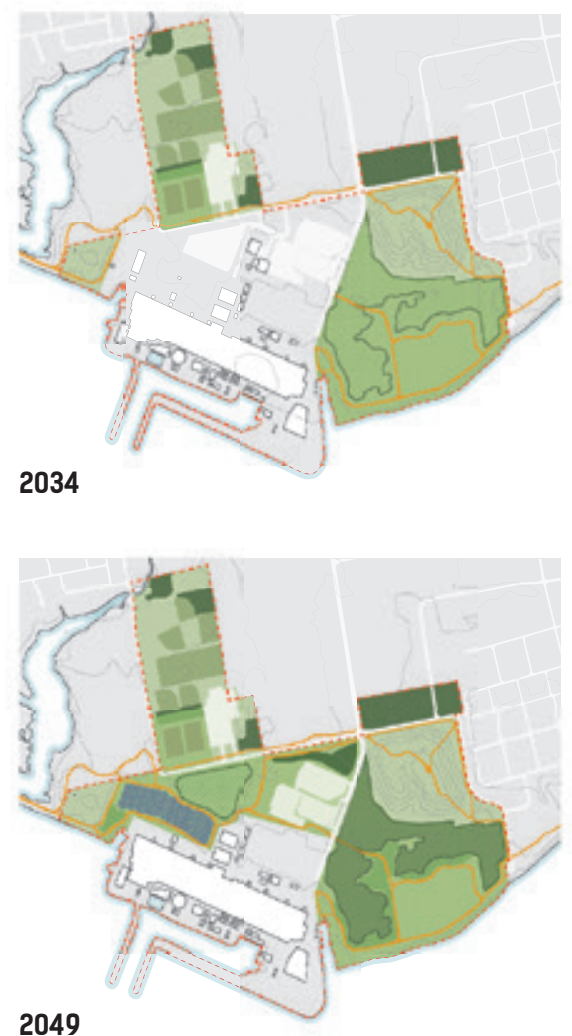

2049

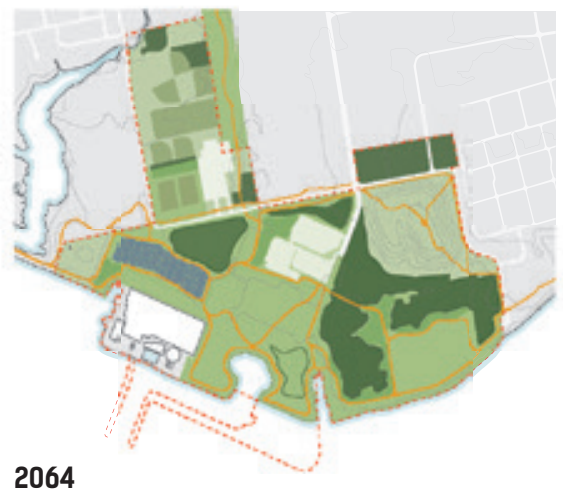

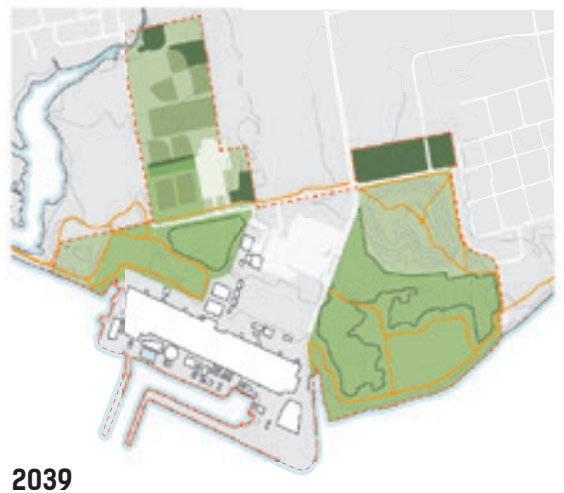
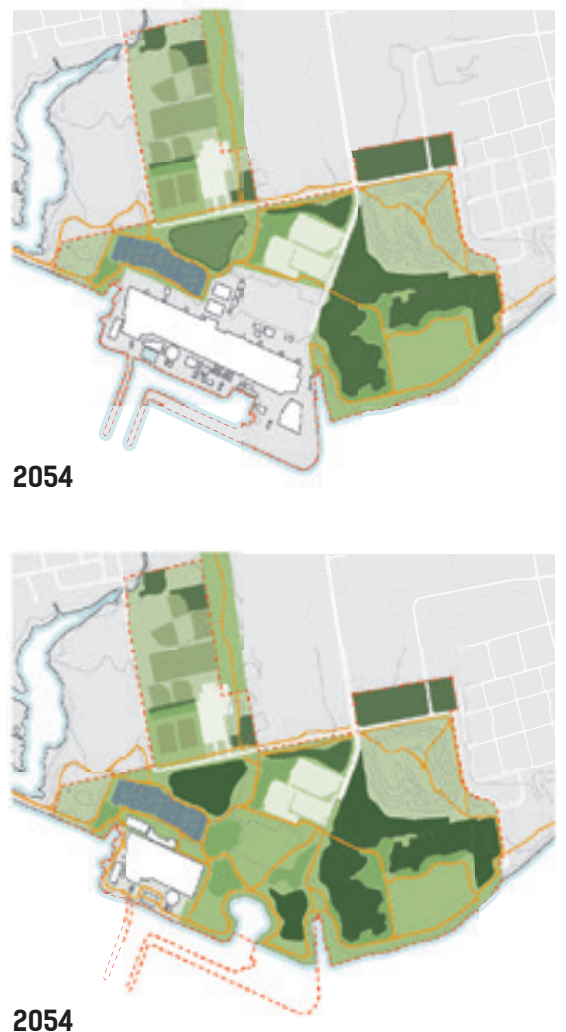
Figure 32: The park in 2029

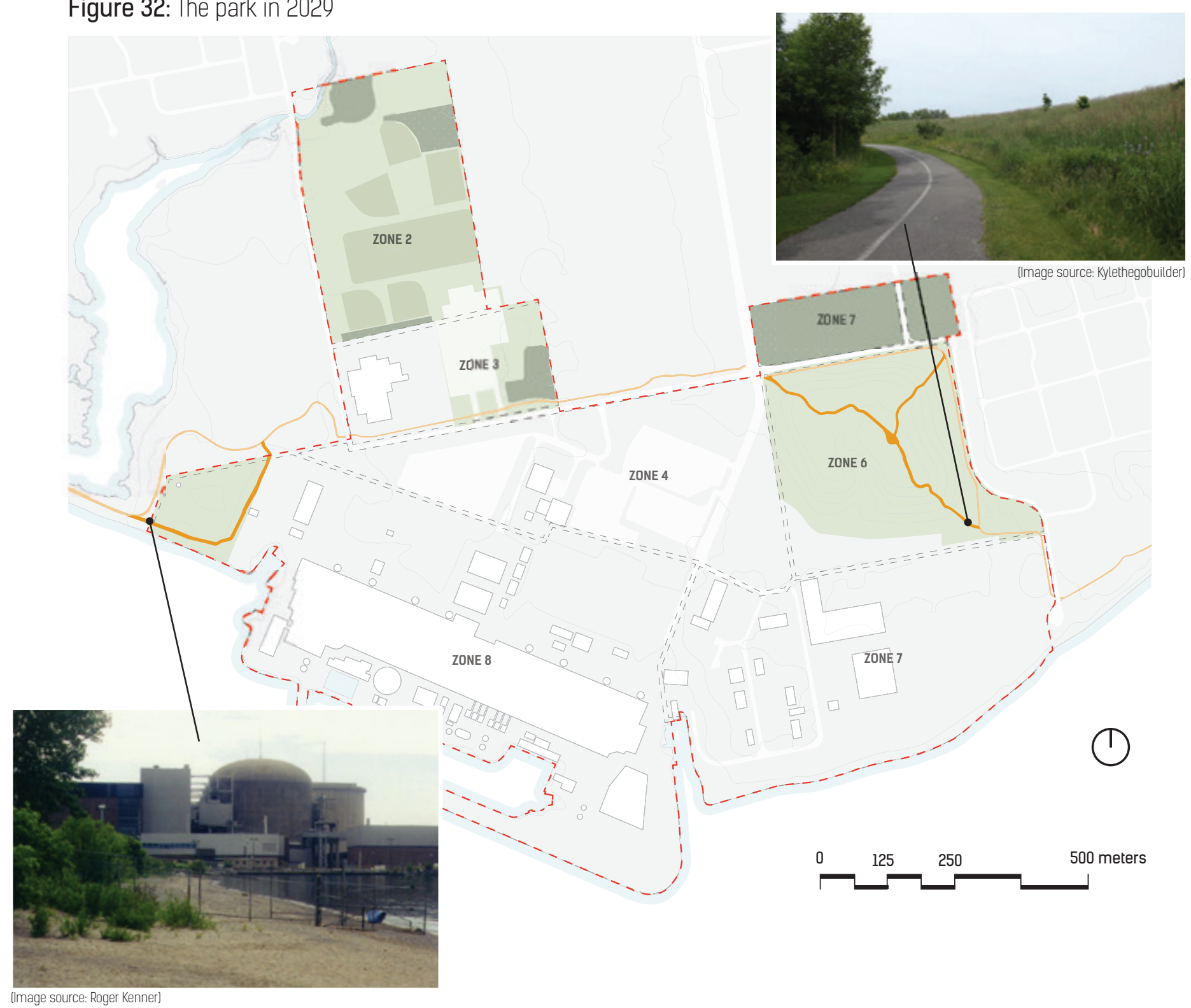

\section{0-5 YEARS:}

Once the station ceases commercial production, it will undertake the necessary duties to prepare the site for safe storage. During this period, there nothing can be done with the site Zone 2 will continued to be used for recreational purposes, and OPG staff will continue to use the training facilities within Zone 3. However, it is proposed that the landfill in Zone 6, and the edge of Zone 8 laround the wind turbine) be opened up and the multi-use trail be introduced to allow the public to see the site from a new lookout point, and to observe the decommissioning process. 
Figure 33: The park in 2034

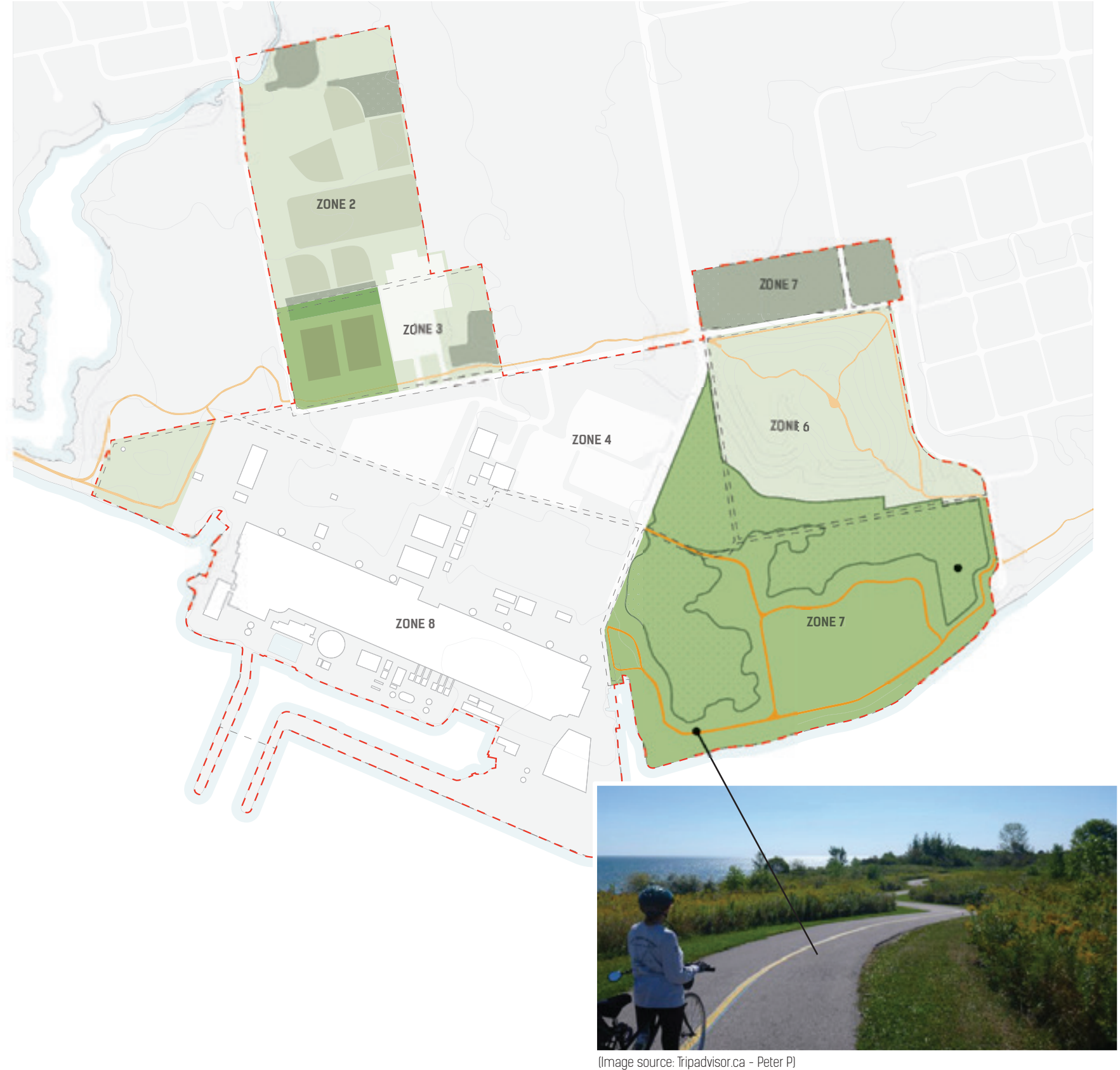

\section{5-10 YEARS:}

At this time, the training building will no longer be required, and will be demolished to introduce an additional recreation area in Zone 3 . The buildings in Zone 7 will also be demolished and the waste storage area for used fuel will be moved to Zone 8 . This will allow this large area to be reclaimed as parkland. A large portion of this area will be established as densely forested woodlands, and be developed as a highly naturalized area with supporting native tree species. The multi-use trail is brought further into the site. 
Figure 34: The park in 2039

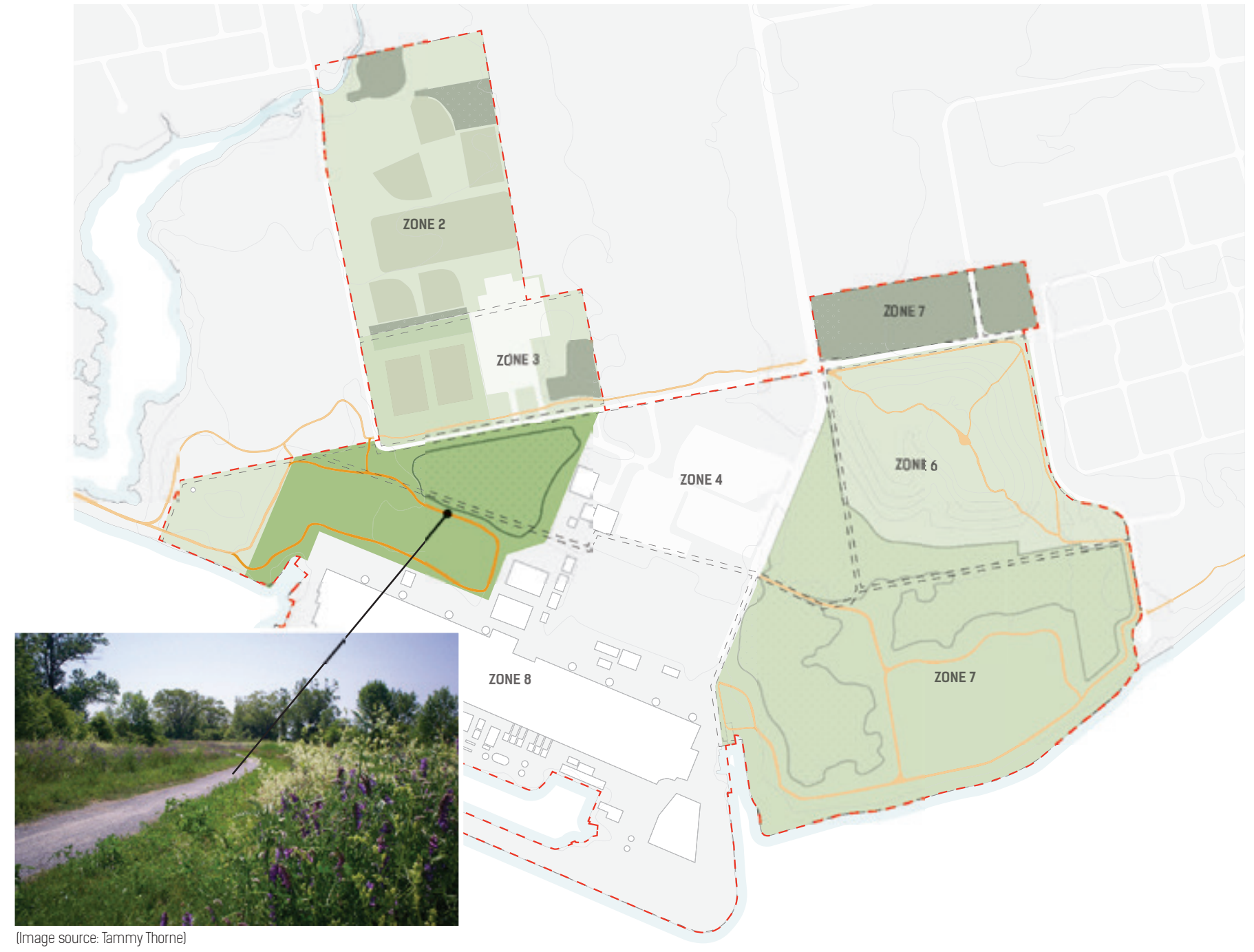

\section{0-15 YEARS:}

Parts of Zone 8 and 4 are cleared to establish additional parkland. This includes the demolition of a number of administration buildings and one of the two hydro transformer areas. An additional wooded area will be established in Zone 4. The multi-use trail will be brought further into the site from the west. 
Figure 35: The park in 2044

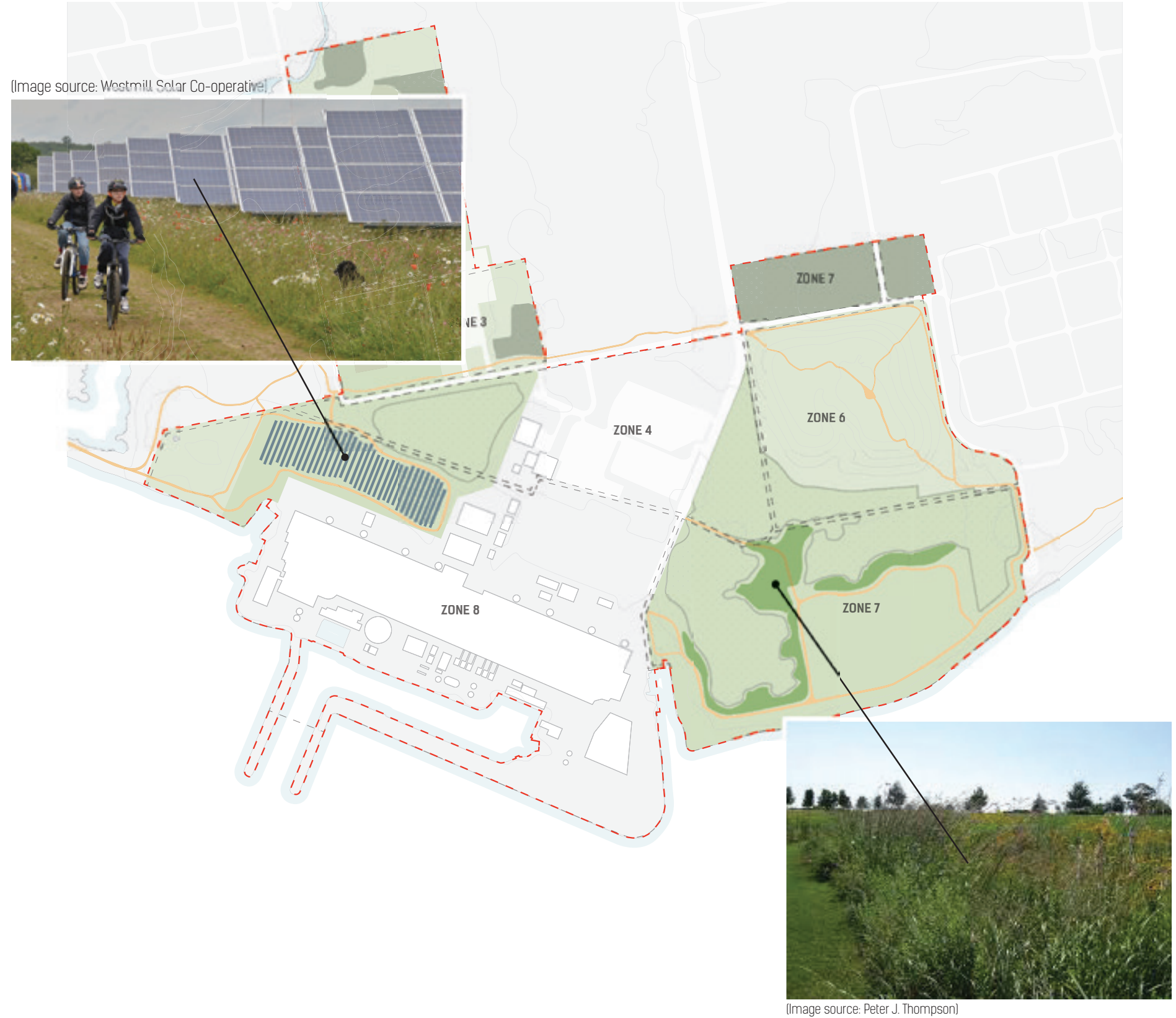

\section{5-20 YEARS:}

Atthistime,asmallsolarparkwillbeestablishedintheparklandsinZone8, withintheHydroOneleasedlands.Thisallows energy to continue to be produced on site, and for Hydro One to continue to distribute energy from the site. Upgrades tothetransformersandsystemwillberequired. Naturalizedgrowthwillcontinueinthewoodedareasandmeadowsin Zone 7. 
Figure 36: The park in 2049

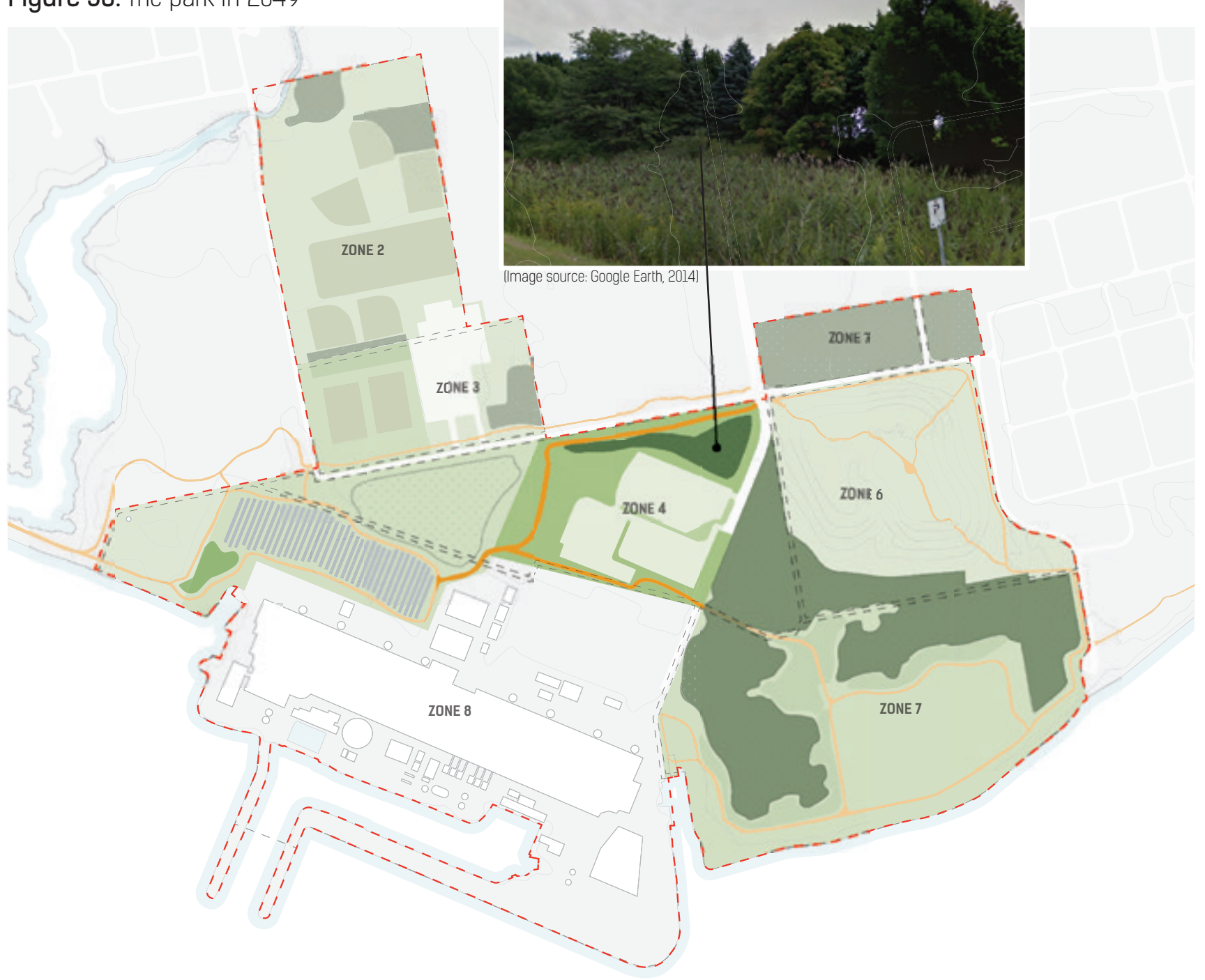

\section{0-25 YEARS:}

The existing parking within Zone 4 will be retained, but additional parkland is created around the parking lot. The existing wooded area will be maintained along Montgomery Park Road and the multi-use trail is continued around the parking lot and connects with the trail in Zone 7. 
Figure 37: The park in 2054

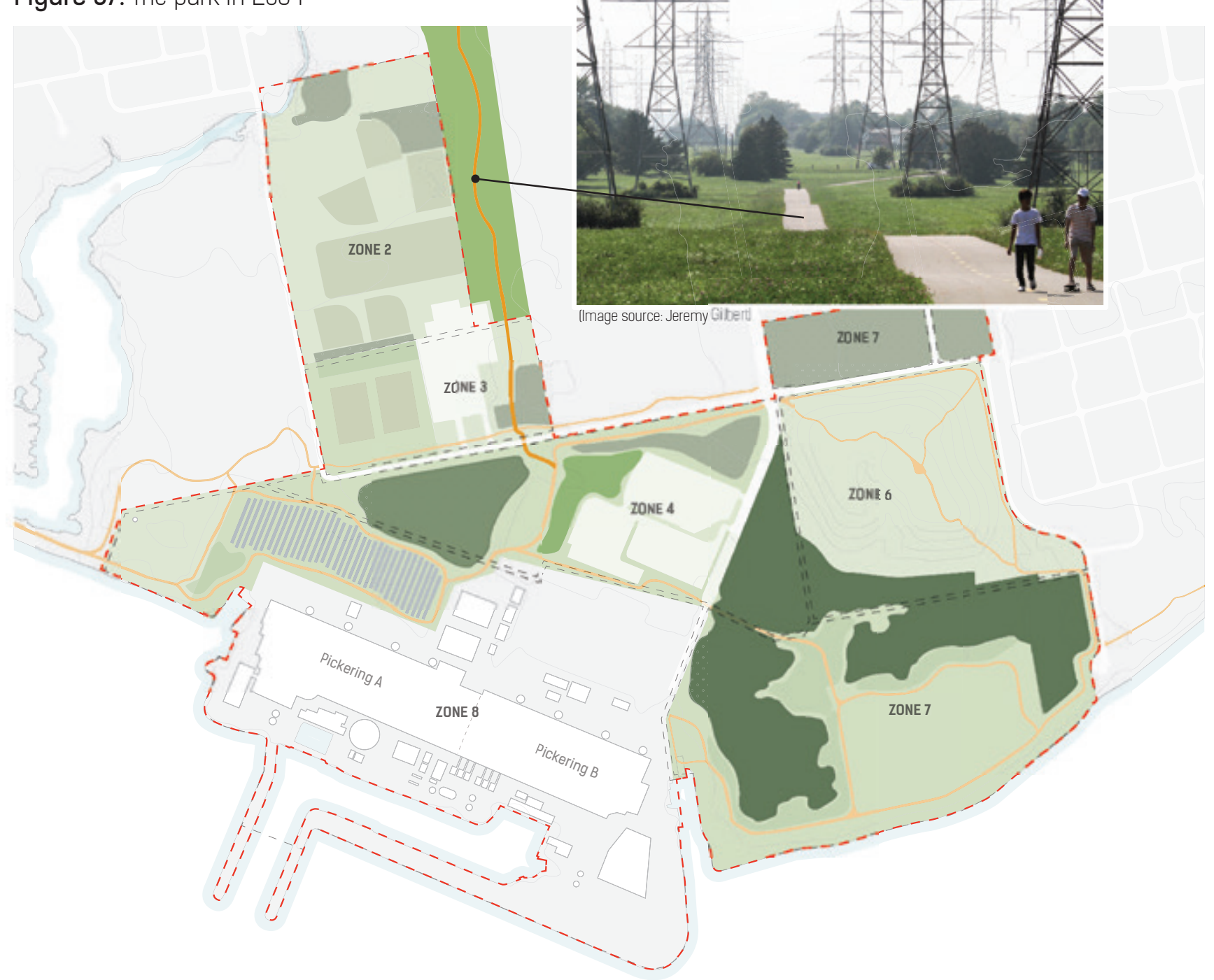

\section{5-30 YEARS:}

Growth within the wooded areas and grasslands will continue. A multi-use trail along the hydro corridor from Downtown Pickering (supported by a proposed pedestrian bridge in the Downtown Pickering Vision) is built, improving the north-south connection to site, and introducing both existing and new residents to the developing parkland. At the same time, the used fuel is almost ready to be transported off site and the reactor and turbine building of Pickering B (Units 4-8) are ready to be dismantled. 
Figure 38: The park in 2059

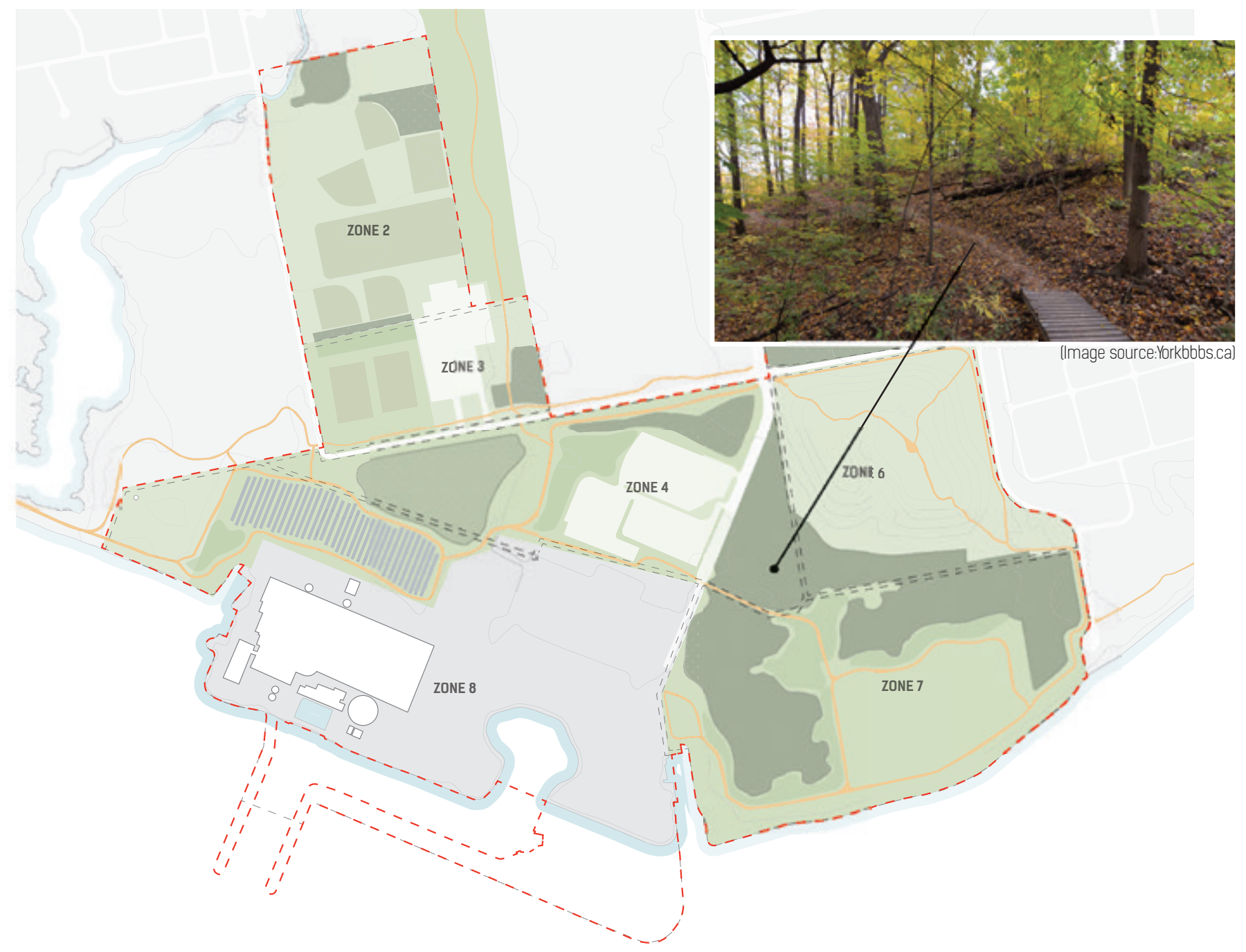

\section{0-35 YEARS:}

Pickering B units are dismantled. Pickering A units will remain on site as they contain historical significance as the first four units on site. The vacuum building and additional structures behind the Pickering A units will also be preserved. During demolition, the artificial shoreline will be restored into more natural a formation. Pipes that were used to feed lake water into the buildings for cooling will be removed, and the excavated land will allow the lake water to extend into the site. 
Figure 39: The park in 2064

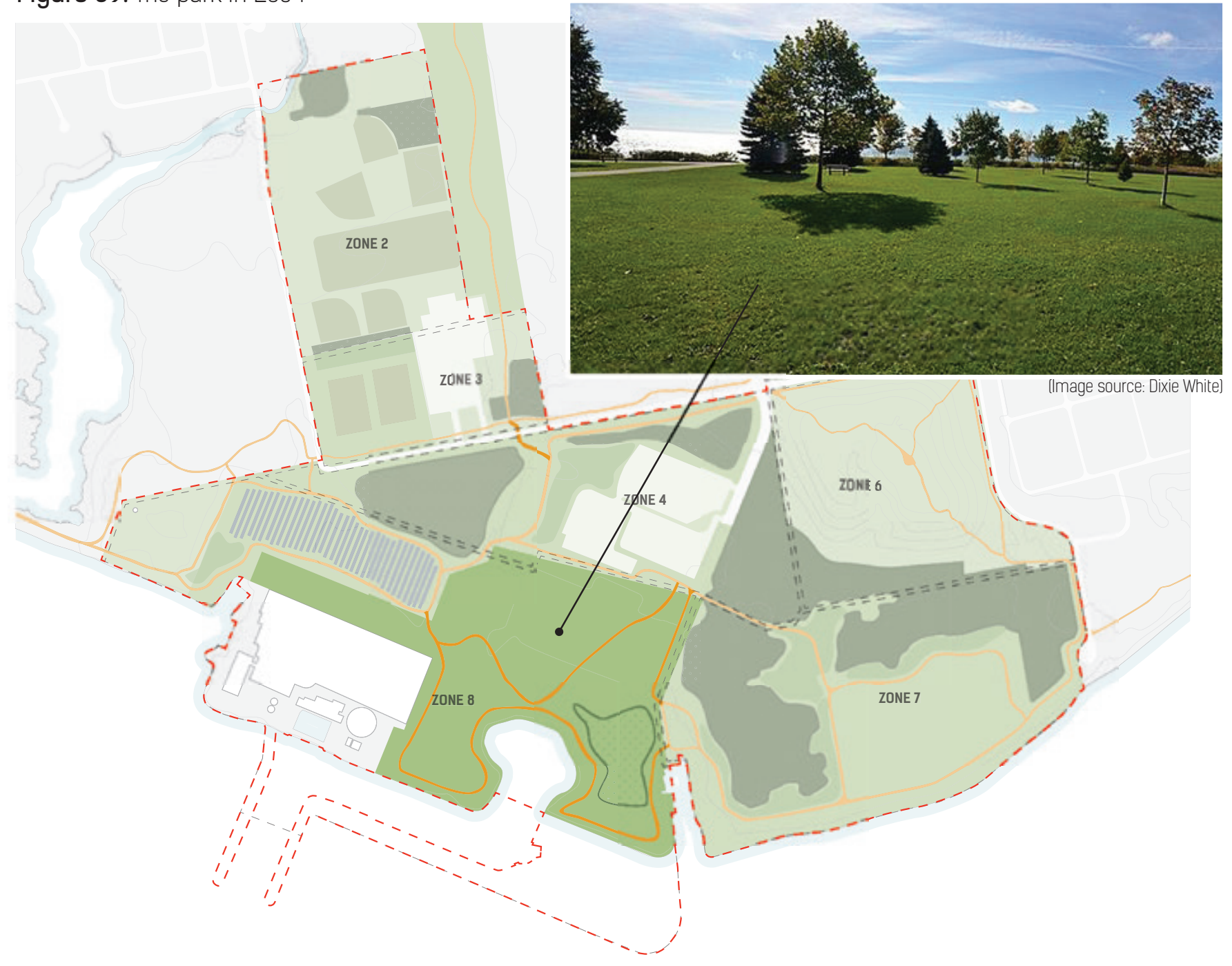

\section{5-40 YEARS:}

Any remaining structures on site are demolished in Zone B and the remaining area is developed into parkland. A small wooded area is established on in the southeastern area, and nature is allowed to reclaim the outdoor space around the preserved Pickering A units. The multi-use trail is also continued through the area and brought down to the water's edge, and connecting it to the path around the solar park. 
Figure 40: The park after 2064, once the vision is complete

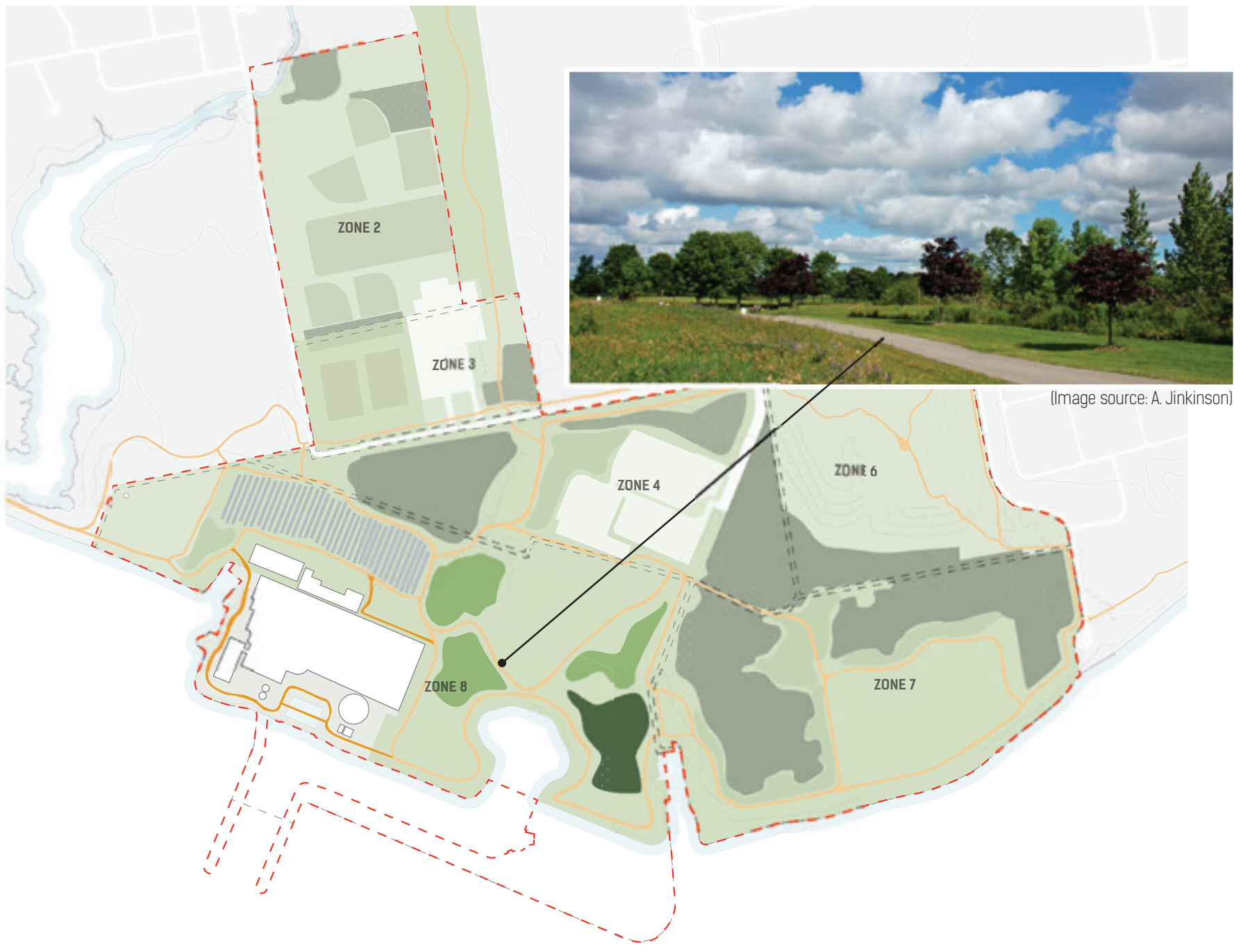

\section{0+ YEARS:}

At this time, the decommissioning process is complete and the site is released from all regulatory control. Pickering A Unit A2 will be opened up, and visitors will be able to explore what is left of the inner workings of the units. The rest of the reactor buildings (Units Al and A3 \& 4) will be sealed and closed off to the public, but will act as a reminder of the nature and scale of energy production that took place on the site. The remaining buildings (turbine buildings) can be repurposed into new uses, while space is reserved for potential new buildings. The natural features of the site continue to grow into diverse parkland areas. The multi-use trail would be completed and bring the Waterfront Trail to the waterfront, while a new destination along its route. 


\subsection{PROGRAMMING}

Due to the extended timeline of the decommissioning process, and the somewhat disjointed opening of the site, it is intended that the vision remain flexible to changing the needs of the community and related programming of the site. However, certain uses were developed to help frame the division of the site into unique spaces.

Figures 41 and 42 highlight some of these proposed uses.

Figure 41: Potential site programming

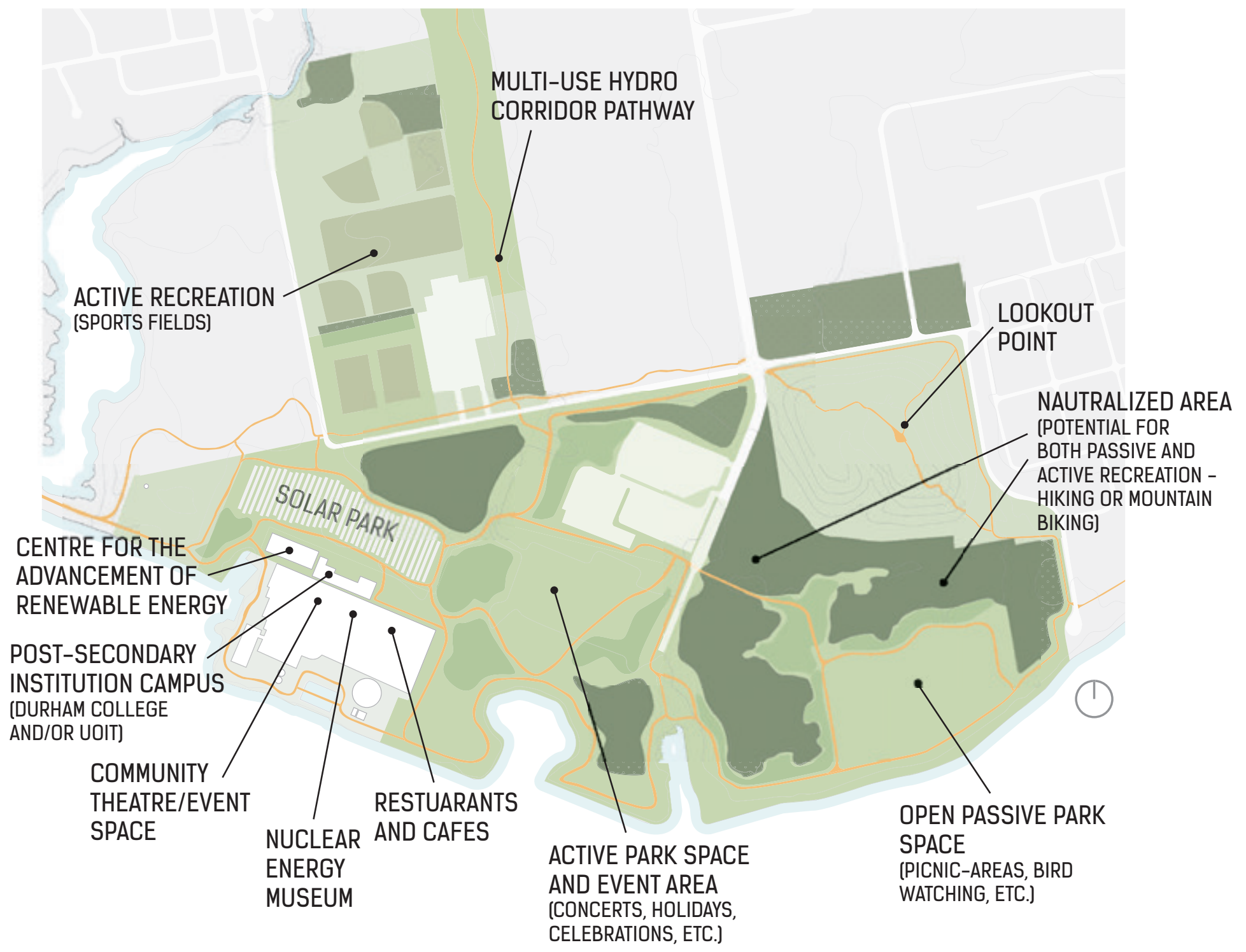


Figure 42: Potential site uses

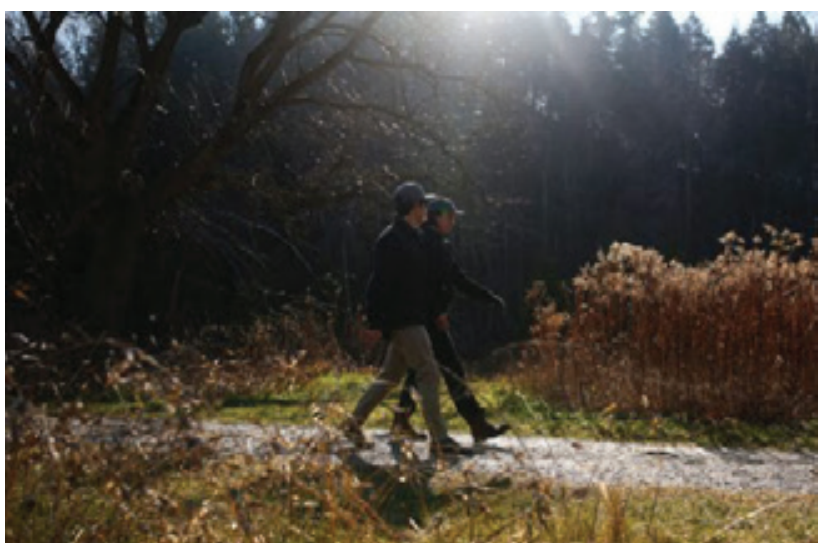

PASSIVE RECREATION

(Image source: Cole Burston)

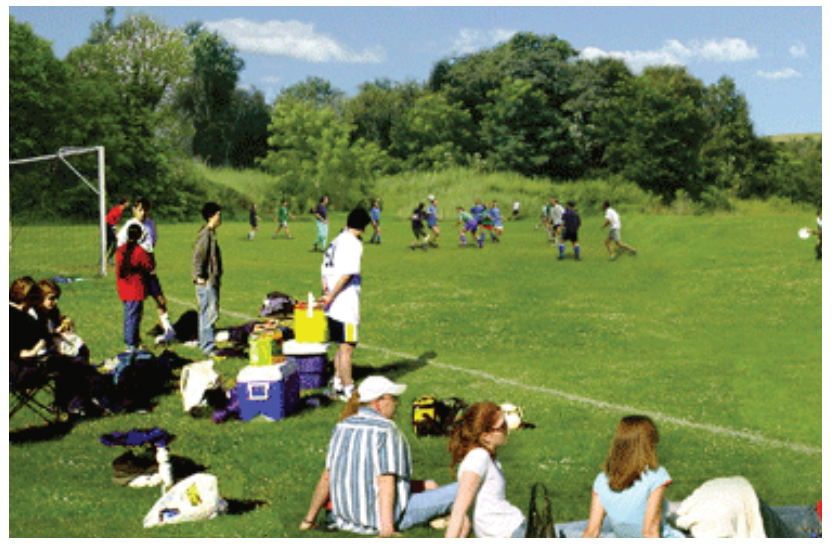

SPORT FIELDS FOR ACTIVE RECREATION

(Image source: New York City Department of Parks \& Recreation)

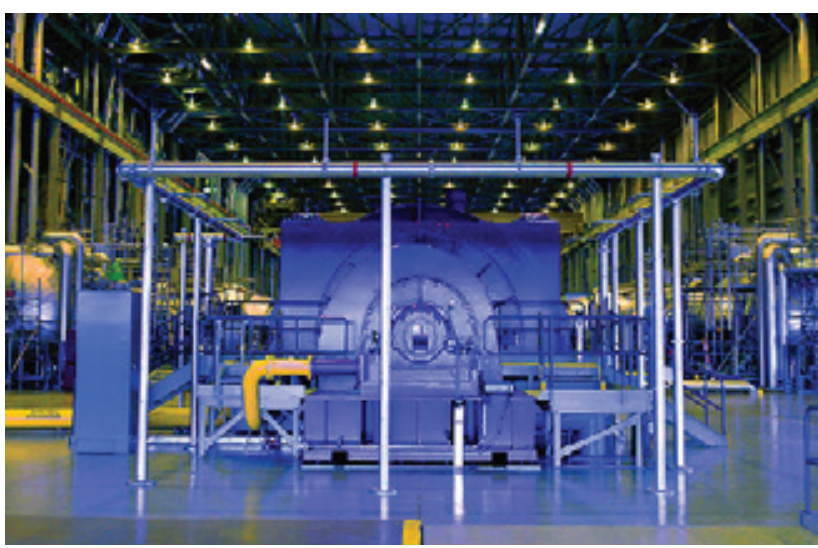

EDUCATIONAL TOURS

(Image source: Ontario Power Generation)

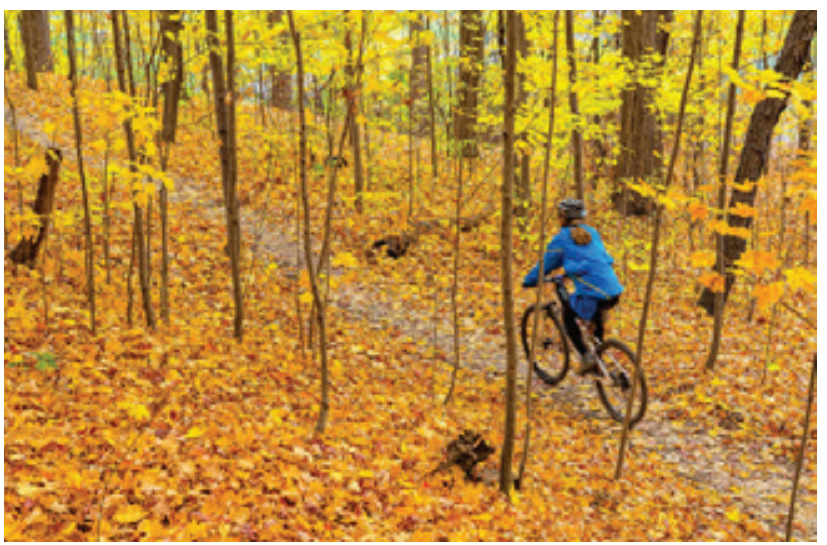

ACTIVE RECREATION

(Image source: Flickr - Subjective Art)

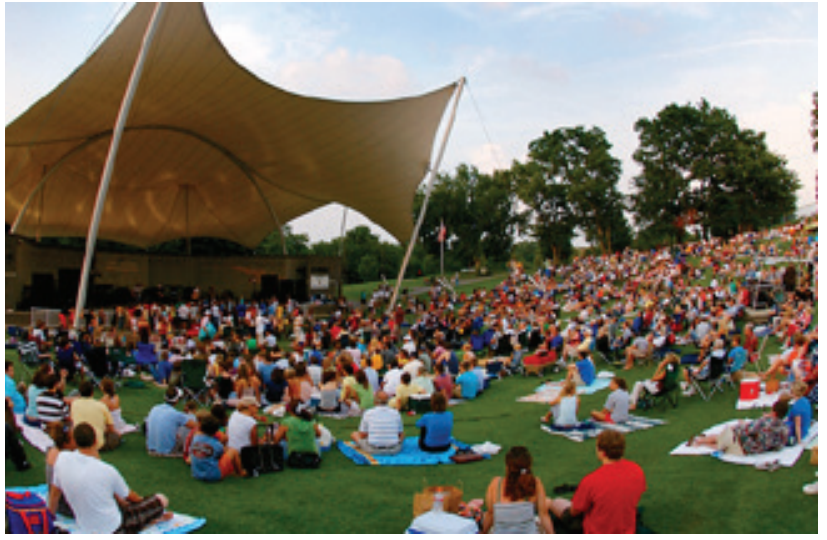

ACTIVE PARK SPACE FOR EVENTS

(Image source: Brentwood)

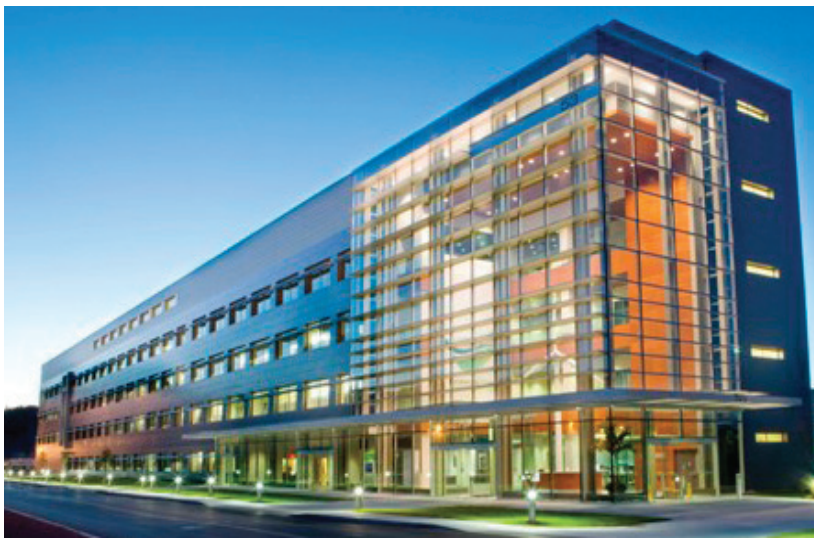

CENTRE FOR THE ADVANCEMENT OF RENEWABLE ENERGY AND POST-SECONDARY CAMPUS

(Image source: General Electric) 


\subsection{THINKING FORWARD}

The intention of this project was to imagine the future use of the Pickering Nuclear Generating Station site. After an analysis of the background research presented in Chapters 2 and 3, it was determined that the best use of the site would be to dedicate it almost exclusively to parkland to create a 400 acre park along Pickering's waterfront. The park's vision and design principles was informed by the research in Chapters 4 and 5 and provided insight into the site's features and decommissioning process, and design strategies that have been applied to international park projects of a similar character.

The design principles of engaging ecology, highlighting heritage and culture, making connections, and linking energy and education, will guide the successful redevelopment of the site into parkland dedicated to a variety of recreational uses, historical and cultural commemoration, education, and the advancement in sustainable energy production. Improved connections will allow users (both human and wildlife) to reconnect with the site, while ensuring the waterfront remains a natural haven and a key destination in the intensifying and rapidly evolving city.

The City of Pickering is currently being presented with a once in a generation opportunity to not only have the ability to redevelop a prime piece of waterfront property of this size, but to be able to dedicate it for a use that can improve the region's resilience for future generations. The population of the City of Pickering alone is expected to more than double within the next three decades, and there will be an increasing need for parks and green spaces. This is the region's last opportunity to create a park of this scale and potential within this rapidly growing region. Large parks do not only provide recreational opportunities, but are able to serve a more important ecological role than their smaller counterparts (Lister, 2007).

While there may not appear to be a present need for a park of this scale, one can simply look to Central Park in New York City. In the 1850s, Andrew Jackson Downing lobbied for a public park in downtown New York, which at the time had a population of 516,000, which doubled to 1.16 million in 1880 (U.S. Bureau of the Census, 1998). Today it supports the most densely populated boroughs in New York.

While it is unlikely that the City of Pickering will grow to a million residents anytime soon, Central Park shows the importance of securing park land land for the future wants and needs of a city. For the City of Pickering, that time is now. 


\section{REFERENCES}

Atomic Energy of Canada Limited. (2015). Home: What we do.

Retrieved from http://www.aecl.ca/en/home/what-we-do/default.aspx [Accessed March 12, 2016].

Bowering, J. (1991). Editorial: The issue of the refereed studio. Landscape Review5(2): 1-4.

Boyd, W.E., Gardiner,J.E. (2005). Stooking the Peanuts: Historical Agriculture and the Management of a

Dying Seasonal Landscape, North-East New South Wales, Australia. Landscape Research 30(2): 193-220.

Braae, E. (2015). Beauty Redeemed: On Recycling Ruinous Industrial Landscapes. Berlin, Basel:

Birkhäuser.

Brassley, P. (1998). On the unrecognized significance of the ephemeral landscape. Landscape Research 23(2): 119-132.

Brassley, P. (1999). Agricultural technology and the ephemeral landscape. In Nye, D. (Ed.), Technologies of Landscape, From Reaping to Recycling (pp. 21-39]. Amherst, MA: University of Massachusetts Press.

Canadian Nuclear Association. (2014). The Canadian Nuclear Factbook.

Retrieved from https://cna.ca/wp-content/uploads/2015/03/CNA-Factbook-2015-Englishl.pdf (Accessed March 12, 2016].

Canadian Nuclear Association. (2016). TeachNuclear: Nuclear Facts

Retrieved from http://teachnuclear.ca/general_resources/facts/how-nuclear-reactors-work/ Accessed March 12, 2016].

Canadian Nuclear Safety Commission. [2016). Nuclear Power Plants.

Retrieved from: https://www.cnsc-ccsn.gc.ca/eng/reactors/power-plants/index.cfm (Accessed April 5, 2016).

Candu. (2011). CANDU Reactors.

Retrieved from http://www.candu.com/en/home/candureactors/default.aspx [Accessed March 12, 2016].

Chappel, B. (2010). Ephemeral Architecture.

Retrieved from http://www.scribd.com/doc/44042590/Ephemeral-Architecture (Accessed March 12 ,

2016).

City of Pickering. (2010). Pickering Official Plan.

Retrieved from: https://www.pickering.ca/en/cityhall/resources/op6.pdf (Accessed March 25, 2016).

City of Pickering. [2013]. Downtown Pickering: A Vision for Intensification and Framework for Investment. Retrieved from: https://www.pickering.ca/en/living/resources/DowntownPickering_FinalVisionDocument_ June2013.pdf (Accessed March 25, 2016).

City of Pickering. (2014). South Pickering Intensification Study (Part of the Pickering Official Plan Review) (Report to Council PLN 24-14].

Retrieved from https://www.pickering.ca/en/cityhall/resources/PLN2414.pdf (Accessed March 25, 2016). 
City of Pickering. (2016a). South Pickering Intensification Study.

Retrieved from: https://www.pickering.ca/en/cityhall SouthPickeringIntensificationStudy.asp (Accessed March 25, 2016].

City of Pickering. (2016b). Beachfront Park \& Millennium Square.

Retrieved from: https://www.pickering.ca/en/discovering/beachfrontparkmillenniumsquare.asp

(Accessed March 25, 2016).

City of Pickering. [2016c]. Parks and Trails.

Retrieved from https://www.pickering.ca/en/discovering/parkstrails.asp (Accessed March 25, 2016).

City of Pickering. (2016d). "Health of Frenchman's Bay". Sustainable Pickering

Retrieved from: http://measuringsustainability.ca/frenchmans-bay-c3.php (Accessed March 25, 2016).

Corner, J. (1996). Ecology and landscapes as agents of creativity. In Tompson, G, Steiner, F. (Eds), Ecological design and planning (pp 82-83) John Wiley \& Sons.

Corner, J. [2005]. Fresh kills Parkland. Topos, 51: 14-21.

Deming, E. M., Swaffield, S. (2011). Landscape Architectural Research: Inquiry, Strategy, Design. New Jersey: John Wiley \& Sons, Inc.

Durham Region. [2013a]. Durham Regional Official Plan (August 13, 2013 Consolidation). Retrieved from: https://www.durham.ca/departments/planed/planning/op_documents/officialplan/ dropoc.pdf (Accessed March 25, 2016).

Durham Region. (2013b). Schedule 'A' - Map 'A4' Regional Structure.

Retrieved from: https://www.durham.ca/departments/planed/planning/op_documents/officialplan/ schedule_a.pdf (Accessed March 25, 2016).

Frayling,C. (1993). Into, through, and for research: Research in art and design. Royal College of Art Research papers 1(1) (cited in Lunefeld 2003).

Furjan, H. [2007]. Design/research: Notes on a Manifesto. Journal of Architectural Education 61[1]: 62-68.

Groat, L., and D. Wang. (2002]. Architectural research methods. New York: John Wiley and Sons.

Hargreaves, G. (2007). Large Parks: A Designers Perspective. In Czerniak, J., Hargreaves, G. (Eds.), Large Parks (pp. 121-175]. New York: Princeton Architectural Press.

Howard, P. (2003). Heritage: Management, Interpretation, Identity. London: Continuum.

International Atomic Energy Agency. (2006). Redevelopment of Nuclear Facilities after Decommissioning. IAEA Nuclear Energy Series. No. 444. Vienna: international Atomic Energy Agency.

International Atomic Energy Agency. [2011]. Redevelopment and Reuse of Nuclear Facilities and Sites: Case Histories and Lessons Learned. IAEA Nuclear Energy Series. No. NW-T.2.2. Vienna: international Atomic Energy Agency. 
Kieran, S. (2007). Research in design: Planning doing monitoring learning. Journal of Architectural Education 61[1]: 27-31.

Kragh, H. [1999]. Quantum Generations: A History of Physics in the Twentieth Century. Princeton NJ: Princeton University Press. p. 286.

Laraia M. (२011]. Decontamination \& decommissioning: Nuclear site redevelopment. Nuclear Engineering International.

Accessed from http://www.neimagazine.com/features/featurenuclear-site-redevelopment/ (Accessed March 12, 2016).

Langhost, J. (2014) Re-presenting transgressive ecologies: Post-industrial sites as contested terrains. Local Environment 19(10): 1110-1133.

Latz, P. (2003). Industriefolgelandschaft als Aufgabe der Gartenkultur - Drei Annäherungen. In Rohde, M., Schomann, R. (eds.): Historische Gärten Heute. p. 64

Lister, N. (2007). Sustainable Large Parks: Ecological Design or Designer Ecology?. In Czerniak, J., Hargreaves, G. (Eds.J, Large Parks (pp. 35-58). New York: Princeton Architectural Press.

Loures, L., Panagopoulous. T. [2007). Landscape ecological urbanism: Origins and trajectories. WIT Transactions on Ecology and the Environment 102: 791-800.

Loures, L. (2008). Post-industrial landscapes as renaissance: the case study research method. WIT Transactions on Ecology and the Environment - The Sustainable City 5(117): 293-302.

Meyer, E. (2007). Uncertain Parks. Disturbed Sites, Citizens and Risk Society. In Czerniak, J., Hargreaves, G. [Eds.J, Large Parks (pp. 59-86). New York: Princeton Architectural Press.

Ministry of Infrastructure. [2006). Growth Plan for the Greater Golden Horseshoe, २००6 [Office Consolidation, June 2013).

Retrieved from: https://www.placestogrow.ca/content/ggh/2013-06-10-Growth-Plan-for-the-GGH-EN.pdf (Accessed March 25, 2016).

Mitchell, D. (1994). Landscape and surplus value: the making of the ordinary in Brentwood, CA, Environment and Planning 12: 7-30

North, A. (2013). Operative Landscapes. Berlin, Basel: DE GRUYTER.

Nuclear Regulatory Commission. (2007). History.

Retrieved from: http://www.nrc.gov/about-nrc/emerg-preparedness/history.html (Accessed April 5, 2016).

Ontario Power Generation. (2015). Repurposing Pickering: Exploring the possibilities for new uses and reuses on the Pickering Nuclear site.

Retrieved from: http://www.opg.com/generating-power/nuclear/stations/pickering-nuclear/ repurposingpickering/Documents/RepurpPick_PrelimAssessmentReport.pdf (Accessed January 15, 2016). 
Qviström, M., Saltzman, K. [2006). Exploring Landscape Dynamics at the Edge of the City: Spatial Plans and Everyday Places at the Inner Urban Fringe of Malmö, Sweden. Landscape Research 31[1]: 21-41. Seggern, H. v., Werner, J. (2008). Design as in integrative process of creating knowledge. In Sggern, H. v., Werner, J., Grosse-Bächle, L. (Eds.], Creating knowledge: Innovationsstrategin im Entwerfen urbaner Landschaften = innovation strategies for designing urban landscapes (pp 34-62). Berlin: Jovis.

Senes Consultants Ltd. [2007). Refurbishment and Continued Operation of Pickering Nuclear Generating Station Environmental Assessment. Retrieved from: http://trca.on.ca/dotAsset/50330.pdf (Accessed March 25, 2016).

Shah, M. (June 22, 2013). "Future of Pickering nuclear plant a hot topic in Durham Region". Toronto Sun. Retrieved from http://www.torontosun.com/2013/06/22/future-of-pickering-nuclear-plant-a-hot-topicin-durham-region

Statistics Canada. (2011). Census subdivision of Pickering, CY -Ontario. Focus on Geography Series, 2011 Census.

Retrieved from: https://wwwl2.statcan.gc.ca/census-recensement/201l/as-sa/fogs-spg/Facts-csdeng.cfm?LANG=Eng\&GK=CSD\&GC=3518001 (Accessed March 5, 2016).

Steed, R. (2007). Nuclear Power: In Canada and Beyond. Renfrew: General Store Publishing House.

Steenbergen, C. (2008). Composing landscapes: Analysis, typology, and experiments for design. Basel: Birkhauser Verlag.

Toronto Regional Conservation Authority. (2009). Frenchman's Bay Harbour Entrance - Environmental Study Report. Retrieved from: http://trca.on.ca/dotAsset/50330.pdf (Accessed March 25, 2016).

Waterfront Regeneration Trust. (2013). General Trail Information. Retrieved from: http://www.waterfronttrail.org/visiting-the-trail/general-trail-information Accessed March $25,2016]$.

World Nuclear. (2016). Nuclear Power in Canada. Retrieved from http://www.world-nuclear.org/information-library/country-profiles/countries-a-f/ canada-nuclear-power.aspx (Accessed March 12, 2016). 